\title{
XREN 1 protects transcription from toxic PARP1 activity during DNA base excision repair
}

\author{
Marek Adamowicz ${ }^{1}$, Richard Hailstone, ${ }^{1,3}$, Annie A. Demin ${ }^{1,3}$, Emilia Komulainen', Hana Hanzlikova $\mathbb{1}^{1,2}$, \\ Jan Brazina', Amit Gautam?', Sophie E. Wells ${ }^{1}$ and Keith W. Caldecott ${ }^{1,2}{ }^{\circledR}$
}

\begin{abstract}
Genetic defects in the repair of DNA single-strand breaks (SSBs) can result in neurological disease triggered by toxic activity of the single-strand-break sensor protein PARP1. However, the mechanism(s) by which this toxic PARP1 activity triggers cellular dysfunction are unclear. Here we show that human cells lacking XRCC1 fail to rapidly recover transcription following DNA base damage, a phenotype also observed in patient-derived fibroblasts with XRCC1 mutations and Xrcc1 ${ }^{-1-}$ mouse neurons. This defect is caused by excessive/aberrant PARP1 activity during DNA base excision repair, resulting from the loss of PARP1 regulation by XRCC1. We show that aberrant PARP1 activity suppresses transcriptional recovery during base excision repair by promoting excessive recruitment and activity of the ubiquitin protease USP3, which as a result reduces the level of monoubiquitinated histones important for normal transcriptional regulation. Importantly, inhibition and/or deletion of PARP1 or USP3 restores transcriptional recovery in $\mathrm{XRCC1}^{-/-}$cells, highlighting PARP1 and USP3 as possible therapeutic targets in neurological disease.
\end{abstract}

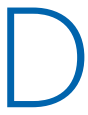
NA single-strand breaks (SSBs) are one of the most common types of DNA damage in cells, arising at a frequency of tens-of-thousands per cell per day ${ }^{1}$. The threat posed by SSBs is illustrated by hereditary genetic diseases in which the repair of SSBs is defective, resulting in neurological pathologies such as cerebellar ataxia, neurodevelopmental delay and seizures ${ }^{2,3}$. Single-strand breaks are rapidly detected by poly-ADP-ribose polymerase 1 (PARP1), which following binding to the DNA break is catalytically activated and modifies itself and other proteins, such as histones, with ADP-ribose ${ }^{4-6}$. ADP-ribosylation accelerates SSB repair in a number of ways-for example, by modifying the structure of chromatin in the vicinity of the break and/or recruiting specific DNA repair factors such as XRCC1 (refs. $\left.{ }^{4,6}\right)$. The extensive auto-ribosylation of PARP1 leads to disassociation of the enzyme from the SSB, enabling other DNA repair enzymes to access and repair the break ${ }^{7}$.

XRCC1 is a scaffold protein that is recruited to SSBs by PARP1 and/or PARP2 activity through direct interaction between poly(ADP-ribose) and the central BRCT domain in XRCC1 ( refs. $^{8-10}$ ). XRCC1 in turn interacts with and recruits the enzymes required for SSB repair, including DNA polymerase $\beta^{11,12}$, DNA ligase $\mathrm{III}^{13}$, polynucleotide kinase/phosphatase ${ }^{14,15}$ and aprataxin ${ }^{16,17}$. Hereditary mutations in XRCC1 and some of these protein partners result in neurodevelopmental disorders and/or progressive neurodegeneration $^{2,3}$. Intriguingly, the deletion and/or inhibition of PARP1 greatly reduces or prevents these pathologies in an Xrcc1-defective mouse model of SSB-associated neurological disease, highlighting excessive/aberrant PARP1 activity as a source of SSB-induced neuropathology ${ }^{18,19}$. However, the molecular mechanism by which excessive/aberrant PARP1 activity triggers cellular dysfunction remains unclear.

Here we show that prolonged PARP1 activity at unrepaired DNA base damage suppresses the recovery of transcription by promoting the excessive recruitment and activity of the ubiquitin-specific protease USP3. Remarkably, excessive USP3 activity reduces global levels of monoubiquitinated histones important for transcriptional regulation, such as histone $\mathrm{H} 2 \mathrm{~A}$ and $\mathrm{H} 2 \mathrm{~B}$ monoubiquitination at K119 and $\mathrm{K} 120$ (H2AmUb and $\mathrm{H} 2 \mathrm{BmUb}$, respectively). Importantly, either PARP1 or USP3 inhibition/depletion rescue normal levels of histone monoubiquitination and transcription recovery following DNA base damage, highlighting these enzymes as possible therapeutic targets in the treatment of base excision repair (BER)-defective neurological disease.

\section{Results}

XRCC1 promotes the recovery of transcription following oxidative damage. Given that SSBs can slow or block the physical progression of RNA polymerases ${ }^{20-22}$, we wondered whether SSB repair-defective cells exhibit defects in transcription following DNA damage. We therefore examined the impact of XRCC1 deletion on global transcription in human RPE-1 cells following treatment with $\mathrm{H}_{2} \mathrm{O}_{2}$ (a physiologically relevant source of oxidative SSBs) by pulse labelling with 5-ethynyluridine (EU). We observed a robust inhibition of global transcription immediately after treatment with $\mathrm{H}_{2} \mathrm{O}_{2}$ in both wild-type (WT) and $X R C C 1^{-/}$RPE-1 cells (Fig. 1a,b). More importantly, whereas the levels of transcription recovered significantly within $2 \mathrm{~h}$ following $\mathrm{H}_{2} \mathrm{O}_{2}$ treatment in the WT RPE-1 cells, they declined further in the $\mathrm{XRCC1}^{-/-}$cells (Fig. 1a,b). The lack of transcription recovery in $\mathrm{XRCC1}^{-1-}$ cells was accompanied by a progressive loss of RNA polymerase I (RNAPI) foci (RPA194; Fig. 1a,c). Given that we did not detect a reduction in the global levels of RPA194 in the $\mathrm{XRCC1}^{-/-}$cells, this most probably reflected the dissociation of RNAPI from nucleolar sites of ribosomal RNA transcription rather than degradation of the RNAP (Extended Data Fig. 1a).

Although most of the EU signal detected in our pulse-labelling experiments was nucleolar, the recovery of EU incorporation in the $\mathrm{XRCC1}^{-1-} \mathrm{RPE}-1$ cells was also reduced in the nucleoplasm (Fig. 1a), suggesting that RNA polymerase II (RNAPII)-dependent

${ }^{1}$ Genome Damage and Stability Centre and Sussex Drug Discovery Centre, School of Life Sciences, University of Sussex, Brighton, UK. ${ }^{2}$ Department of Genome Dynamics, Institute of Molecular Genetics of the Czech Academy of Science, Prague, Czech Republic. ${ }^{3}$ These authors contributed equally: Richard M. Hailstone, Annie A. Demin.凶e-mail: k.w.caldecott@sussex.ac.uk 
a

DAPI
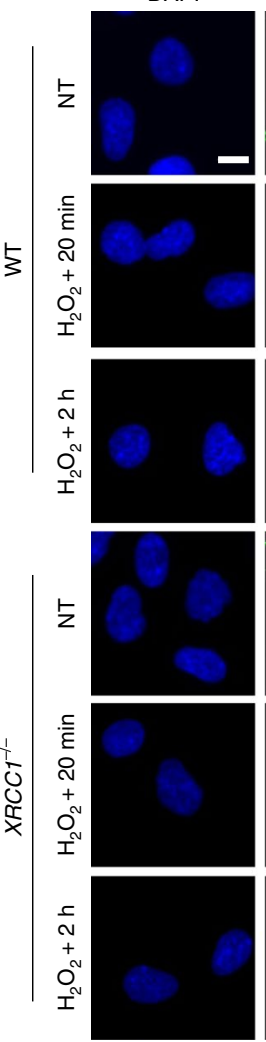

RPA194
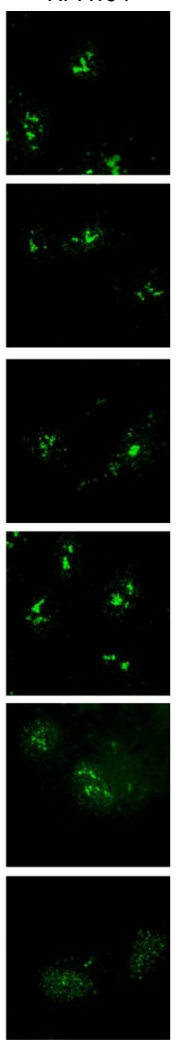

EU

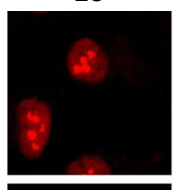

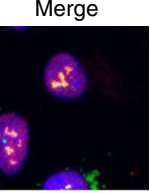

b

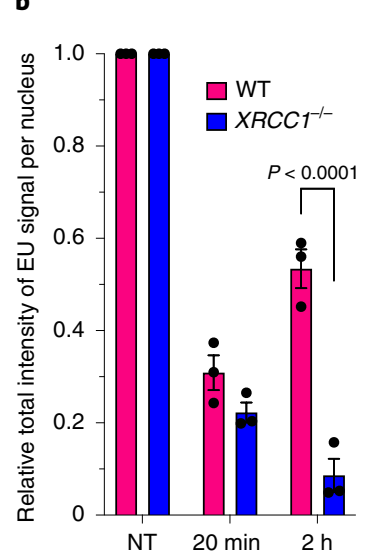

c

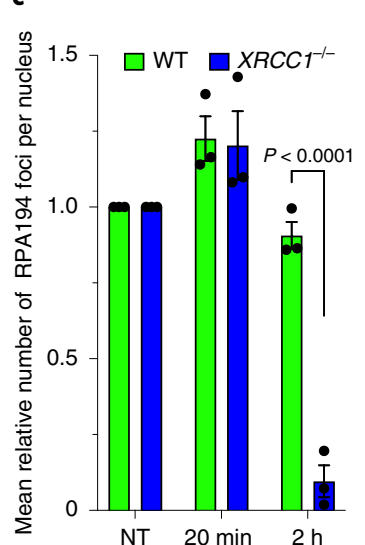

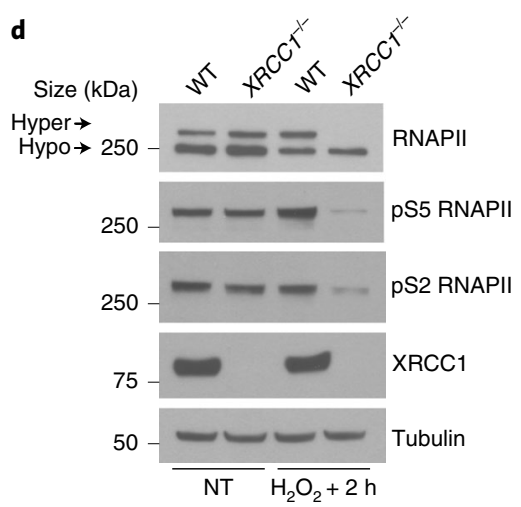

Fig. 1 XRCC1 promotes the recovery of transcription following oxidative damage. a, Representative images of RNAPI foci (RPA194) showing the levels of global transcription (EU pulse labelling) in WT and XRCC1 ${ }^{-1-}$ RPE-1 cells following mock treatment (NT) or at the indicated times after treatment with $250 \mu \mathrm{M} \mathrm{H}_{2} \mathrm{O}_{2}$ for 5 min. The cells were labelled with EU for 20 min before fixation. Scale bar, 10 $\mu$ m; DAPI, 4,6-diamidino-2-phenylindole. b,c, Levels of global transcription (b; EU immunofluorescence) and RNAPI foci (c; RPA194) from the experiment shown in $\mathbf{a}$. Data are the mean \pm s.e.m. of three independent experiments. Statistical significance was determined using a two-way analysis of variance (ANOVA) with Sidak's multiple comparisons test (significantly different $P$ values are indicated). d, Immunoblot of RNAPII hyperphosphorylation (hyper) in WT and XRCC1-/- RPE-1 cells following mock treatment or $2 \mathrm{~h}$ after treatment with $250 \mu \mathrm{M} \mathrm{H}_{2} \mathrm{O}_{2}$ for $5 \mathrm{~min}$. A representative blot from one of three independent experiments is shown. The positions of the molecular mass markers are indicated; hypo, hypophosphorylation.

transcription was also affected. To confirm this, we compared the levels of hyperphosphorylated RNAPII, which is an established measure of the RNAPII transcriptional activity ${ }^{23,24}$, in WT and $X R C C 1^{-1-}$ RPE-1 cells before and after $\mathrm{H}_{2} \mathrm{O}_{2}$ treatment. The level of RNAPII hyperphosphorylation was markedly reduced in the $X R C 1^{-1-}$ RPE-1 cells following $\mathrm{H}_{2} \mathrm{O}_{2}$ treatment, an observation we verified with antibodies specific to two phosphorylated sites (S2 and S5) within the carboxy (C)-terminal domain of RNAPII that are associated with transcriptional activity (Fig. 1d) ${ }^{25}$. The loss of hyperphosphorylated RNAPII seemed to involve, at least partly, proteolysis of RNAPII, given that incubation with proteasome inhibitors restored normal levels of the hyperphosphorylated RNAP (Extended Data Fig. 1b). However, proteasome inhibitors did not restore normal levels of transcription recovery, indicating that degradation of hyperphosphorylated RNAPII was a result of failed transcription recovery rather than a cause (Extended Data Fig. 1b-e). Importantly, the defect in transcription recovery was neither limited to RPE-1 cells nor an off-target effect of gene editing because we observed similar results in $\mathrm{XRCC1}^{-1-} \mathrm{U} 2 \mathrm{OS}$ cells and the defect in transcriptional recovery in these cells was corrected by stable expression of recombinant human XRCC1 (Extended Data Fig. 2a-d). Collectively, these data indicate that XRCC1 is required for the rapid recovery of transcription by both RNAPI and RNAPII following oxidative stress.
Reduced transcriptional recovery in XRCC1-deficient cells and neurons is a result of PARP1. Hereditary mutations in human XRCC1 result in cerebellar ataxia, a phenotype that is also observed in $X r c c^{\text {Nes-cre }}$ mice in which $\mathrm{Xrccl}$ is conditionally deleted in the brain $^{18,19,26}$. This phenotype is largely rescued by the deletion of Parp1, the primary sensor of unrepaired SSBs in mammalian cells ${ }^{18,19}$. We therefore examined the impact of PARP1 deletion on the recovery of transcription in $\mathrm{XRCC1}^{-1-}$ cells. Strikingly, PARP1 deletion rescued the transcriptional recovery in $X R C C 1^{-1-} \mathrm{RPE}-1$ cells, as measured by EU pulse labelling, RNAPI foci and RNAPII phosphorylation (Fig. $2 \mathrm{a}-\mathrm{d}$ ). In addition, transcription recovery was rescued in both $X R C C 1^{-1-}$ RPE-1 and U2OS cells by incubation with PARP inhibitor (PARPi), confirming that the transcription defect was the result of toxic/aberrant ADP-ribosylation (Fig. 2e and Extended Data Fig. 3). Consistent with this idea, the defect observed in the $\mathrm{XRCC1}^{-1-}$ cells was recapitulated in WT RPE-1 cells by incubation with an inhibitor of PARG (the enzyme primarily responsible for poly(ADP-ribose) degradation), which suppressed the recovery of global transcription for up to $8 \mathrm{~h}$ following $\mathrm{H}_{2} \mathrm{O}_{2}$ treatment (Fig. $2 \mathrm{f}-\mathrm{h}$ ). Importantly, reduced transcriptional recovery following oxidative stress was also observed in patient-derived human fibroblasts with XRCC1 mutations as well as $X r c c 1^{\text {Nes-cre }}$ mouse cerebellar neurones, and these defects were again prevented by PARPi, implicating PARP1-induced transcriptional repression in neurological disease (Fig. 3 and Extended Data Fig. 4). 
The poly(ADP-ribose)-binding activity of XRCC1 promotes transcriptional recovery by directly regulating PARP1 activity. To understand how XRCC1 prevents toxic PARP1 activity, we identified the protein domain/s important for this process. A truncated Myc-histidine (Myc-His)-tagged fragment of XRCC1 encoding only the central one-third of the protein (Myc-His-XRCC1 $1^{161-406}$ ) rescued transcription recovery in $\mathrm{XRCC1}^{-1-} \mathrm{U} 2 \mathrm{OS}$ cells (Fig. 4a,b and Extended Data Fig. 5a-e). This was surprising because this fragment lacks the protein-interaction domains that underpin the role of XRCC1 as a molecular scaffold ${ }^{27}$ and so cannot support normal rates of SSB repair (Extended Data Fig. 5f,g). The ability of XRCC1 to bind directly to poly(ADP-ribose) was required to prevent PARP1-mediated transcriptional suppression, as indicated by the failure of a mutant derivative of Myc-His-XRCC $1{ }^{161-406}$ harbouring mutations that prevent binding to this polymer (R335A/ K369A; denoted Myc-His-XRCC1 $\left.{ }^{161-406, R K}\right)^{9}$ to rescue transcriptional recovery, thereby suggesting that XRCC1 might regulate poly(ADP-ribosylation) directly (Fig. $4 \mathrm{~b}$ and Extended Data Fig. 5a-e). The most probable target of this regulation is PARP1 itself, given that this protein was the most abundant, if not the only, ribosylated protein detected in Myc-His-XRCC1 ${ }^{161-406}$ immunoprecipitates following $\mathrm{H}_{2} \mathrm{O}_{2}$ treatment and its recovery was prevented by the mutations that prevent poly(ADP-ribose) binding (Fig. 4c). Consistent with direct regulation of PARP1 activity by the poly(ADP-ribose)-binding domain of XRCC1, both recombinant full-length XRCC1 and XRCC1 $1^{161-406}$ reduced PARP1 auto-ribosylation in vitro, whereas the mutant derivatives of these proteins that cannot bind poly(ADP-ribose) were unable to do so (Fig. 4d).

These data suggest that XRCC1 can suppress aberrant PARP1 activity not only by accelerating SSB repair but also by direct binding to, and suppression of, poly(ADP-ribose) chain extension. To confirm this idea, we examined whether transcriptional recovery could be rescued by the overexpression of APLF, a structurally distinct poly(ADP-ribose)-binding protein that can also negatively regulate poly(ADP-ribose) synthesis ${ }^{28}$. Recombinant APLF suppressed poly(ADP-ribose) chain extension in vitro, albeit less effectively than XRCC1, and overexpression of high levels of APLF restored transcriptional recovery in $\mathrm{XRCC1}^{-1-} \mathrm{U} 2 \mathrm{OS}$ cells in a manner dependent on the poly(ADP-ribose)-binding zinc finger domain $^{29}$ (Fig. 4e,f and Extended Data Fig. 5h-k). These data indicate that the negative regulation of PARP1 activity by direct binding of XRCC1 to poly(ADP-ribose) is both required and sufficient for normal transcription recovery following oxidative stress.

Prolonged transcriptional suppression is triggered by low but persistent PARP1 activity at unrepaired DNA BER intermediates. Collectively, the experiments described so far indicate that although the initial suppression of transcription by $\mathrm{H}_{2} \mathrm{O}_{2}$ is independent of PARP1 activity and probably reflects the stalling/inefficient bypass of DNA lesions by $\mathrm{RNAPs}^{20-22}$, the prolonged suppression observed in $\mathrm{XRCC1}^{-1-}$ cells is imposed by excessive/aberrant PARP1 activity at persistent SSBs. To address this further we conducted time-course experiments to determine when and for how long transcriptional suppression occurs. Whereas WT RPE-1 cells continued to recover transcription from $2 \mathrm{~h}$ following $\mathrm{H}_{2} \mathrm{O}_{2}$ treatment, with the transcription levels restored to normal within $24 \mathrm{~h}$, $\mathrm{XRCC}^{-1-}$ cells exhibited little or no transcriptional recovery for at least $9 \mathrm{~h}$ following $\mathrm{H}_{2} \mathrm{O}_{2}$ treatment (Fig. 5a and Extended Data Fig. $6 \mathrm{a}, \mathrm{b})$. Moreover, incubation with PARPi for $1 \mathrm{~h}$ rescued transcription even if applied $8 \mathrm{~h}$ after the $\mathrm{H}_{2} \mathrm{O}_{2}$ treatment, indicating that the failure to recover transcription in the $X R C C 1^{-1-}$ cells was a result of prolonged and ongoing ADP-ribosylation (Fig. 5a and Extended Data Fig. 6a,b). Consistent with this idea, although $\mathrm{H}_{2} \mathrm{O}_{2}$-induced protein ADP-ribosylation declined below detectable levels in both WT and $\mathrm{XRCC1}^{-/-}$cell extracts $2 \mathrm{~h}$ after $\mathrm{H}_{2} \mathrm{O}_{2}$ treatment, as measured by western blotting, we detected low but persistent levels of PARP1 auto-ribosylation in the $\mathrm{XRCC1^{-/- }}$ cell extracts following enrichment with anti-ADP-ribose antibodies (Extended Data Fig. 6c,d).

We reasoned that the low level of persistent PARP1 activity in the $X R C C 1^{-1-}$ cells most probably reflected SSBs arising as intermediates of BER, given that while SSBs induced directly by disintegration of oxidized deoxyribose arise immediately, SSBs arising during BER require the enzymatic excision of oxidized DNA bases and thus arise more slowly. Moreover, we recently showed that PARP1 can become 'trapped' on SSB intermediates in $X R C C 1^{-1-}$ cells during BER and that low but persistent levels of PARP1 auto-ribosylation is a feature of this phenomenon ${ }^{30}$. Consistent with this idea, short interfering RNA (siRNA)-mediated depletion of NTH1-a DNA glycosylase that excises a broad spectrum of oxidized DNA bases ${ }^{31-33}$-rescued the recovery of transcription in $\mathrm{H}_{2} \mathrm{O}_{2}$-treated $\mathrm{XRCC1}^{-1-}$ cells (Fig. 5b,c and Extended Data Fig. 6e). Furthermore, global transcription was substantially suppressed in $\mathrm{XRCC1}^{-/}$cells following prolonged treatment with methyl methanesulfonate (MMS), an alkylating agent that induces SSBs largely or entirely via BER (Fig. 5d-f). This repression was also accompanied by a loss of RNAPII hyperphosphorylation, which once again was rescued by PARPi (Fig. 5f). Together, these data indicate that transcriptional recovery is suppressed in $X R C C 1^{-1-}$ cells by low levels of persistent PARP1 activity at unrepaired BER intermediates.

Aberrant PARP1 activity disrupts global histone monoubiquitination. Next, we examined the mechanism/s by which aberrant PARP1 activity inhibits transcription recovery during BER. Given that PARP1 can affect transcription by ADP-ribosylating histones $^{34-36}$, we examined the impact of the deletion of histone parylation factor-1 (HPF1), a protein partner of PARP1 that is required for histone ADP-ribosylation ${ }^{37-40}$. However, although HPF1 deletion prevented detectable histone ADP-ribosylation in $\mathrm{XRCC1}^{-1-} \mathrm{U} 2 \mathrm{OS}$ cells as expected, it did not rescue transcription recovery, suggesting

Fig. 2 | Reduced transcriptional recovery in XRCC1-deficient cells is a result of toxic PARP1 activity. a, Representative images of RNAPI foci (RPA194)

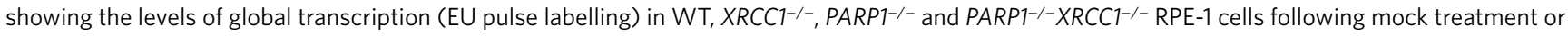
at the indicated times after treatment with $250 \mu \mathrm{M} \mathrm{H}_{2} \mathrm{O}_{2}$ for 5 min. The cells were incubated with dimethylsulfoxide (DMSO) vehicle or $10 \mu \mathrm{M}$ PARPi for $1 \mathrm{~h}$ before, during and following $\mathrm{H}_{2} \mathrm{O}_{2}$ treatment as indicated. The cells were pulse labelled with EU as in Fig. 1. b,c, Levels of global transcription (b; EU immunofluorescence) and RNAPI foci (c; RPA194) from the experiment shown in a. d, Immunoblot of RNAPII hyperphosphorylation in WT, XRCC1-/-, PARP1-/- and PARP1-/-XRCC1-/- RPE-1 cells following mock treatment or $2 \mathrm{~h}$ after treatment with $250 \mu \mathrm{M} \mathrm{H}_{2} \mathrm{O}_{2}$ for 5 min. e, Immunoblot of RNAPII hyperphosphorylation in WT and $X R C C 1^{-1-}$ RPE-1 cells following mock treatment or $2 \mathrm{~h}$ after treatment with $250 \mu \mathrm{M} \mathrm{H}_{2} \mathrm{O}_{2}$ for 5 min. The cells were incubated with DMSO vehicle or $10 \mu \mathrm{M}$ PARPi for $1 \mathrm{~h}$ before, during and following $\mathrm{H}_{2} \mathrm{O}_{2}$ treatment as indicated. $\mathbf{f}$, Immunoblot of the poly(ADP-ribose) levels in WT RPE-1 cells treated with PARG inhibitor following mock treatment or treatment with $250 \mu \mathrm{M} \mathrm{H} \mathrm{O}_{2}$ for 5 min. Ponceau S staining is also shown as a loading control. For $\mathbf{d - f}$, representative blots from one of three independent experiments are shown. $\mathbf{g}$, Representative images of RNAPI foci (RPA194) and levels of global transcription (EU pulse labelling) in WT RPE-1 cells treated with PARG inhibitor following mock treatment or at the indicated times after treatment with $250 \mu \mathrm{M} \mathrm{H}_{2} \mathrm{O}_{2}$ for 5 min. $\mathbf{h}$, Levels of global transcription (EU immunofluorescence) from the experiment shown in $\mathbf{g}$. b,c,h, Data are the mean \pm s.e.m. of three independent experiments. Statistical significance was determined using a two-way ANOVA with Tukey's (b,c) or Sidak's (h) multiple comparisons test (significantly different $P$ values are indicated). Scale bars, $10 \mu \mathrm{m}$. PARGi, PARG inhibitor. 
that histone ribosylation is not the cause of transcriptional suppression (Extended Data Fig. 7).

As PARP1 can also affect transcription indirectly, via the recruitment of chromatin remodelling proteins ${ }^{41,42}$, we examined whether aberrant ADP-ribosylation affected the levels of histone marks known to promote transcriptional activity. Although the global levels of methylation and acetylation on histone $\mathrm{H} 3$ (H3K4me3 and $\mathrm{H} 3 \mathrm{~K} 9 \mathrm{Ac}$, respectively) were slightly, albeit not statistically
.

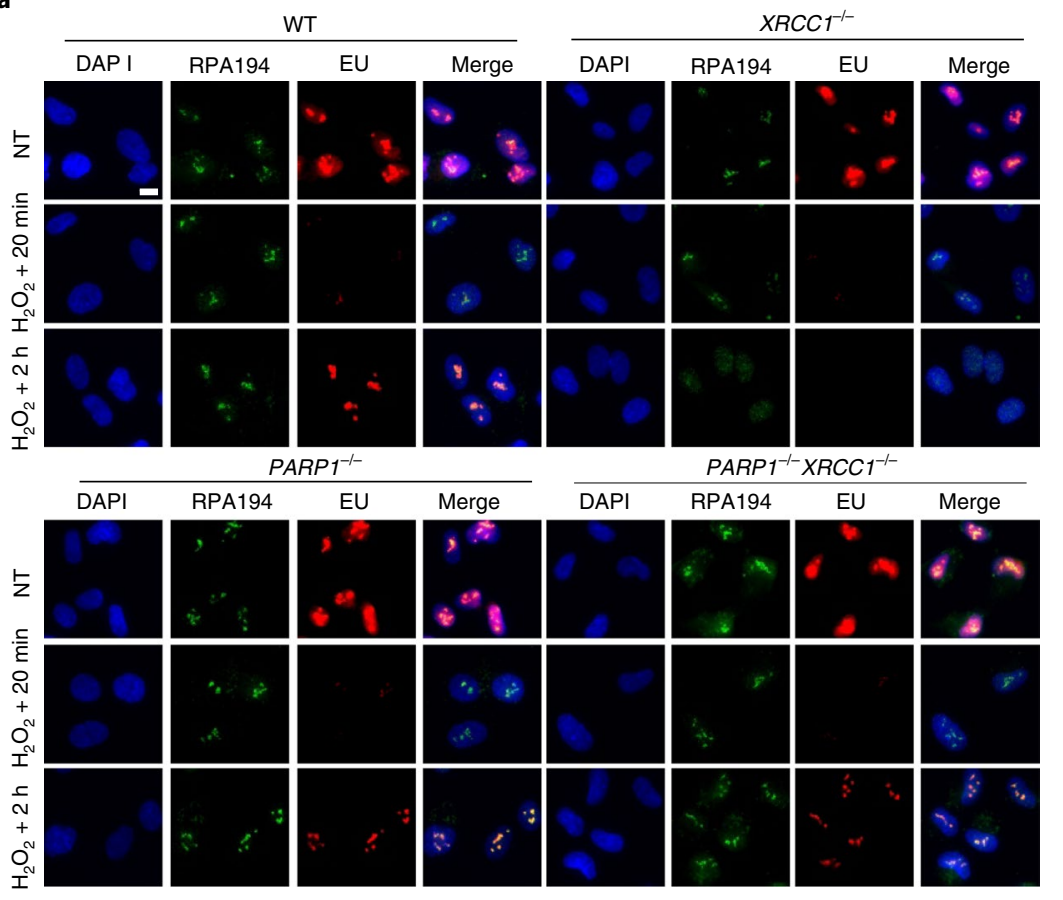

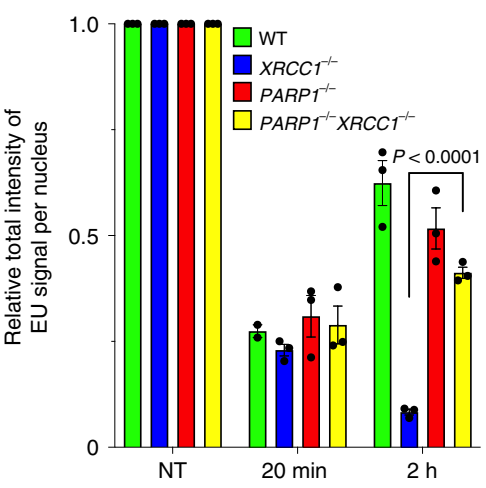

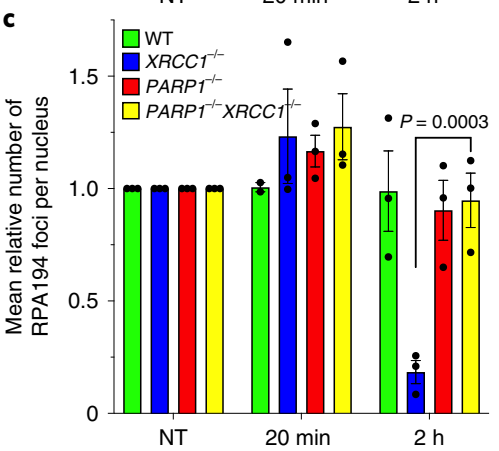

d

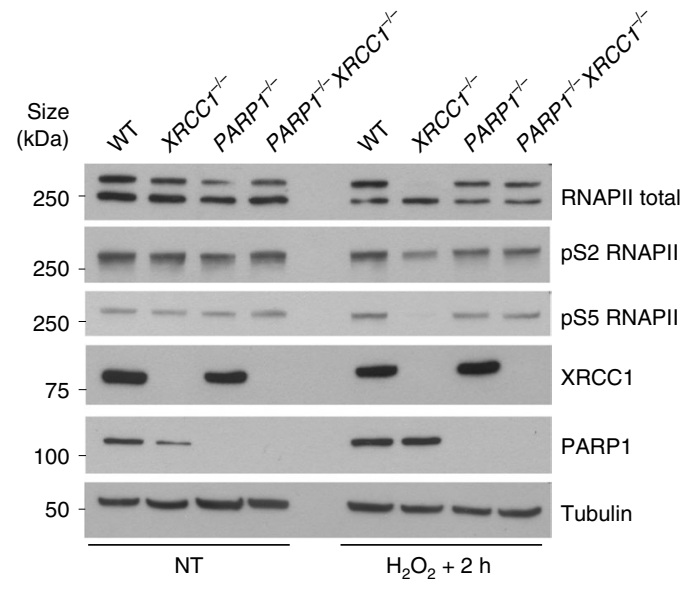

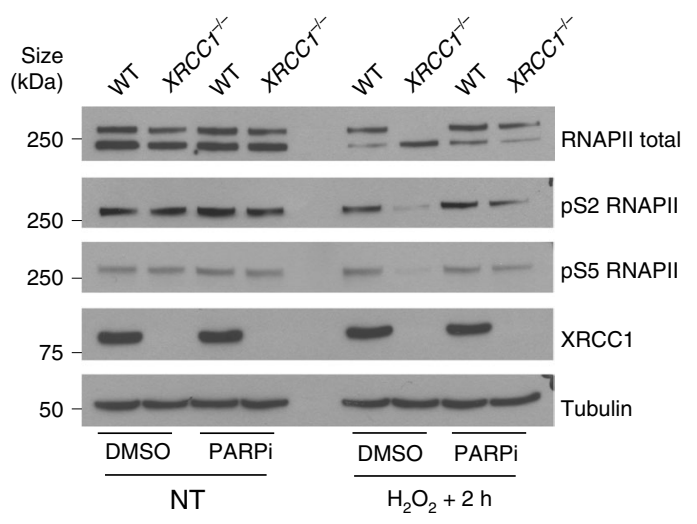
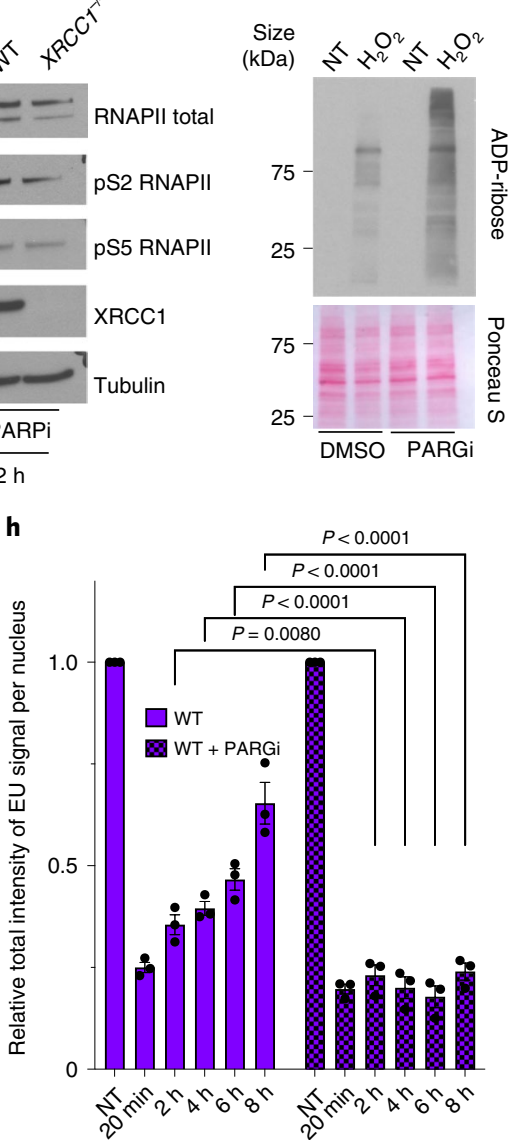

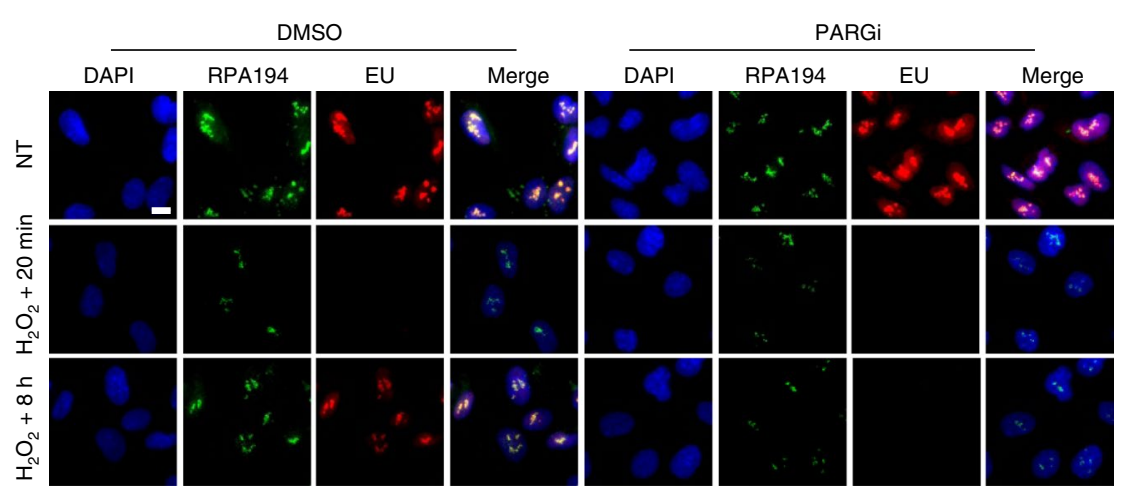




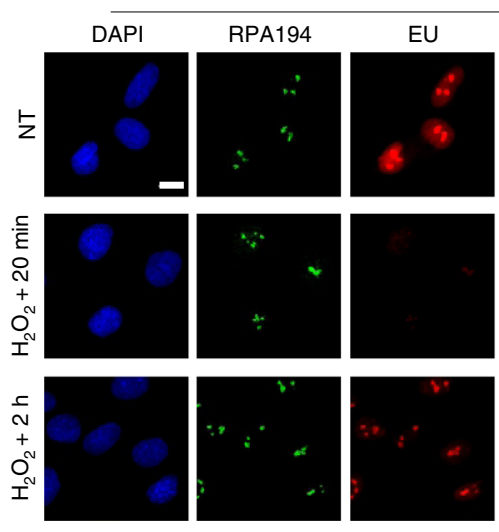

XD1

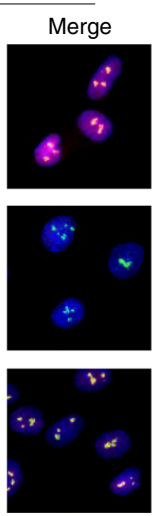

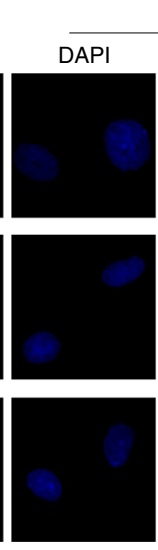

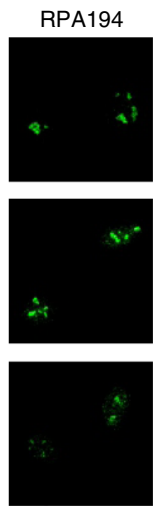

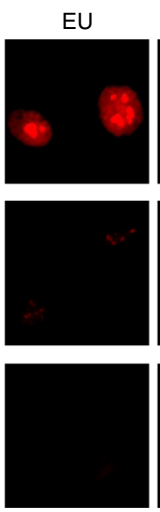

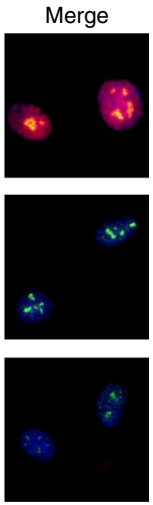

b

C

WT
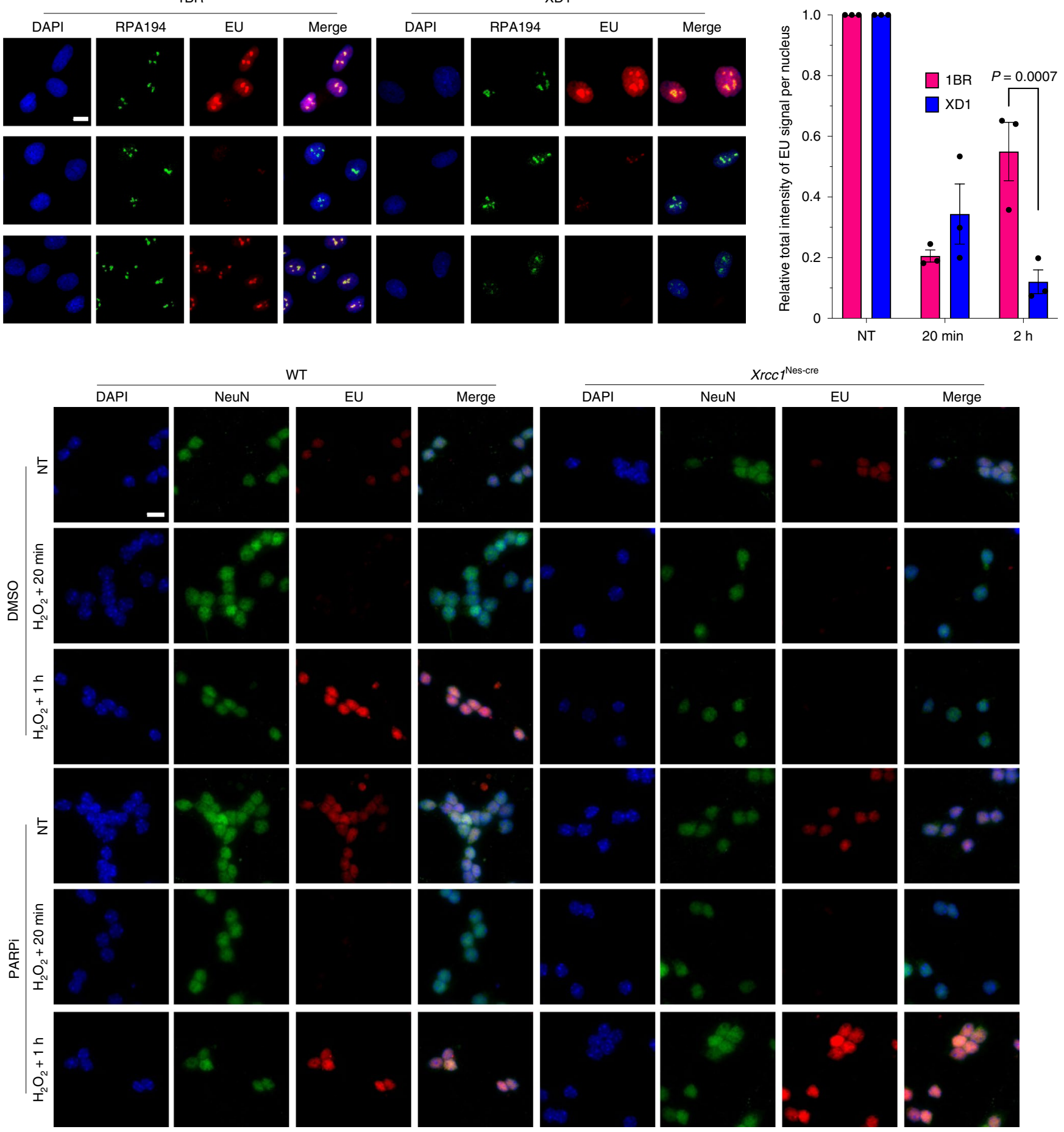

Fig. 3 | Toxic PARP1 activity suppresses transcriptional recovery in patient-derived fibroblasts with XRCC1 mutations and Xrcc1-deficient mouse cerebellar neurons. a, Representative images of RNAPI foci (RPA194) showing the levels of global transcription (EU pulse labelling) in normal (1BR) and patient-derived fibroblasts with XRCC1 mutations (XD1) following mock treatment or at the indicated times after treatment with $60 \mu \mathrm{M} \mathrm{H}_{2} \mathrm{O}_{2}$ for 5 min. The cells were pulse labelled with EU as in Fig. 1. b, Levels of global transcription (EU immunofluorescence) from the experiment shown in a. Data are the mean \pm s.e.m. of three independent experiments. Statistical significance was determined using a two-way ANOVA with Sidak's multiple comparisons test (significantly different $P$ values are indicated). c, Representative images of the global transcription levels (EU immunofluorescence) in WT and $X$ rcc $^{\text {Nes-cre }}$ mouse cerebellar neurons ( $\mathrm{NeuN}$ ), pretreated with PARPi, following mock treatment or at the indicated times after treatment with $250 \mu \mathrm{M} \mathrm{H} \mathrm{O}_{2}$ for 5 min. Representative images from one of three independent experiments are shown. Scale bars, $10 \mu \mathrm{m}$.

significantly, reduced in $\mathrm{XRCC1}^{-/-}$cells compared with WT cells $2 \mathrm{~h}$ after $\mathrm{H}_{2} \mathrm{O}_{2}$ treatment (Extended Data Fig. 8a,b), the global levels of $\mathrm{H} 2 \mathrm{AmUb}$ and $\mathrm{H} 2 \mathrm{BmUb}$ were dramatically reduced (Fig. $6 \mathrm{a}, \mathrm{b}$, respectively). The reduction in levels of $\mathrm{H} 2 \mathrm{BmUb}$ was particularly noteworthy because this modification promotes transcriptional activity by a number of different mechanisms, including the direct 
a

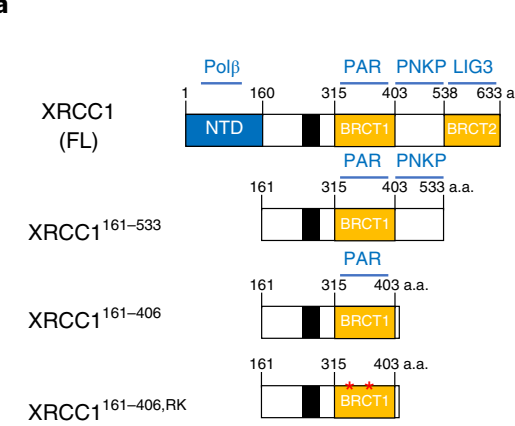

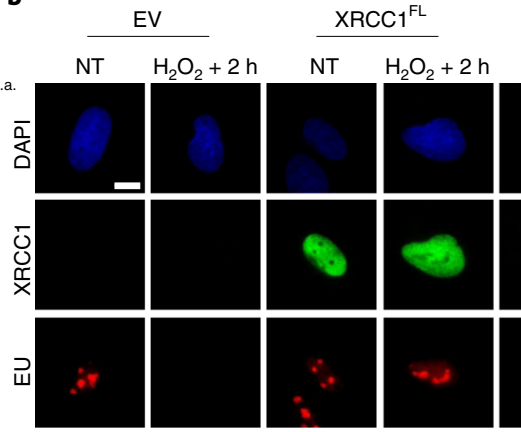

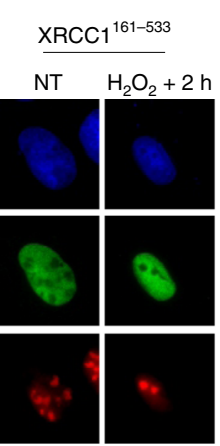

$\operatorname{XRCC1} 1^{161-406, R K}$

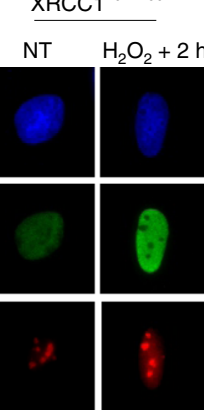

XRCC1 $101-406, R K$

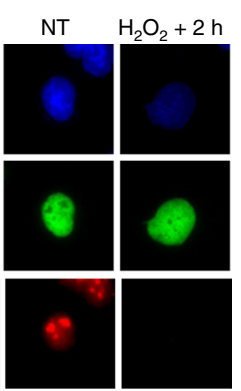

NLS: 241-279 a.a.

* R335A and K369A mutations

c Input (4\%)

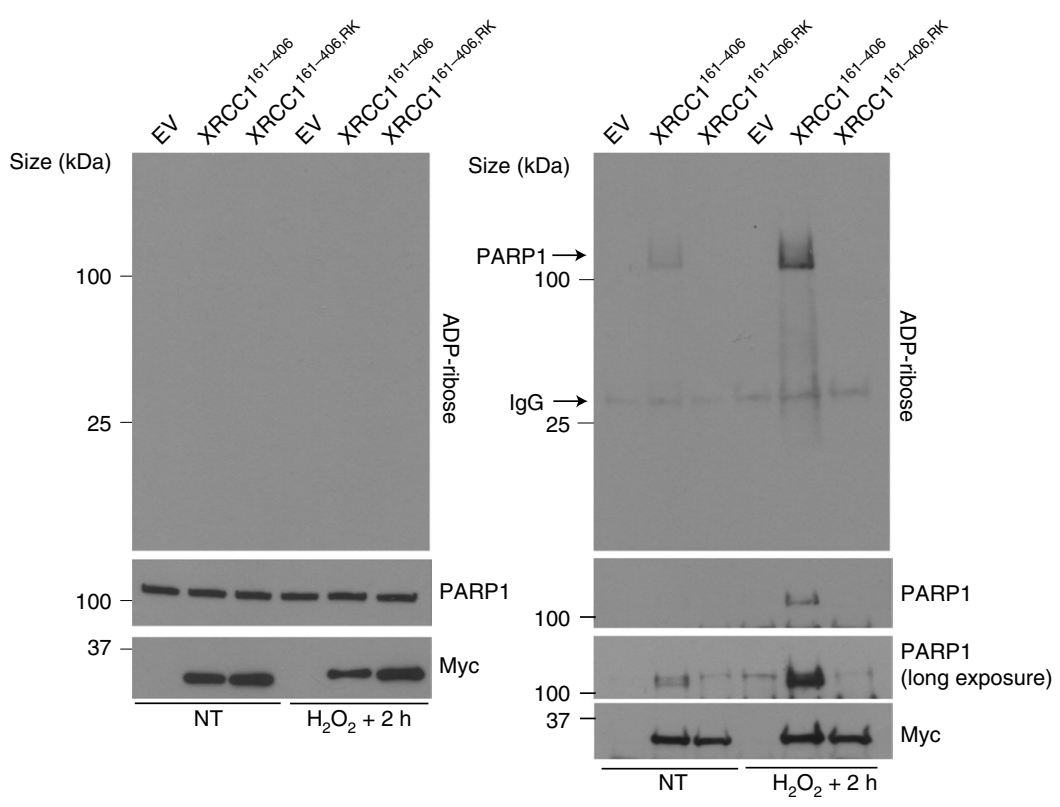

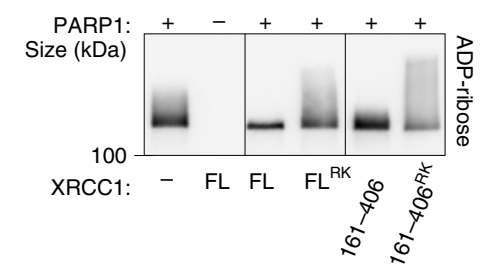

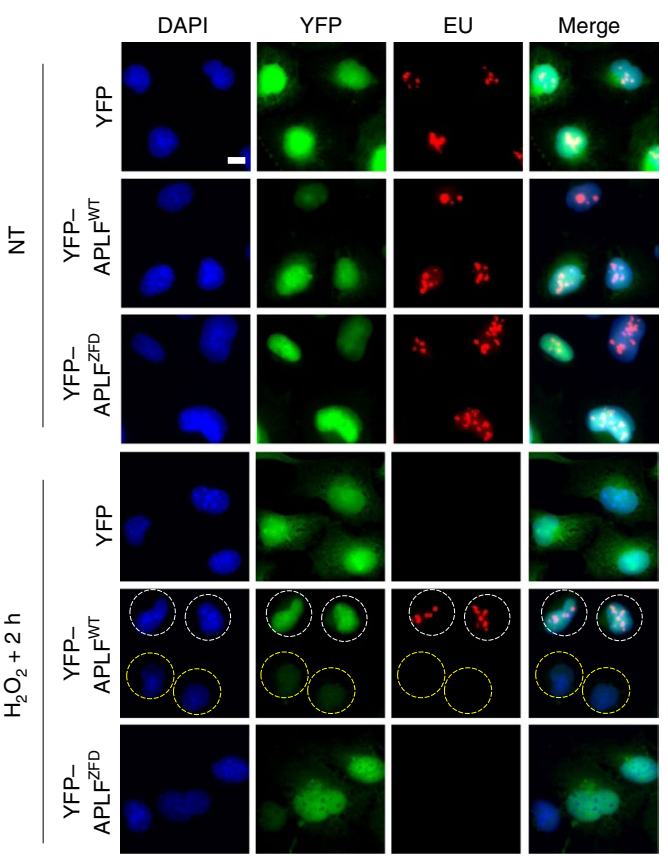

Fig. 4 | The poly(ADP-ribose)-binding activity of XRCC1 promotes transcriptional recovery following oxidative damage. a, Cartoon of full-length $(\mathrm{FL})$ and truncated XRCC1 proteins encoded by the Myc-and/or His-tagged expression constructs employed in this work. The interaction partners are shown (top): Pol $\beta$, DNA polymerase $\beta$; PAR, poly(ADP-ribose); PNKP, polynucleotide kinase phosphatase; LIG3, DNA ligase III. The N-terminal domain (NTD), nuclear localization signal (NLS) and two BRCT domains are also shown; a.a., amino acids. b, Representative images showing the levels of global transcription (EU pulse labelling; bottom) in XRCC1-/- U2OS cells, transiently transfected with expression constructs encoding the indicated XRCC1 proteins, following mock treatment or $2 \mathrm{~h}$ after treatment with $1 \mathrm{mM} \mathrm{H}_{2} \mathrm{O}_{2}$ for $20 \mathrm{~min}$. The XRCC1 protein levels are also shown (middle). The cells were pulse labelled with EU as in Fig. 1. EV, empty vector. c, Immunoblot of Myc-tagged XRCC1 proteins, PARP1 and ADP-ribose levels in cell extract from the indicated transiently transfected $X R C C 1^{-/-}$U2OS cells before (left, input) and after (right) anti-Myc immunoprecipitation, $2 \mathrm{~h}$ after mock treatment or treatment with $1 \mathrm{mM} \mathrm{H}_{2} \mathrm{O}_{2}$ for $20 \mathrm{~min}$ (right). d, XRCC1 suppresses PARP1 auto-ADP-ribosylation in vitro. Human recombinant PARP1 (100 nM) was incubated in the presence of single-stranded DNA $(100 \mathrm{nM}), \mathrm{NAD}^{+}(2.5 \mu \mathrm{M})$ and with or without $1 \mu \mathrm{M}$ of full-length XRCC1 or the indicated XRCC1 protein fragment for $30 \mathrm{~min}$. The reaction products were fractionated by SDS-PAGE and detected by western blotting with ADP-ribose detection reagent. e, Representative images showing the levels of global transcription (EU pulse labelling) in XRCC1-/- U2OS cells stably transfected with expression constructs encoding WT APLF (yellow fluorescent protein (YFP)-APLF ${ }^{W T}$ ) or its ADP-ribose binding mutant (YFP-APLF ${ }^{\text {ZFD }}$ ) following mock treatment or $2 \mathrm{~h}$ after treatment with $1 \mathrm{mM} \mathrm{H}_{2} \mathrm{O}_{2}$ for $20 \mathrm{~min}$. White and yellow circles indicate examples of cells over-expressing or not YFP-APLF, respectively. For b,e, representative images from one of three independent experiments are shown. Scale bars, $10 \mu \mathrm{m}$. $\mathbf{f}$, APLF suppresses PARP1 auto-ADP-ribosylation in vitro. Human recombinant PARP1 $(100 \mathrm{nM})$ was incubated in the presence of single-stranded DNA $(100 \mathrm{nM}), \mathrm{NAD}^{+}(2.5 \mu \mathrm{M})$ and with or without $0.25,0.5,1$ or $1.5 \mu \mathrm{M}$ WT recombinant human APLF or XRCC1 for $30 \mathrm{~min}$. The reaction products were fractionated by SDS-PAGE and detected by western blotting with ADP-ribose detection reagent. $\mathbf{c}, \mathbf{d}, \mathbf{f}$, Representative blots from one of three independent experiments are shown. 
a

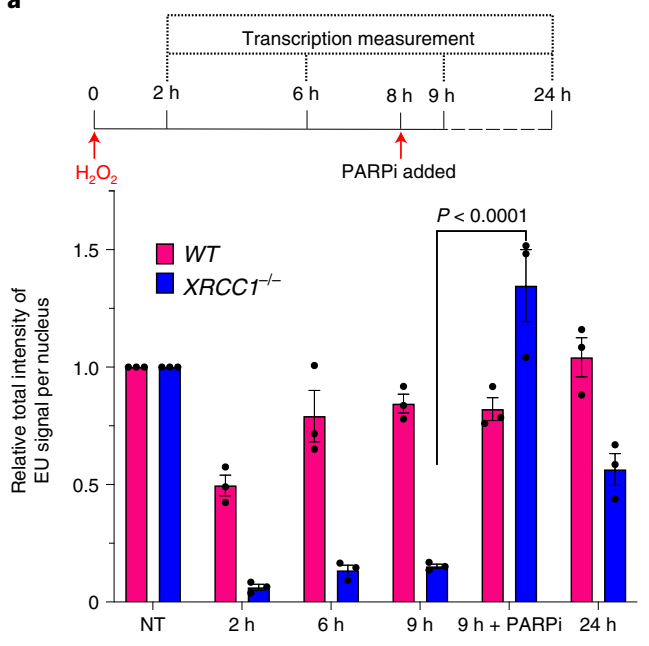

b

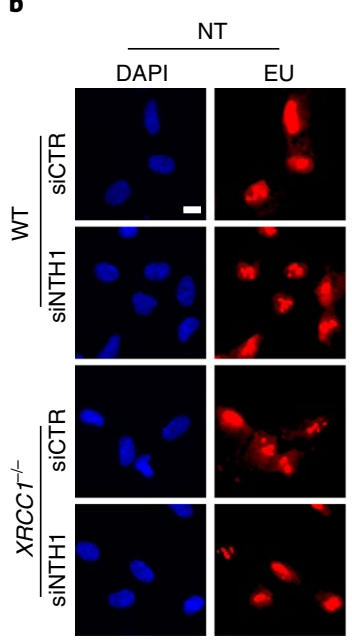

c d

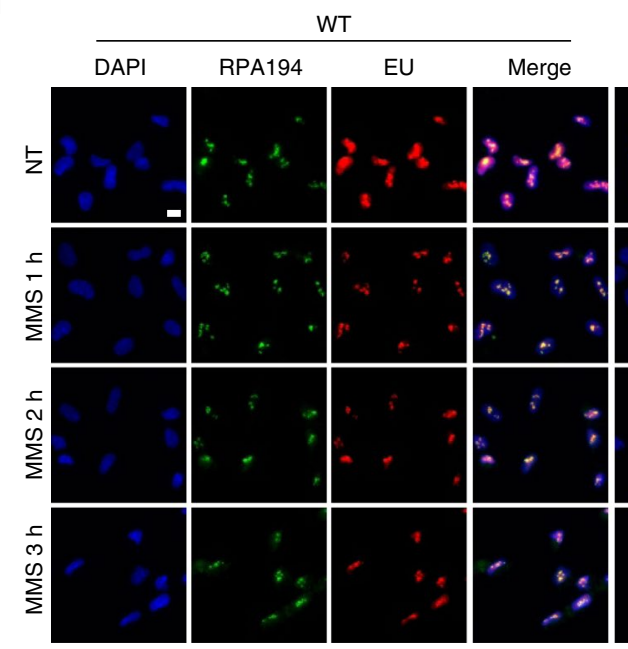

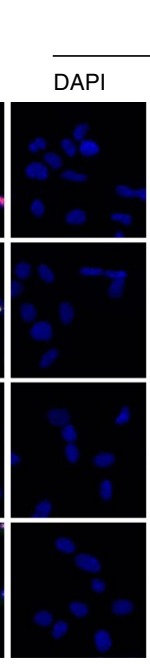

$X R C C 1^{-1-}$

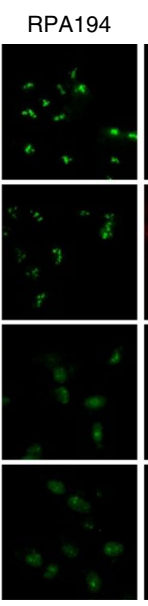

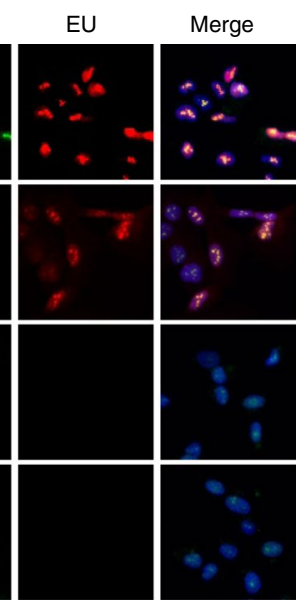

e
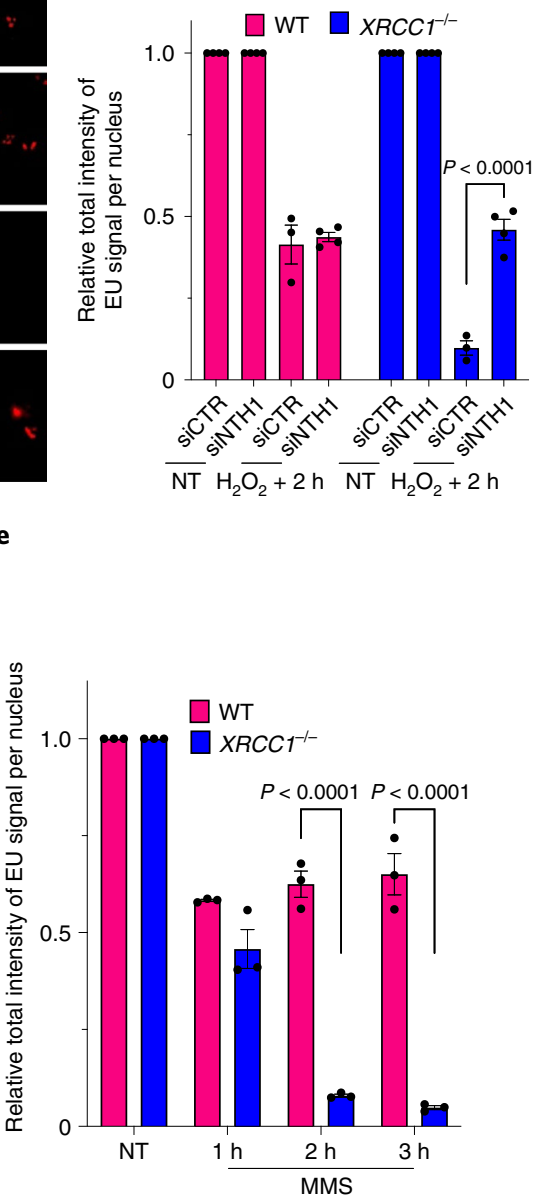

f

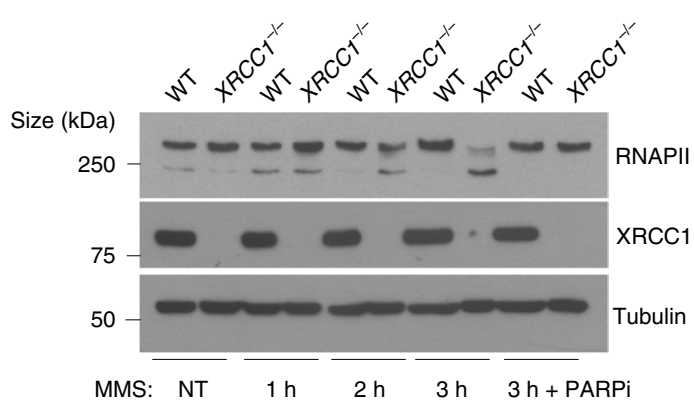

Fig. 5 | Unrepaired BER intermediates are a source of toxic PARP1 activity and transcriptional suppression in XRCC1-defective cells. a, Levels of global transcription (EU immunofluorescence; bottom) from the experiment outlined in the schematic (top; see also Extended Data Fig. 6a). b, Representative images of the levels of global transcription (EU pulse labelling) in WT and XRCC1-/- RPE-1 cells following mock treatment or at $2 \mathrm{~h}$ after treatment with $250 \mu \mathrm{M} \mathrm{H}_{2} \mathrm{O}_{2}$ for 5 min. The cells were pretreated with control (siCTR) or siRNA targeting NTH1 (siNTH1) for $72 \mathrm{~h}$. The cells were pulse labelled with $\mathrm{EU}$ as in Fig. 1. c, Levels of global transcription from the experiment in b. d, Representative images of the levels of global transcription (EU pulse labelling) in WT and $\mathrm{XRCC1}^{-1-} \mathrm{RPE}-1$ cells following mock treatment or at the indicated times after treatment with $0.1 \mathrm{mg} \mathrm{ml}^{-1} \mathrm{MMS}$ (continuous treatment). The cells were pulse labelled with EU as in Fig. 1. b,d, Scale bars, $10 \mu \mathrm{m}$. e, Levels of global transcription (EU pulse labelling) from the experiment shown in d. $\mathbf{a}, \mathbf{c}, \mathbf{e}$, Data are the mean \pm s.e.m. of three independent experiments. Statistical significance was determined using a two-way ANOVA with Sidak's multiple comparisons test (significantly different $P$ values are indicated). f, Immunoblot of RNAPII hyperphosphorylation in WT and XRCC1-/- RPE-1 cells following mock treatment or after treatment for the indicated times with $0.1 \mathrm{mg} \mathrm{ml}^{-1} \mathrm{MMS}$. Where indicated, $10 \mu \mathrm{M}$ PARPi was present throughout the MMS treatment. A representative blot from one of three independent experiments is shown.

relaxation of chromatin structure, facilitation of RNAP elongation and modulation of the activity of different transcriptional regulators $^{43-45}$. Similar results were observed following MMS treatment, thereby confirming that the loss of histone monoubiquitination in $\mathrm{XRCC}^{-1-}$ cells was a result of DNA base damage (Fig. $6 \mathrm{c}, \mathrm{d}$ ). Moreover, normal levels of histone ubiquitination were restored in 

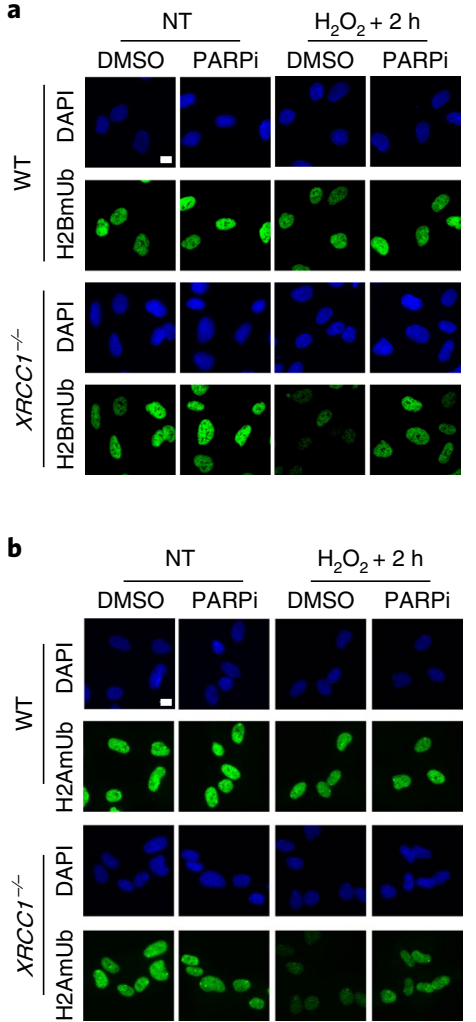

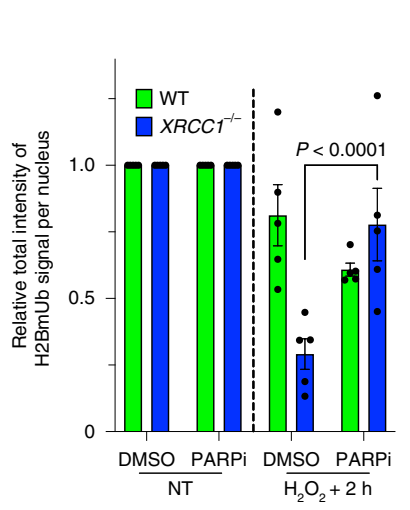

C
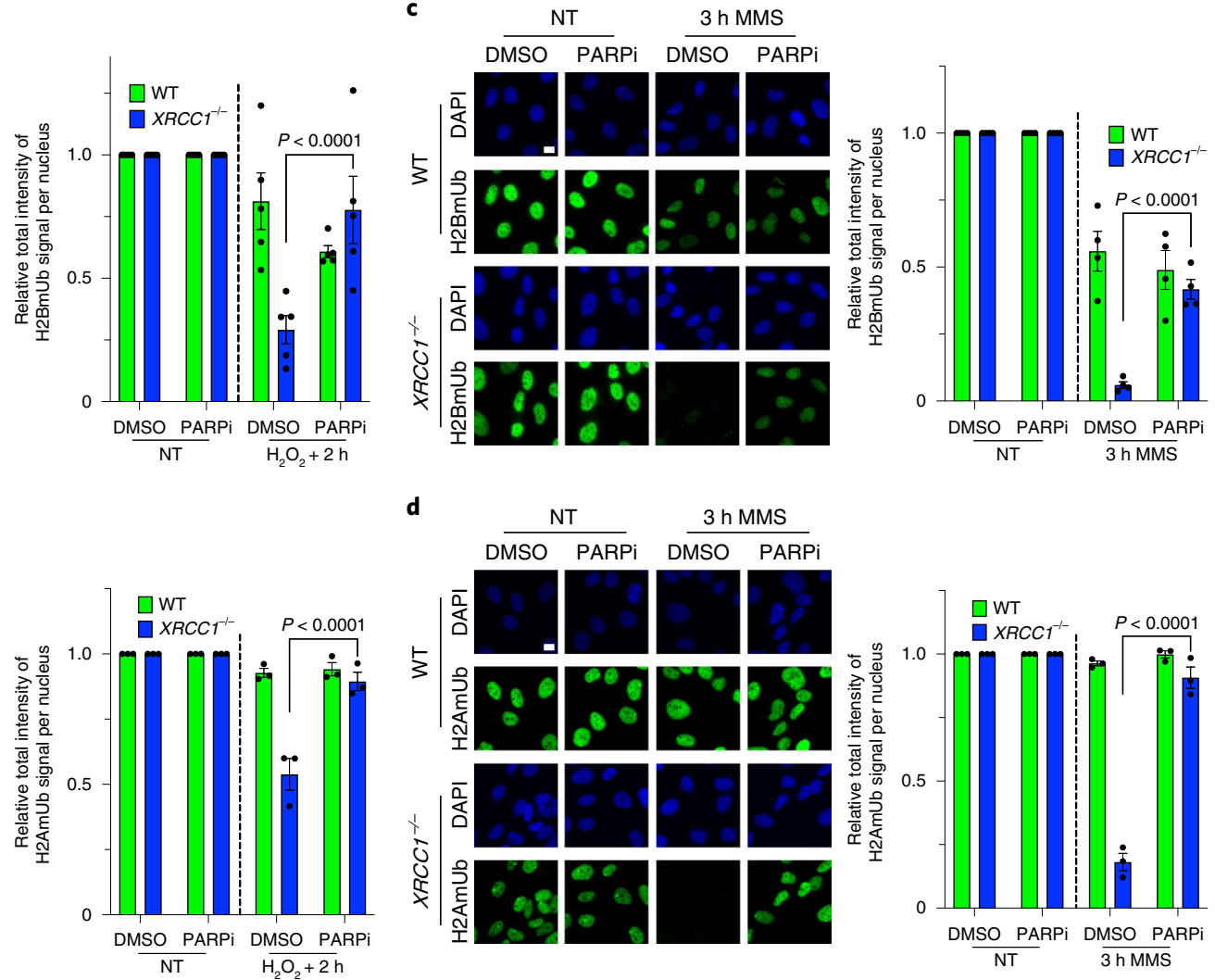

d

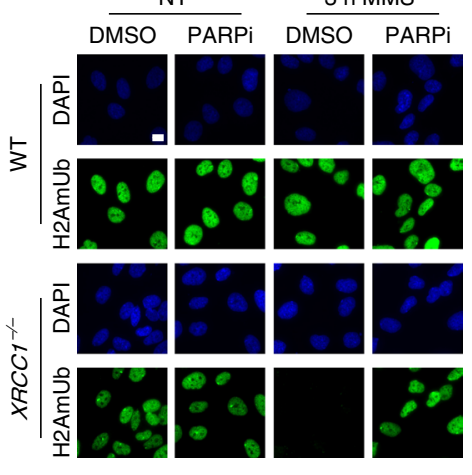

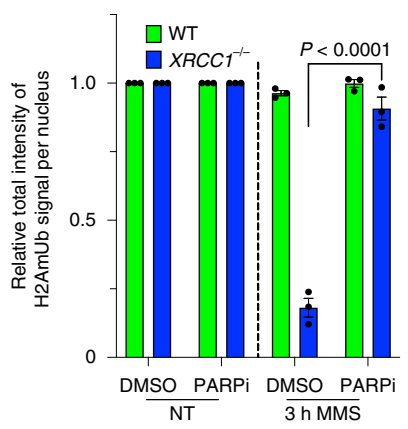

Fig. 6 | Toxic PARP1 activity during BER disrupts global histone monoubiquitination. a, Representative images (left) and levels (right) of $\mathrm{H} 2 \mathrm{BmUB}$ in WT and $\mathrm{XRCC1}^{-1-}$ RPE-1 cells following mock treatment or at the indicated times after treatment with $250 \mu \mathrm{M} \mathrm{H}_{2} \mathrm{O}_{2}$ for 5 min. $\mathbf{b}$, Representative images (left) and levels (right) of H2AmUb in WT and XRCC1-/- RPE-1 cells following mock treatment or at the indicated times after treatment with $250 \mu \mathrm{M}$ $\mathrm{H}_{2} \mathrm{O}_{2}$ for 5 min. $\mathbf{a}, \mathbf{b}$, The cells were incubated with DMSO vehicle or $10 \mu M$ PARPi for $1 \mathrm{~h}$ before, during and following $\mathrm{H}_{2} \mathrm{O}_{2}$ treatment as indicated. c, Representative images (left) and levels (right) of H2BmUB in WT and XRCC1-1- RPE-1 cells following mock treatment or at the indicated times after treatment with $0.1 \mathrm{mg} \mathrm{ml}^{-1} \mathrm{MMS}$ (continuous treatment). d, Representative images (left) and levels (right) of H2AmUb in WT and XRCC1-/- RPE-1 cells following mock treatment or at the indicated times after treatment with $0.1 \mathrm{mg} \mathrm{ml}^{-1} \mathrm{MMS}$ (continuous treatment). c,d, The cells were incubated with DMSO vehicle or $10 \mu \mathrm{M}$ PARPi during the MMS treatment. a-d, Data are the mean \pm s.e.m. of five (a), three (b,d) and four (c) independent experiments. Statistical significance was determined using a two-way ANOVA with Tukey's multiple comparisons test (significantly different $P$ values are indicated). Scale bars, $10 \mu \mathrm{m}$.

$X R C C 1^{-1-}$ cells by incubation with PARPi, demonstrating that the loss of these important histones modifications was the result of aberrant ADP-ribosylation (Fig. 6a-d). This impact of aberrant PARP activity on histone ubiquitination was particularly pronounced given that we did not detect a reduction in total chromatin ubiquitination, as detected by the anti-ubiquitin antibody FK2 (Extended Data Fig. 8c).

PARP1 suppresses histone monoubiquination and transcription recovery by triggering aberrant recruitment of the ubiquitin protease USP3. Finally, to identify the mechanism by which aberrant PARP1 activity reduces histone monoubiquitination, we depleted enzymes that are known to deubiquitinate histone $\mathrm{H} 2 \mathrm{~A}$ and/or $\mathrm{H} 2 \mathrm{~B}^{46-53}$. Whereas siRNA directed against either of the deubiquitylases USP22 and USP36 failed to rescue transcription recovery in $X R C C 1^{-1-}$ cells following $\mathrm{H}_{2} \mathrm{O}_{2}$ treatment, siRNA to USP11 resulted in a small but significant rescue of transcription recovery (Extended Data Fig. 9a). More importantly, however, siRNA directed against USP3 resulted in almost complete rescue of transcription recovery in $X R C C 1^{-/-}$RPE-1 cells following $\mathrm{H}_{2} \mathrm{O}_{2}$ treatment, whether measured by EU pulse labelling (Fig. 7a and Extended Data Fig. 9a) or RNAPII hyperphosphorylation (Fig. 7b). Consistent with these data, USP3 siRNA prevented the PARP1-dependent reduction in histone monoubiquitination following $\mathrm{H}_{2} \mathrm{O}_{2}$ treatment
(Fig. $7 \mathrm{c}$ and Extended Data Fig. 9b). The USP3 siRNA also reduced the loss of histone monoubiquitination in $\mathrm{XRCC1}^{-1-}$ cells during continuous treatment with MMS (Fig. $7 \mathrm{~d}$ and Extended Data Fig. 9c) throughout the $3 \mathrm{~h}$ time course. We also detected the accumulation of green fluorescent protein (GFP)-tagged USP3 in the chromatin of the $X R C C 1^{-1-}$ cells during MMS treatment, which was prevented by treatment with PARPi, providing support for PARP1 activity as a source of aberrant USP3 recruitment during BER (Fig. 8a). Interestingly, the amino (N)-terminal zinc finger domain of USP3 was sufficient for PARP-dependent recruitment at BER intermediates. However, we were unable to detect any evidence of direct binding of this domain to poly(ADP-ribose) (Extended Data Fig. 10a-f), which suggests that PARP1 mediates USP3 recruitment indirectly, perhaps via its well-established role in regulating chromatin compaction ${ }^{6,54,55}$.

\section{Discussion}

XRCC1 is a molecular scaffold protein that interacts with many of the enzymatic components of SSB repair ${ }^{27}$. At SSBs arising during BER, as obligate intermediates of base excision, XRCC1 interacts with and stabilizes DNA polymerase $\beta$ and DNA ligase III ${ }^{56}$. Another critical role of XRCC1 during SSB repair is to prevent excessive activation of PARP1, which can otherwise lead to neurological dysfunction ${ }^{18,19}$. However, the mechanisms by which excessive/aberrant PARP1 

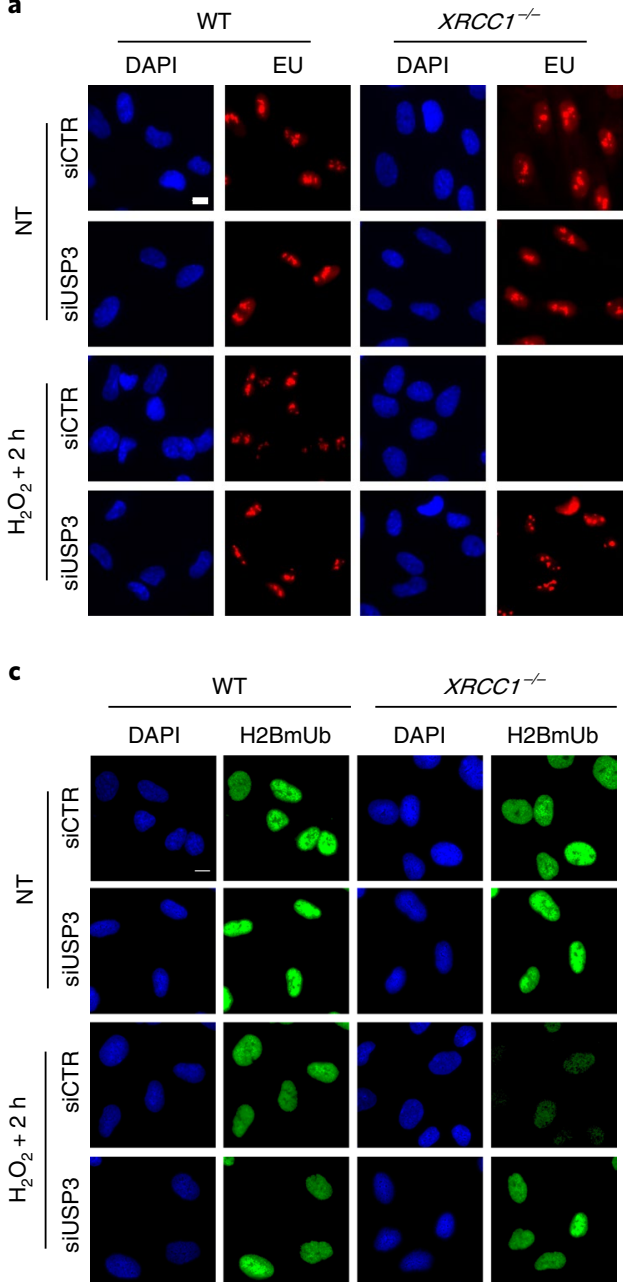

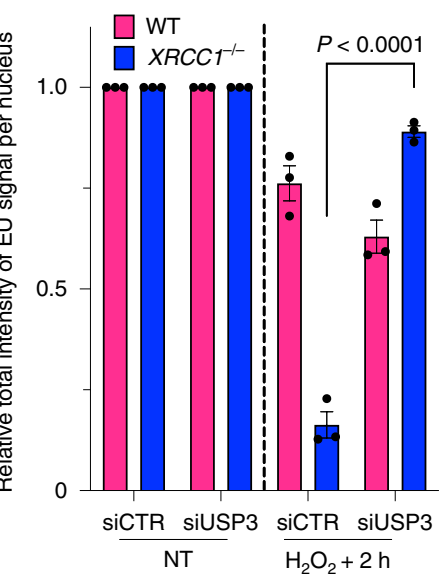

b

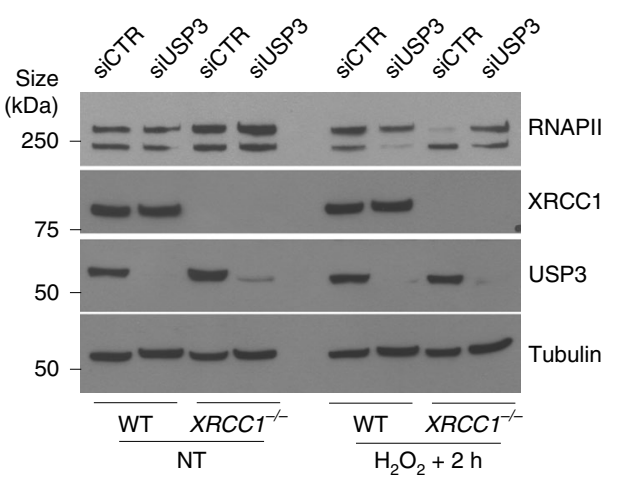

d
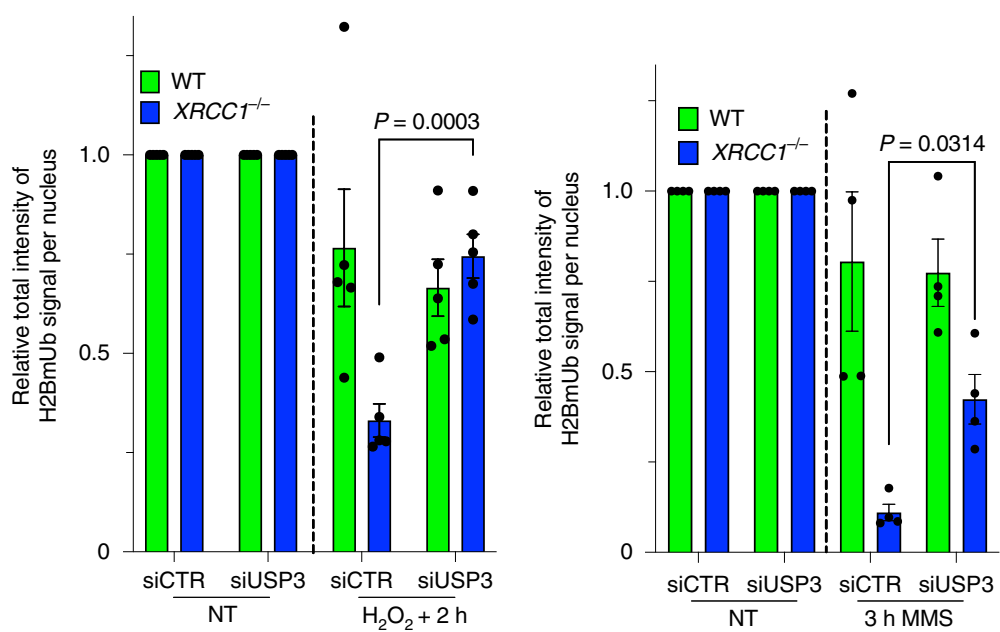

Fig. 7 | Toxic PARP1 activity disrupts histone monoubiquitination and promotes transcriptional suppression via USP3. a, Representative images (left) and levels (right) of global transcription (EU pulse labelling) in WT and XRCC1-/- RPE-1 cells following mock treatment or at the indicated times after $\mathrm{H}_{2} \mathrm{O}_{2}$ treatment ( $250 \mu \mathrm{M} ; 5 \mathrm{~min}$ ). The cells were pretreated with control (siCTR) or USP3 siRNA (siUSP3) and pulse labelled with EU. b, RNAPII hyperphosphorylation in WT and XRCC1-/- RPE-1 cells, pretreated with control or USP3 siRNA as indicated, following mock treatment or $2 \mathrm{~h}$ after treatment with $\mathrm{H}_{2} \mathrm{O}_{2}$ as in $\mathbf{a}$. A representative blot of the whole-cell extracts from one of three independent experiments is shown. $\mathbf{c}$, Representative images (left) and levels (right) of $\mathrm{H} 2 \mathrm{BmUb}$ in WT and $X \mathrm{RCC1}^{-1-} \mathrm{RPE}-1$ cells, pretreated with control or USP3 siRNA as in a following $\mathrm{H}_{2} \mathrm{O}_{2}$ treatment. a,c, Scale bars, $10 \mu \mathrm{m}$. d, Levels of $\mathrm{H} 2 \mathrm{BmUb}$ in WT and XRCC1-1- RPE-1 cells following mock treatment or treatment with $0.1 \mathrm{mg} \mathrm{ml} \mathrm{m}^{-1} \mathrm{MMS}$ for $3 \mathrm{~h}$. The cells were pretreated with control or USP3 siRNA. a,c,d, Data are the mean \pm s.e.m. of three (a), five (c) and four (d) independent experiments. Statistical significance was determined using a two-way ANOVA with Tukey's multiple comparisons test (significantly different $P$ values are indicated).

activity triggers this pathology have been unclear. One recent clue emerged from the discovery that the assembly of DNA repair protein complexes by XRCC1 is necessary to prevent excessive engagement and activity of PARP1 during BER, which otherwise leads to PARP1 'trapping' on BER intermediates and consequently their reduced access and repair by other BER enzymes ${ }^{30}$. The data presented in this study demonstrate that the low but persistent levels of PARP1 activity associated with this 'trapped' PARP1 in XRCC1-defective cells lead to prolonged transcriptional suppression. This delay in transcription recovery is not simply a result of slower BER because PARP inhibition by a chemical inhibitor or overexpression of either of two distinct poly(ADP-ribose)-binding domains is sufficient to rescue transcription recovery in XRCC1-defective cells, even in the continued presence of unrepaired BER intermediates. The recovery of transcription at BER intermediates can thus be separated mechanistically from the completion of BER. This result may indicate that although SSBs may initially impede RNAP progression, these lesions can eventually be bypassed, as long as PARP1 signalling at the unrepaired SSBs is suppressed. Alternatively, the prolonged suppression of transcription by PARP1 detected in our experiments may reflect an impact on RNAP initiation and/or elongation in trans at sites distal to unrepaired SSBs.

PARP1 is a dynamic regulator of gene activity and is able to either repress or activate gene transcription in response to different physiological stimuli ${ }^{57-59}$. PARP activity can regulate transcription in a number of ways, such as by relaxing higher-order chromatin compaction and/or regulating RNAP activity ${ }^{60-62}$. PARP1 can also recruit polycomb and NuRD transcriptional repressor complexes, thereby facilitating the initial suppression of transcription following DNA damage ${ }^{41,42}$. However, we did not detect a requirement for PARP1 for the initial suppression of transcription following DNA damage-the initial reduction in EU pulse labelling observed following $\mathrm{H}_{2} \mathrm{O}_{2}$ treatment was not prevented by PARP1 deletion or inhibition. Thus, in our experiments the initial suppression of transcription probably reflects a PARP-independent mechanism, such as the pausing of RNAPII by BER intermediates ${ }^{21,63}$. 


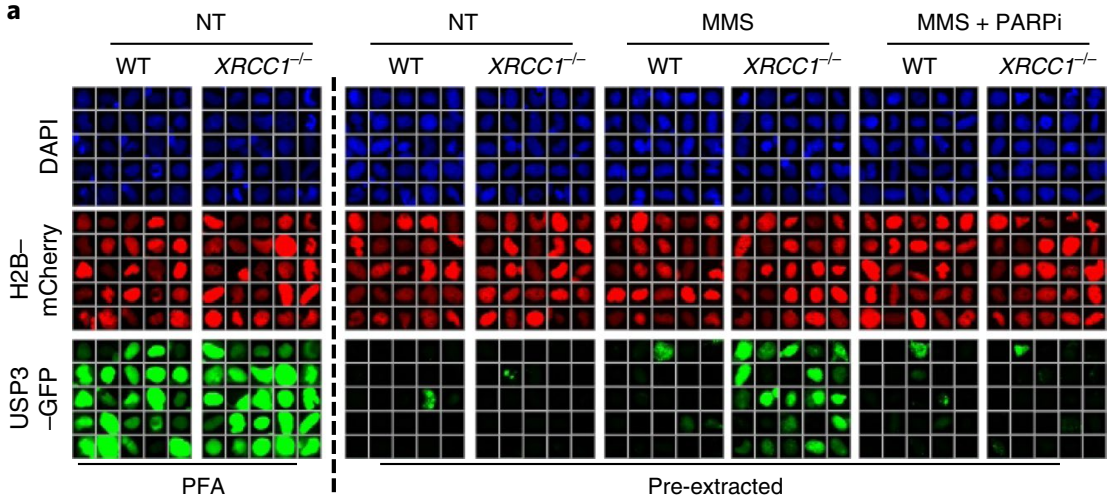

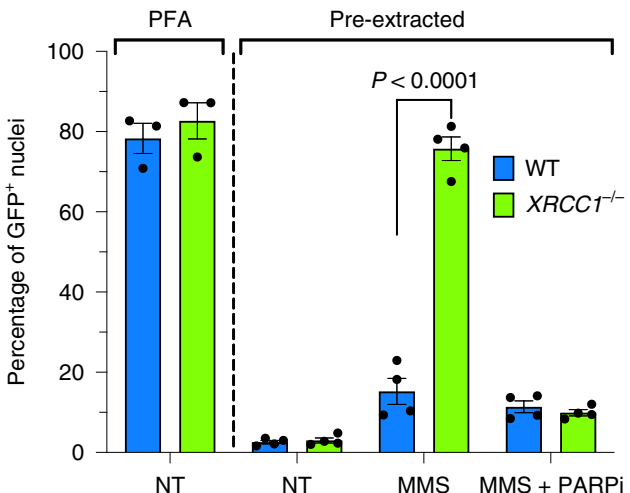

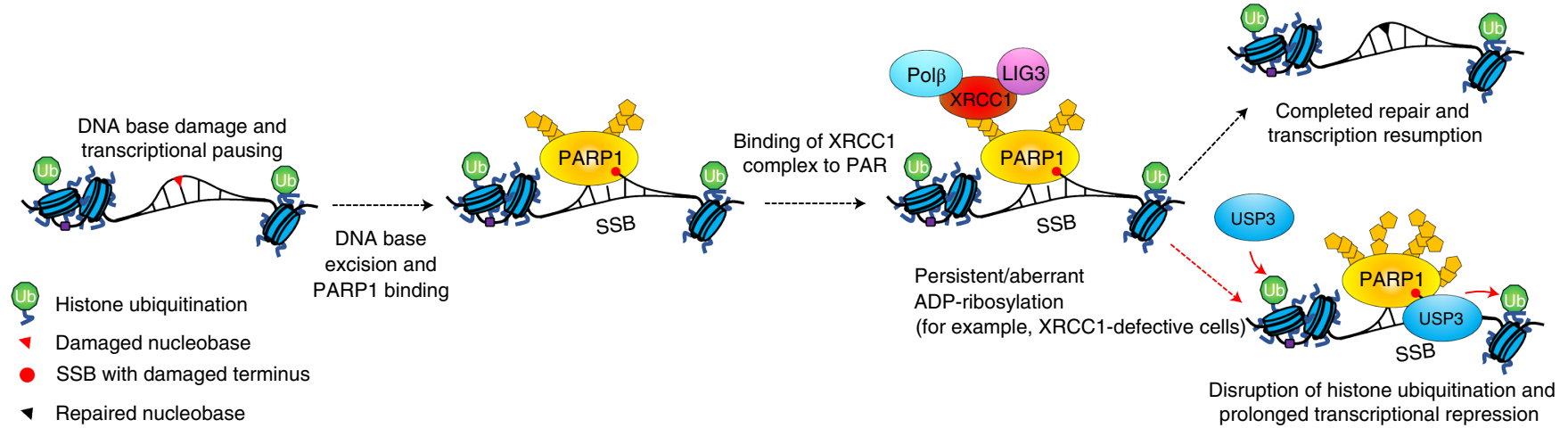

Fig. 8 | PARP1-dependent recruitment of USP3 into chromatin during BER in XRCC1-defective cells. a, Chromatin retention of USP3-GFP in WT and $X R C C 1^{-1-}$ U2OS cells transiently expressing $\mathrm{H} 2 \mathrm{~B}-\mathrm{mCherry}$ and USP3-GFP following mock treatment or treatment with $0.1 \mathrm{mg} \mathrm{ml}^{-1} \mathrm{MMS}^{-1}$ the presence or absence of $10 \mu \mathrm{M}$ PARPi as indicated. The cells were either immediately fixed with paraformaldehyde (PFA) to detect total protein or first extracted with detergent to remove the soluble proteins (pre-extracted), as indicated. Data are the mean \pm s.e.m. of four independent experiments. Statistical significance was determined using a two-way ANOVA with Sidak's multiple comparisons test (significantly different $P$ values are indicated). Representative scanR galleries of individual cells (left) and quantification (right) are shown. Scale bar, $10 \mu \mathrm{m}$. b. Model for prolonged PARP1/USP3-dependent suppression of transcription during BER. In WT cells, RNAP pausing at BER intermediates is accompanied by PARP1 activation, completion of BER by XRCC1 protein complexes and transcription resumption. In XRCC1-defective cells, persistent PARP1 activity at unrepaired BER intermediates leads to aberrant USP3 recruitment, extensive/excessive protein deubiquitination (including histones) at damaged and proximal/nearby undamaged sites, and prolonged transcriptional suppression. Note that PARP1 inhibition prevents USP3 recruitment and rescues global transcription recovery, most probably reflecting the eventual bypass of unrepaired SSBs by RNAP and/or transcription resumption at proximal/nearby undamaged sites.

A striking feature of our work is the discovery that excessive/ aberrant PARP1 activity prolongs transcriptional suppression via recruitment of the ubiquitin protease USP3. We do not yet know how poly(ADP-ribose) synthesis recruits USP3 into chromatin at unrepaired BER intermediates. Although the N-terminal zinc finger of USP3 is sufficient for this recruitment, we have so far not detected binding of this domain to poly(ADP-ribose). PARP1 might therefore mediate USP3 recruitment indirectly, such as via its ability to regulate chromatin compaction. For example, the ability of poly(ADP-ribose) to relax chromatin structure directly ${ }^{64,65}$ or indirectly via the recruitment of one or more chromatin remodelling enzymes $^{41,42,66-68}$ may allow the USP3 zinc finger to detect its ubiquitylated substrate $/ \mathrm{s}^{51}$. USP3 deubiquitinates multiple substrates, including the histones $\mathrm{H} 2 \mathrm{~A}, \gamma \mathrm{H} 2 \mathrm{AX}$ and $\mathrm{H} 2 \mathrm{~B}$, and is implicated in the cellular response to DNA damage both in vitro and in vivo ${ }^{51-53,69}$. In particular, reduced USP3 levels are associated with increased levels of DNA breakage and DNA replication stress as well as slower S phase progression ${ }^{51,52}$. USP3 reduces the level of $\gamma \mathrm{H} 2 \mathrm{AX}$ and $\mathrm{H} 2 \mathrm{~A}$ ubiquitination at $\mathrm{K} 13$ and $\mathrm{K} 15$, which are key sites of RNF8- and RNF168-mediated ubiquitination that regulate the repair of DNA double-strand breaks ${ }^{53,69,70}$. However, these modifications are unlikely to explain the impact of USP3 on transcription repression in our experiments, which result from unrepaired SSBs. Moreover, these modifications are not known to regulate transcriptional activity.

USP3 also deubiquitinates $\mathrm{H} 2 \mathrm{~A}$ and $\mathrm{H} 2 \mathrm{~B}$ monoubiquitination at K119 and K120, respectively ${ }^{51,52}$, both of which are critical for normal transcriptional control and are regulated in response to DNA damage $\mathrm{e}^{42,71-74}$. Of these two modifications, it is the loss of $\mathrm{H} 2 \mathrm{BmUb}$ that is a more likely explanation for the prolonged transcriptional suppression observed in our experiments. This is because this modification promotes transcriptional activity, whereas loss of $\mathrm{H} 2 \mathrm{AmUb}$ ought to increase transcription. We do not yet know why loss of $\mathrm{H} 2 \mathrm{BmUb}$ might dominate the transcriptional response in our experiments but it may relate to the different mechanisms and/ or kinetics by which $\mathrm{H} 2 \mathrm{AmUb}$ and $\mathrm{H} 2 \mathrm{BmUb}$ regulate transcription. For example, loss of $\mathrm{H} 2 \mathrm{BmUb}$ can reduce RNAP progression directly, and thus rapidly, by affecting nucleosome unwinding mediated by the histone chaperone FACT ahead of $\mathrm{RNAP}^{44}$. In contrast, loss of $\mathrm{H} 2 \mathrm{AmUb}$ may increase gene transcription more slowly via the progressive loss of polycomb-repressive complexes from chromatin $^{75}$. Consistent with this idea, we did not detect changes in the levels of $\mathrm{H} 3 \mathrm{~K} 4 \mathrm{me} 3$, which is a downstream target of $\mathrm{H} 2 \mathrm{AmUb}^{76}$, in our experiments (Extended Data Fig. 8).

$\mathrm{H} 2 \mathrm{BmUb}$ is tightly coupled with RNAP elongation ${ }^{44,77,78}$ and promotes transcription in several ways, including facilitating histone 
$\mathrm{H} 3 \mathrm{~K} 4$ and $\mathrm{H} 3 \mathrm{~K} 79$ methylation ${ }^{79,80}$ and cooperating with $\mathrm{FACT}^{44}$ $\mathrm{H} 2 \mathrm{BmUb}$ is also regulated in response to DNA damage. For example, $\mathrm{H} 2 \mathrm{BmUb}$ is introduced at DNA double-strand breaks as a result of ATM-mediated phosphorylation and recruitment of the RNF20-RNF40 heterodimer, the ubiquitin E3 ligase that promotes this modification ${ }^{81}$. More intriguingly, with respect to the current work, $\mathrm{H} 2 \mathrm{BmUb}$ is deubiquitinated at sites of DNA damage that have stalled RNAP ${ }^{82}$. In yeast, $\mathrm{H} 2 \mathrm{BmUb}$ is deubiquitinated by Ubp 8 and Ubp10, the former of which is the ubiquitin protease most closely related to USP3. It is thus tempting to speculate that a similar process occurs at sites of stalled RNAP in human cells and that the prolonged transcriptional suppression by USP3 in BER-defective cells is a pathological extension of this process (Fig. 8b).

Finally, hereditary XRCC1 mutations result in cerebellar ataxia and deletion of XRCC1 in the mouse brain results in cerebellar ataxia, seizures and juvenile mortality ${ }^{18,19,26}$. The impact of excessive/aberrant PARP1 activity on these phenotypes is illustrated by PARP1 inhibition and/or deletion, which alleviate the neuropathology in Xrccl-defective neurons and mice ${ }^{19}$. Xrcc1-defective neurons also exhibit a defect in pre-synaptic $\mathrm{Ca}^{2+}$ signalling, which is rescued by PARP inhibition/deletion, which in light of our recent data might reflect an impact of aberrant PARP1 activity on the expression of genes critical for normal neuronal activity ${ }^{19}$. Consistent with this idea, we recently demonstrated that neuronal enhancers are hotspots of SSB repair ${ }^{83}$, most probably as a result of cytosine demethylation during the epigenetic (re)programming of neuronal gene expression; a process in which XRCC1-mediated BER is strongly implicated ${ }^{84-86}$. It is also possible that PARP1 activity might impact on transcription in other pathophysiological conditions that induce DNA base damage, such as chronic inflammation ${ }^{87}$.

\section{Online content}

Any methods, additional references, Nature Research reporting summaries, source data, extended data, supplementary information, acknowledgements, peer review information; details of author contributions and competing interests; and statements of data and code availability are available at https://doi.org/10.1038/ s41556-021-00792-w.

Received: 7 May 2021; Accepted: 11 October 2021;

Published online: 22 November 2021

\section{References}

1. Lindahl, T. Instability and decay of the primary structure of DNA. Nature 362, 709-715 (1993)

2. Yoon, G. \& Caldecott, K. W. Nonsyndromic cerebellar ataxias associated with disorders of DNA single-strand break repair. Handb. Clin. Neurol. 155, 105-115 (2018).

3. McKinnon, P. J. Genome integrity and disease prevention in the nervous system. Genes Dev. 31, 1180-1194 (2017)

4. Caldecott, K. W. Protein ADP-ribosylation and the cellular response to DNA strand breaks. DNA Repair 19, 108-113 (2014).

5. Jungmichel, S. et al. Proteome-wide identification of poly(ADP-ribosyl)ation targets in different genotoxic stress responses. Mol. Cell 52, 272-285 (2013).

6. Ray Chaudhuri, A. \& Nussenzweig, A. The multifaceted roles of PARP1 in DNA repair and chromatin remodelling. Nat. Rev. Mol. Cell Biol. 18, 610-621 (2017).

7. Satoh, M. S. \& Lindahl, T. Role of poly(ADP-ribose) formation in DNA repair. Nature 356, 356-358 (1992)

8. Hanzlikova, H., Gittens, W., Krejcikova, K., Zeng, Z. \& Caldecott, K. W. Overlapping roles for PARP1 and PARP2 in the recruitment of endogenous XRCC1 and PNKP into oxidized chromatin. Nucleic Acids Res. 45, 2546-2557 (2017)

9. Breslin, C. et al. The XRCC1 phosphate-binding pocket binds poly(ADP-ribose) and is required for XRCC1 function. Nucleic Acids Res. 43 6934-6944 (2015).

10. Masson, M. et al. XRCC1 is specifically associated with poly(ADP-ribose) polymerase and negatively regulates its activity following DNA damage. Mol. Cell Biol. 18, 3563-3571 (1998).
11. Caldecott, K. W., Aoufouchi, S., Johnson, P. \& Shall, S. XRCC1 polypeptide interacts with DNA polymerase $\beta$ and possibly poly(ADP-ribose) polymerase, and DNA ligase III is a novel molecular 'nick-sensor' in vitro. Nucleic Acids Res. 24, 4387-4394 (1996).

12. Kubota, Y. et al. Reconstitution of DNA base excision-repair with purified human proteins: interaction between DNA polymerase $\beta$ and the XRCC1 protein. EMBO J. 15, 6662-6670 (1996).

13. Caldecott, K. W., McKeown, C. K., Tucker, J. D., Ljungquist, S. \& Thompson, L. H. An interaction between the mammalian DNA repair protein XRCC1 and DNA ligase III. Mol. Cell Biol. 14, 68-76 (1994).

14. Loizou, J. I. et al. The protein kinase CK2 facilitates repair of chromosomal DNA single-strand breaks. Cell 117, 17-28 (2004).

15. Whitehouse, C. J. et al. XRCC1 stimulates human polynucleotide kinase activity at damaged DNA termini and accelerates DNA single-strand break repair. Cell 104, 107-117 (2001).

16. Clements, P. M. et al. The ataxia-oculomotor apraxia 1 gene product has a role distinct from ATM and interacts with the DNA strand break repair proteins XRCC1 and XRCC4. DNA Repair 3, 1493-1502 (2004).

17. Luo, H. et al. A new XRCC1-containing complex and its role in cellular survival of methyl methanesulfonate treatment. Mol. Cell Biol. 24, 8356-8365 (2004).

18. Hoch, N. C. et al. XRCC1 mutation is associated with PARP1 hyperactivation and cerebellar ataxia. Nature 541, 87-91 (2017).

19. Komulainen, E. et al. Parp1 hyperactivity couples DNA breaks to aberrant neuronal calcium signalling and lethal seizures. EMBO Rep. 22, e51851 (2021).

20. Zhou, W. \& Doetsch, P. W. Effects of abasic sites and DNA single-strand breaks on prokaryotic RNA polymerases. Proc. Natl Acad. Sci. USA 90, 6601-6605 (1993).

21. Kathe, S. D., Shen, G. P. \& Wallace, S. S. Single-stranded breaks in DNA but not oxidative DNA base damages block transcriptional elongation by RNA polymerase II in HeLa cell nuclear extracts. J. Biol. Chem. 279, 18511-18520 (2004).

22. Neil, A. J., Belotserkovskii, B. P. \& Hanawalt, P. C. Transcription blockage by bulky end termini at single-strand breaks in the DNA template: differential effects of 5' and 3' adducts. Biochemistry 51, 8964-8970 (2012).

23. Payne, J. M., Laybourn, P. J. \& Dahmus, M. E. The transition of RNA polymerase II from initiation to elongation is associated with phosphorylation of the carboxyl-terminal domain of subunit IIa. J. Biol. Chem. 264, 19621-19629 (1989).

24. O'Brien, T., Hardin, S., Greenleaf, A. \& Lis, J. T. Phosphorylation of RNA polymerase II C-terminal domain and transcriptional elongation. Nature 370, 75-77 (1994).

25. Zaborowska, J., Egloff, S. \& Murphy, S. The pol II CTD: new twists in the tail. Nat. Struct. Mol. Biol. 23, 771-777 (2016).

26. Lee, Y. et al. The genesis of cerebellar interneurons and the prevention of neural DNA damage require XRCC1. Nat. Neurosci. 12, 973-980 (2009).

27. Caldecott, K. W. XRCC1 protein; Form and function. DNA Repair 81, 102664 (2019).

28. Rulten, S. L., Cortes-Ledesma, F., Guo, L., Iles, N. J. \& Caldecott, K. W. APLF (C2orf13) is a novel component of poly(ADP-ribose) signaling in mammalian cells. Mol. Cell Biol. 28, 4620-4628 (2008).

29. Ahel, I. et al. Poly(ADP-ribose)-binding zinc finger motifs in DNA repair/ checkpoint proteins. Nature 451, 81-85 (2008).

30. Demin, A. A. et al. XRCC1 prevents toxic PARP1 trapping during DNA base excision repair. Mol. Cell 81, 3018-3030 (2021).

31. Ikeda, S. et al. Purification and characterization of human NTH1, a homolog of Escherichia coli endonuclease III. Direct identification of Lys-212 as the active nucleophilic residue. J. Biol. Chem. 273, 21585-21593 (1998).

32. Aspinwall, R. et al. Cloning and characterization of a functional human homolog of Escherichia coli endonuclease III. Proc. Natl Acad. Sci. USA 94, 109-114 (1997).

33. Xu, G., Herzig, M., Rotrekl, V. \& Walter, C. A. Base excision repair, aging and health span. Mech. Ageing Dev. 129, 366-382 (2008).

34. Bartlett, E. et al. Interplay of histone marks with serine ADP-ribosylation. Cell Rep. 24, 3488-3502 (2018).

35. Hanzlikova, H. et al. Pathogenic ARH3 mutations result in ADP-ribose chromatin scars during DNA strand break repair. Nat. Commun. 11, 3391 (2020).

36. Huang, D. et al. Functional interplay between histone H2B ADP-ribosylation and phosphorylation controls adipogenesis. Mol. Cell 79, 934-949 (2020).

37. Bonfiglio, J. J. et al. Serine ADP-ribosylation depends on HPF1. Mol. Cell 65 , 932-940 (2017)

38. Gibbs-Seymour, I., Fontana, P., Rack, J. G. M. \& Ahel, I. HPF1/C4orf27 Is a PARP-1-interacting protein that regulates PARP-1 ADP-ribosylation activity. Mol. Cell 62, 432-442 (2016).

39. Rudolph, J., Roberts, G., Muthurajan, U. M. \& Luger, K. HPF1 and nucleosomes mediate a dramatic switch in activity of PARP1 from polymerase to hydrolase. eLife 10, e65773 (2021).

40. Suskiewicz, M. J. et al. HPF1 completes the PARP active site for DNA damage-induced ADP-ribosylation. Nature 579, 598-602 (2020). 
41. Polo, S. E., Kaidi, A., Baskcomb, L., Galanty, Y. \& Jackson, S. P. Regulation of DNA-damage responses and cell-cycle progression by the chromatin remodelling factor CHD4. EMBO J. 29, 3130-3139 (2010).

42. Chou, D. M. et al. A chromatin localization screen reveals poly(ADP ribose)-regulated recruitment of the repressive polycomb and NuRD complexes to sites of DNA damage. Proc. Natl Acad. Sci. USA 107, 18475-18480 (2010)

43. Fierz, B. et al. Histone $\mathrm{H} 2 \mathrm{~B}$ ubiquitylation disrupts local and higher-order chromatin compaction. Nat. Chem. Biol. 7, 113-119 (2011).

44. Pavri, R. et al. Histone H2B monoubiquitination functions cooperatively with FACT to regulate elongation by RNA polymerase II. Cell $\mathbf{1 2 5}$, 703-717 (2006).

45. Tanny, J. C., Erdjument-Bromage, H., Tempst, P. \& Allis, C. D. Ubiquitylation of histone $\mathrm{H} 2 \mathrm{~B}$ controls RNA polymerase II transcription elongation independently of histone H3 methylation. Genes Dev. 21, 835-847 (2007).

46. Ting, X. et al. USP11 acts as a histone deubiquitinase functioning in chromatin reorganization during DNA repair. Nucleic Acids Res. 47, 9721-9740 (2019).

47. Zhang, X. Y. et al. The putative cancer stem cell marker USP22 is a subunit of the human SAGA complex required for activated transcription and cell-cycle progression. Mol. Cell 29, 102-111 (2008).

48. DeVine, T., Sears, R. C. \& Dai, M. S. The ubiquitin-specific protease USP36 is a conserved histone H2B deubiquitinase. Biochem. Biophys. Res. Commun. 495, 2363-2368 (2018)

49. Gardner, R. G., Nelson, Z. W. \& Gottschling, D. E. Ubp10/Dot4p regulates the persistence of ubiquitinated histone $\mathrm{H} 2 \mathrm{~B}$ : distinct roles in telomeric silencing and general chromatin. Mol. Cell Biol. 25, 6123-6139 (2005).

50. Henry, K. W. et al. Transcriptional activation via sequential histone H2B ubiquitylation and deubiquitylation, mediated by SAGA-associated Ubp8. Genes Dev. 17, 2648-2663 (2003).

51. Nicassio, F. et al. Human USP3 is a chromatin modifier required for S phase progression and genome stability. Curr. Biol. 17, 1972-1977 (2007).

52. Lancini, C. et al. Tight regulation of ubiquitin-mediated DNA damage response by USP3 preserves the functional integrity of hematopoietic stem cells. J. Exp. Med. 211, 1759-1777 (2014).

53. Mosbech, A., Lukas, C., Bekker-Jensen, S. \& Mailand, N. The deubiquitylating enzyme USP44 counteracts the DNA double-strand break response mediated by the RNF8 and RNF168 ubiquitin ligases. J. Biol. Chem. 288, 16579-16587 (2013)

54. Posavec Marjanović, M., Crawford, K. \& Ahel, I. PARP, transcription and chromatin modeling. Semin. Cell Dev. Biol. 63, 102-113 (2017)

55. Kraus, W. L. Transcriptional control by PARP-1: chromatin modulation, enhancer-binding, coregulation, and insulation. Curr. Opin. Cell Biol. 20, 294-302 (2008).

56. Caldecott, K. W. Mammalian DNA base excision repair: dancing in the moonlight. DNA Repair 93, 102921 (2020).

57. Krishnakumar, R. et al. Reciprocal binding of PARP-1 and histone $\mathrm{H} 1$ at promoters specifies transcriptional outcomes. Science $\mathbf{3 1 9}$ 819-821 (2008).

58. Wacker, D. A. et al. The DNA binding and catalytic domains of poly(ADP-ribose) polymerase 1 cooperate in the regulation of chromatin structure and transcription. Mol. Cell Biol. 27, 7475-7485 (2007).

59. Kim, M. Y., Mauro, S., Gévry, N., Lis, J. T. \& Kraus, W. L. NAD ${ }^{+}$-dependent modulation of chromatin structure and transcription by nucleosome binding properties of PARP-1. Cell 119, 803-814 (2004).

60. Tulin, A. \& Spradling, A. Chromatin loosening by poly(ADP)-ribose polymerase (PARP) at Drosophila puff loci. Science 299, 560-562 (2003).

61. Poirier, G. G., de Murcia, G., Jongstra-Bilen, J., Niedergang, C. \& Mandel, P. Poly(ADP-ribosyl)ation of polynucleosomes causes relaxation of chromatin structure. Proc. Natl Acad. Sci. USA 79, 3423-3427 (1982).

62. Gibson, B. A. et al. Chemical genetic discovery of PARP targets reveals a role for PARP-1 in transcription elongation. Science 353, 45-50 (2016).

63. Kuraoka, I. et al. Effects of endogenous DNA base lesions on transcription elongation by mammalian RNA polymerase II. Implications for transcription-coupled DNA repair and transcriptional mutagenesis. J. Biol. Chem. 278, 7294-7299 (2003).

64. Realini, C. A. \& Althaus, F. R. Histone shuttling by poly(ADP-ribosylation). J. Biol. Chem. 267, 18858-18865 (1992).

65. Muthurajan, U. M. et al. Automodification switches PARP-1 function from chromatin architectural protein to histone chaperone. Proc. Natl Acad. Sci. USA 111, 12752-12757 (2014).
66. Luijsterburg, M. S. et al. PARP1 links CHD2-mediated chromatin expansion and H3.3 deposition to DNA repair by non-homologous end-joining. Mol. Cell 61, 547-562 (2016)

67. Rother, M. B. et al. CHD7 and 53BP1 regulate distinct pathways for the re-ligation of DNA double-strand breaks. Nat. Commun. 11, 5775 (2020).

68. Smith, R., Sellou, H., Chapuis, C., Huet, S. \& Timinszky, G. CHD3 and CHD4 recruitment and chromatin remodeling activity at DNA breaks is promoted by early poly(ADP-ribose)-dependent chromatin relaxation. Nucleic Acids Res. 46, 6087-6098 (2018).

69. Sharma, N. et al. USP3 counteracts RNF168 via deubiquitinating H2A and $\gamma \mathrm{H} 2 \mathrm{AX}$ at lysine 13 and 15. Cell Cycle 13, 106-114 (2014).

70. Schwertman, P., Bekker-Jensen, S. \& Mailand, N. Regulation of DNA double-strand break repair by ubiquitin and ubiquitin-like modifiers. Nat. Rev. Mol. Cell Biol. 17, 379-394 (2016).

71. Bergink, S. et al. DNA damage triggers nucleotide excision repair-dependent monoubiquitylation of histone H2A. Genes Dev. 20, 1343-1352 (2006).

72. Ginjala, V. et al. BMI1 is recruited to DNA breaks and contributes to DNA damage-induced H2A ubiquitination and repair. Mol. Cell Biol. 31, 1972-1982 (2011).

73. Marteijn, J. A. et al. Nucleotide excision repair-induced $\mathrm{H} 2 \mathrm{~A}$ ubiquitination is dependent on MDC1 and RNF8 and reveals a universal DNA damage response. J. Cell Biol. 186, 835-847 (2009).

74. Wu, J. et al. Histone ubiquitination associates with BRCA1-dependent DNA damage response. Mol. Cell Biol. 29, 849-860 (2009).

75. Tamburri, S. et al. Histone H2AK119 mono-ubiquitination is essential for polycomb-mediated transcriptional repression. Mol. Cell 77, 840-856 (2020).

76. Nakagawa, T. et al. Deubiquitylation of histone H2A activates transcriptional initiation via trans-histone cross-talk with $\mathrm{H} 3 \mathrm{~K} 4 \mathrm{di}$ - and trimethylation. Genes Dev. 22, 37-49 (2008).

77. Kim, J., Hake, S. B. \& Roeder, R. G. The human homolog of yeast BRE1 functions as a transcriptional coactivator through direct activator interactions. Mol. Cell 20, 759-770 (2005).

78. Zhang, F. \& Yu, X. WAC, a functional partner of RNF20/40, regulates histone H2B ubiquitination and gene transcription. Mol. Cell 41, 384-397 (2011).

79. Sun, Z. W. \& Allis, C. D. Ubiquitination of histone H2B regulates H3 methylation and gene silencing in yeast. Nature 418, 104-108 (2002).

80. Kim, J. et al. RAD6-mediated transcription-coupled H2B ubiquitylation directly stimulates H3K4 methylation in human cells. Cell 137, 459-471 (2009).

81. Moyal, L. et al. Requirement of ATM-dependent monoubiquitylation of histone H2B for timely repair of DNA double-strand breaks. Mol. Cell 41, 529-542 (2011).

82. Mao, P., Meas, R., Dorgan, K. M. \& Smerdon, M. J. UV damage-induced RNA polymerase II stalling stimulates H2B deubiquitylation. Proc. Natl Acad. Sci. USA 111, 12811-12816 (2014).

83. Wu, W. et al. Neuronal enhancers are hotspots for DNA single-strand break repair. Nature 593, 440-444 (2021)

84. Weber, A. R. et al. Biochemical reconstitution of TET1-TDG-BER-dependent active DNA demethylation reveals a highly coordinated mechanism. Nat. Commun. 7, 10806 (2016).

85. Hajkova, P. et al. Genome-wide reprogramming in the mouse germ line entails the base excision repair pathway. Science 329, 78-82 (2010).

86. Steinacher, R. et al. SUMOylation coordinates BERosome assembly in active DNA demethylation during cell differentiation. EMBO J. 38, e99242 (2019).

87. Haider, L. Inflammation, iron, energy failure, and oxidative stress in the pathogenesis of multiple sclerosis. Oxid. Med. Cell Longev. 2015, 725370 (2015).

Publisher's note Springer Nature remains neutral with regard to jurisdictional claims in published maps and institutional affiliations.

Open Access This article is licensed under a Creative Commons Attribution 4.0 International License, which permits use, sharing, adap tation, distribution and reproduction in any medium or format, as long as you give appropriate credit to the original author(s) and the source, provide a link to the Creative Commons license, and indicate if changes were made. The images or other third party material in this article are included in the article's Creative Commons license, unless indicated otherwise in a credit line to the material. If material is not included in the article's Creative Commons license and your intended use is not permitted by statutory regulation or exceeds the permitted use, you will need to obtain permission directly from the copyright holder. To view a copy of this license, visit http://creativecommons. org/licenses/by/4.0/.

(C) The Author(s) 2021 


\section{Methods}

Cell lines, treatments and culture conditions. All cell lines were cultured in a low-oxygen $(3 \%)$ incubator $\left(37^{\circ} \mathrm{C}\right.$ and $\left.5 \% \mathrm{CO}_{2}\right)$. RPE- 1 cells (American Type Culture Collection) were cultured in DMEM-F12 GlutaMAX medium containing $10 \%$ FBS supplemented with penicillin-streptomycin. U2OS cells (American Type Culture Collection) were cultured in DMEM containing 10\% FBS supplemented with penicillin-streptomycin and L-glutamine. Primary fibroblasts from patients with XRCC1 mutations (XD1) ${ }^{18}$ as well as control counterparts 1BR.3 (denoted as $1 \mathrm{BR}$ ) were cultured in MEM medium containing 15\% FBS supplemented with penicillin-streptomycin and L-glutamine. Unless stated otherwise, $\mathrm{H}_{2} \mathrm{O}_{2}(8.8 \mathrm{M}$ stock; Sigma) was freshly diluted in serum-free medium (DMEM-F12 GlutaMAX) for each experiment and used at a final concentration of $60 \mu \mathrm{M}$ for $5 \mathrm{~min}$ (XD1 fibroblasts), $250 \mu \mathrm{M}$ for $5 \mathrm{~min}$ (RPE-1 cells and mouse cerebellar neurons) or $1 \mathrm{mM}$ for $20 \mathrm{~min}$ with refreshment after $10 \mathrm{~min}$ (U2OS cells) in serum-free medium at $37^{\circ} \mathrm{C}$. Note that relatively frequent replacement of the $\mathrm{H}_{2} \mathrm{O}_{2}$ stock (2-3 months) was required for robust $\mathrm{H}_{2} \mathrm{O}_{2}$-induced inhibition of transcription. Following treatment, the cells were washed twice in complete medium to inactivate the $\mathrm{H}_{2} \mathrm{O}_{2}$ and harvested at the indicated time points. MMS (Sigma) was diluted in complete medium and employed at a final concentration of $0.1 \mathrm{mg} \mathrm{ml}^{-1}(0.01 \%)$. Where indicated, PARPi (KU0058948, Axon Medchem) was used at $10 \mu \mathrm{M}$ for $1 \mathrm{~h}$ before the $\mathrm{H}_{2} \mathrm{O}_{2}$ treatment, and PARG inhibitor (Tocris) at $10 \mu \mathrm{M}$ during and following $\mathrm{H}_{2} \mathrm{O}_{2}$ treatment, until the cells were harvested. MG132 (Tocris) and bortezomib (Millipore) were used at concentrations of $10 \mu \mathrm{M}$ and $1 \mu \mathrm{M}$, respectively, for $1 \mathrm{~h}$ before and $2 \mathrm{~h}$ following $\mathrm{H}_{2} \mathrm{O}_{2}$ treatment until the cells were harvested. For the siRNA treatments, the cells were transfected $72 \mathrm{~h}$ before analysis with $10 \mathrm{nM}$ of siRNA to NTH1, USP11, USP22, USP36 or USP3 (Supplementary Table 4) using RNAiMAX lipofectamine (Invitrogen).

$X R C C 1^{-1-}, P A R P 1^{-1-}$ and $P A R P 1^{-1-} X_{R C C 1^{-/-}}$RPE-1 and U2OS cells have been described/employed previously ${ }^{8,18,88}$. Derivatives of these cell lines harbouring expression constructs (Supplementary Table 2) encoding full-length or truncated recombinant XRCC1 (ref. ${ }^{89}$ ) or $A P L F^{90}$ were generated by co-transfection with a plasmid encoding puromycin resistance. Stably transfected cells were selected with puromycin $\left(2 \mu \mathrm{g} \mathrm{ml}^{-1}\right)$ and single colonies were isolated, amplified and verified by western blotting after one week. For the transient transfection experiments, $\mathrm{U} 2 \mathrm{OS}$ cells were incubated with poly(ethyleneimine) solution (Sigma) for $6 \mathrm{~h}$ in serum-free medium and the cells were fixed and analysed after $24 \mathrm{~h} . H P F 1^{-/}$and $\mathrm{XRCC1}^{-/} \mathrm{HPF1}^{-/-} \mathrm{U} 2 \mathrm{OS}$ cells were generated by transfection of WT U2OS or $\mathrm{XRCC1}^{-/-} \mathrm{U} 2 \mathrm{OS}$ cells with a Cas9-GFP plasmid (Addgene., 48138) and plasmids encoding HPF1 guide RNA (gRNA) no. 1 and no. 2, targeting the first exon of the HPF1 gene (a gift from I. Ahel ${ }^{38}$; Supplementary Table 4), at a 1:1:1 ratio using Lipofectamine LTX (Invitrogen). USP3 ${ }^{-/-}$and $X R C C 1^{-1-} U S P 3^{-1-} \mathrm{RPE}-1$ cells were generated as described above, with the use USP3 gRNA no. 1 and 2 (Supplementary Table 4). Transfected cells were sorted (BD FACSMelody) for $\mathrm{GFP}^{+}$cells two days after transfection and seeded into 96-wells plates for the amplification of single-cell clones, which were subsequently validated by immunoblotting. Gene editing was confirmed by Sanger sequencing.

Primary cerebellar neurons were established from seven-day-old (P7) male and female WT and $\mathrm{Xrccl}^{\text {Nes-Cre }}$ (ref. ${ }^{18}$ ) mouse pups using the Papain Dissociation System (Worthington). The mice from which these neurons were obtained were maintained in accordance with the UK Animal (Scientific Procedures) Act 1986 and satisfied local institutional regulations at the University of Sussex and under the auspices of UK Home Office project licence number P3CDBCBA8. The cells were seeded onto poly-L-lysine-coated coverslips at $6 \times 10^{5}$ cells per well and maintained in Neurobasal A medium (Gibco) supplemented with B27 (Invitrogen), $5.25 \mathrm{mM} \mathrm{KCl}, 0.5 \mathrm{mM}$ glutamine and penicillin-streptomycin in a humidified incubator $\left(3 \% \mathrm{O}_{2}\right.$ and $5 \% \mathrm{CO}_{2}$ at $\left.37^{\circ} \mathrm{C}\right)$. The cultures were employed for transcription experiments between 4 and $11 \mathrm{~d}$ in vitro.

Western blotting. RPE-1 cells were harvested and lysed in TEB150 lysis buffer (50 mM HEPES pH 7.4, $150 \mathrm{mM} \mathrm{NaCl}, 2 \mathrm{mM} \mathrm{MgCl}$, $5 \mathrm{mM}$ EGTA pH 8, $1 \mathrm{mM}$ dithiothreitol (DTT), $0.5 \%$ Triton X-100 and 10\% glycerol) containing protease inhibitor cocktail (Roche), phosphatase inhibitor cocktail (PhosSTOP, Sigma) and $1: 1,000$ benzonase (Sigma) for $45 \mathrm{~min}$ on ice. Lysis was stopped by the addition of SDS-PAGE sample buffer and boiling for $5 \mathrm{~min}$ at $90^{\circ} \mathrm{C}$. The other cell lines were harvested directly in sample buffer and boiled as described for the RPE- 1 cells. The protein extracts were fractionated by SDS-PAGE, transferred to nitrocellulose, blocked in $0.1 \%$ TBS-Tween containing $5 \%$ non-fat dried milk and incubated with the indicated appropriate antibodies (Supplementary Table 1).

ADP-ribose immunoprecipitation. Cells were harvested by trypsinization and lysed in TEB250 lysis buffer (50 mM HEPES pH 7.4, $250 \mathrm{mM} \mathrm{NaCl}^{2} \mathrm{mM} \mathrm{MgCl}_{2}$, 5 mM EGTA pH 8, 1 mM DTT, $0.5 \%$ Triton X-100, 10\% glycerol, protease inhibitor cocktail (Roche), phosphatase inhibitors cocktail (PhosSTOP, Sigma), $50 \mu \mathrm{M}$ PARPi, $100 \mu \mathrm{M}$ PARG inhibitor and benzonase (Sigma; 1:1,000)) for $45 \mathrm{~min}$ on ice, followed by centrifugation $(15 \mathrm{~min}$ at $16,000 \mathrm{~g}$ ). For immunoprecipitation, $0.5 \mathrm{mg}$ or more of the protein lysate was incubated with antibody to mono/poly-ADP-ribose antibody (Cell Signalling; Supplementary Table 1) for $2 \mathrm{~h}$ and then with Protein $\mathrm{G}$ Dynabeads (Invitrogen) for $2 \mathrm{~h}$. The beads were then washed $(3 \times)$ with lysis buffer, resuspended in sample buffer and heated for $5 \mathrm{~min}$ at $90^{\circ} \mathrm{C}$ and subjected to
SDS-PAGE. The proteins were transferred to nitrocellulose and immunoblotted with ADP-ribose-binding reagent (Millipore; Supplementary Table 1).

Immunofluorescence. For immunofluorescence, cells were fixed in 4\% PFA in PBS for $10 \mathrm{~min}$, permeabilized in $0.2 \%$ Triton X-100 solution in PBS for $10 \mathrm{~min}$, rinsed in PBS and blocked in 5\% BSA solution. For the purpose of $\mathrm{H} 2 \mathrm{BmUb}$ staining, the cells were fixed in $100 \%$ methanol at room temperature for $10 \mathrm{~min}$, rinsed in PBS and blocked in 5\% BSA solution. The cells were incubated with the appropriate primary antibody (Supplementary Table 1 ) for $1 \mathrm{~h}$, washed in PBS, incubated with the appropriate fluorophore-conjugated secondary antibody (Invitrogen) for $1 \mathrm{~h}$ and then counterstained with DAPI. For global chromatin ubiquitination (staining with antibody to FK2), the cells were pre-extracted on ice for 2 min with $0.2 \%$ Triton $\mathrm{X}-100$ in PBS, rinsed quickly in cold PBS and fixed in 4\% PFA in PBS. To measure the global sites of nascent RNA synthesis, the cells were pulse labelled in medium containing $1 \mathrm{mM}$ EU (Abcam) for $20 \mathrm{~min}$ before fixation. The EU pulse-labelled cells were subjected to click chemistry using a Click-iT kit (Invitrogen) according to the manufacturer's protocol. Click chemistry was performed after the blocking step of the immunofluorescence protocol described above. All images for quantitation were acquired using the automated wide-field microscope scanR image acquisition and analysis software, with $>500$ cells scored per sample (Olympus). Representative images were acquired with the use a wide-field microscope (Apotome; Zeiss). Where displayed, scanR cell galleries were generated by the Olympus Analysis Software as a representative example of the cell populations that were quantified.

DNA strand-break measurements. To measure DNA strand breaks under the conditions at which transcription is inhibited in $\mathrm{XRCC1}^{-/-}$cells, the cells were treated with $100 \mu \mathrm{M} \mathrm{H}_{2} \mathrm{O}_{2}$ for $20 \mathrm{~min}$ (the $\mathrm{H}_{2} \mathrm{O}_{2}$ was refreshed after $10 \mathrm{~min}$ ) in serum-free medium at $37^{\circ} \mathrm{C}$ and then in drug-free medium for $2 \mathrm{~h}$ (Extended Data Fig. $4 \mathrm{~g}$ ). To measure the kinetics of SSB repair, the cells were treated with $50 \mu \mathrm{M}$ $\mathrm{H}_{2} \mathrm{O}_{2}$ for $10 \mathrm{~min}$ on ice and then in drug-free medium at $37^{\circ} \mathrm{C}$ for the indicated time periods (Extended Data Fig. 4f). The DNA strand breaks were measured using alkaline comet assays, as described previously ${ }^{91}$, using the Comet Assay IV software (Perceptive Instruments).

Protein purification. N-terminal His-tagged APLF and APLF ${ }^{\mathrm{ZFD}}$ (harbouring the mutations C379A and C385A, and C421A and C427A in the PAR-binding zinc fingers ZF1 and ZF2, respectively $)^{28}$ were expressed from the pET16b-APLF $^{90}$ and pET16b-APLF ${ }^{\mathrm{ZFD}}$ plasmids in BL21(DE3) Escherichia coli (NEB) by overnight induction with $0.5 \mathrm{mM}$ isopropylthiogalactoside (IPTG) at $20^{\circ} \mathrm{C}$. Full-length $\mathrm{C}$-terminal His-tagged XRCC1 and XRCC1 ${ }^{\mathrm{RK}}$ were expressed from $\mathrm{pET} 16 \mathrm{~b}-\mathrm{XH}$ (ref. ${ }^{89}$ ) and pET16b-XH ${ }^{\mathrm{RK}}$ (ref. ${ }^{18}$ ), and $\mathrm{N}$-terminal His-tagged XRCC1 ${ }^{161-406}$ and XRCC $1^{161-406 R K}$ from pTWO-E-His-XRCC $1^{161-406}$ and pTWO-E-His-XRCC1 ${ }^{161-}$ ${ }_{406 \mathrm{RK}}$ (ref. ${ }^{9}$ ) by induction with $1 \mathrm{mM}$ IPTG in Luria-Bertani medium at $30^{\circ} \mathrm{C}$ for $3 \mathrm{~h}$. N-terminal His-tagged human USP3 was expressed from pET16b-USP3 in BL21(DE3) E. coli (NEB) by overnight induction with $0.5 \mathrm{mM}$ IPTG at $20^{\circ} \mathrm{C}$. The proteins were purified by metal-chelate affinity chromatography and gel filtration before the buffer was exchanged to $150 \mathrm{mM} \mathrm{NaCl}, 50 \mathrm{mM}$ Tris- $\mathrm{HCl} \mathrm{pH} 7.5,10 \%$ glycerol and $1 \mathrm{mM}$ DTT. Aliquots were then snap-frozen in liquid nitrogen and stored at $-80^{\circ} \mathrm{C}$.

In vitro analysis of PARP1 auto-ribosylation. Recombinant high-specific-activity PARP1 (100 nM; Trevigen) was either mock ribosylated in the absence of NAD ${ }^{+}$ or auto-ribosylated in the presence of $2.5 \mu \mathrm{M} \mathrm{NAD}^{+}(\mathrm{NEB})$ and the indicated recombinant proteins. The reactions were carried out in $50 \mathrm{mM}$ Tris- $\mathrm{HCl}$ $\mathrm{pH} 8,0.8 \mathrm{mM} \mathrm{MgCl}_{2}, 1 \%$ glycerol, $1.5 \mathrm{mM}$ DTT and $100 \mathrm{nM}$ of single-stranded oligodeoxyribonucleotide (5'-CATATGCCGGAGATCCGCCTCC-3'; Eurogentec), in a final volume of $20 \mu \mathrm{l}$ at room temperature for $30 \mathrm{~min}$. The reaction products were heated to $90^{\circ} \mathrm{C}$ for $3 \mathrm{~min}$ in sample buffer and subjected to SDS-PAGE. The proteins were transferred to nitrocellulose and immunoblotted with ADP-ribose binding reagent (Millipore; Supplementary Table 1).

USP3 expression construct. To create the USP3-GFP and USP $3^{\mathrm{ZnF}(1-110)}-\mathrm{GFP}$ expression constructs, USP3 complimentary DNA (Source Bioscience) was amplified with the use of the indicated primers (Supplementary Table 4) and cloned in-frame into the BamHI and XhoI restriction sites of the $\mathrm{pEGFP-N1}$ vector (Addgene).

USP3 chromatin retention assay. U2OS cells were transiently transfected with USP3-GFP or USP3 $3^{\mathrm{ZnF}(1-110)}-\mathrm{GFP}$ and H2B-mCherry constructs $24 \mathrm{~h}$ before the experiment. The cells were then treated with $0.01 \mathrm{mg} \mathrm{ml}^{-1} \mathrm{MMS}$ for $4 \mathrm{~h}$ in the presence or absence of $10 \mu \mathrm{M}$ PARPi. The cells were washed once with PBS before incubation in CSK buffer (10 mM PIPES, pH 7.0, $100 \mathrm{mM} \mathrm{NaCl}, 300 \mathrm{mM}$ sucrose, $3 \mathrm{mM} \mathrm{MgCl}_{2}$ and $0.7 \%$ Triton X-100) for $3 \mathrm{~min}$ at room temperature. The cells were subsequently washed in PBS and fixed in $4 \%$ PFA for $10 \mathrm{~min}$. Next, the cells were counterstained with DAPI, mounted in Moviol and subjected to immunofluorescence analysis. Between 50 and $100 \mathrm{H} 2 \mathrm{~B}-\mathrm{mCherry}$-expressing cells were counted per condition.

In vitro ADP-ribose binding assay. First, 96-well plates were washed with $\mathrm{H}_{2} \mathrm{O}$ and then incubated overnight with $0.1 \mathrm{mg} \mathrm{ml}^{-1}$ of calf thymus histones (Sigma) at 
$4{ }^{\circ} \mathrm{C}$. Next, the plates were blocked with $5 \%$ BSA in PBST (PBS containing $0.1 \%$ Tween-20) for $30 \mathrm{~min}$. The absorbed histones were mock ADP-ribosylated in the absence of $\mathrm{NAD}^{+}$or ADP-ribosylated in the presence of $50 \mu \mathrm{M} \mathrm{NAD}^{+}($Sigma) in PARP1 reaction buffer ( $50 \mathrm{mM}$ Tris- $\mathrm{HCl}$ pH 8, $0.8 \mathrm{mM} \mathrm{MgCl}, 1 \%$ glycerol and $1.5 \mathrm{mM}$ DTT) containing $40 \mathrm{nM}$ single-stranded oligodeoxyribonucleotide (5'-CATATGCCGGAGATCCGCCTCC-3') and $10 \mathrm{nM}$ high-specific-activity PARP1 (Trevigen) for $2 \mathrm{~h}$. After subsequent washes with PBST, $500 \mathrm{nM}$ of XRCC1-His, XRCC1-His ${ }^{\mathrm{RK}}$, His-XRCC1 $1^{161-406}$, His-APLF, His-APLFZFD and His-USP3 were added and incubated for $30 \mathrm{~min}$ on ice in Dilution buffer $(20 \mathrm{mM}$ Tris- $\mathrm{HCl}$ pH 7.5 and $130 \mathrm{mM} \mathrm{NaCl}$ ). The plates were washed with PBST and incubated for $30 \mathrm{~min}$ with Dilution buffer containing mouse anti-polyhistidine antibody (Sigma) followed by three washes with PBST and subsequent incubation with horseradish peroxidase-conjugated secondary antibody (DAKO) for $30 \mathrm{~min}$. After washing out the secondary antibody, 3,3',5,5'-tetramethylbenzidine liquid substrate (slow kinetic form; Sigma) was added to the wells for $5 \mathrm{~min}$. The reactions were stopped by the addition of $0.2 \mathrm{M} \mathrm{HCl}$. Absorbance was read at $450 \mathrm{~nm}$ using a CLARIOstar microplate reader (BMG Labtech).

Statistics and reproducibility. No statistical method was used to predetermine the sample size, but we routinely employed at least three biological repeats for each experiment, in each case scoring as many technical replicates as possible (typically several hundred/thousand cells) using the applicable automated microscope software (scanR or Comet Assay IV). All replicates were successful and included in the data. No data were excluded from the analyses. The samples/ experiments were not randomized because all samples were specific genetic cell lines or samples derived from such and so randomization was not appropriate. The investigators were not blinded to allocation during the experiments and outcome assessment because all numerical data were software automated and independent of investigator subjectivity. All data presented in the manuscript are represented as the mean \pm s.e.m., unless stated otherwise, and were analysed using GraphPad Prism (version 8/9). The statistical test employed for each dataset has been specified in the figure legends.

Reporting Summary. Further information on research design is available in the Nature Research Reporting Summary linked to this article.

\section{Data availability}

Because of their large number, all microscope quantification datasets from this work, such as Excel and scanR/comet fluorescence quantification tables, are available from the corresponding author on reasonable request, citing the experiments of interest. Source data are provided with this paper.

\section{References}

88. Polo, L. M. et al. Efficient single-strand break repair requires binding to both poly(ADP-ribose) and DNA by the central BRCT domain of XRCC1. Cell Rep. 26, 573-581 (2019).

89. Caldecott, K. W., Tucker, J. D., Stanker, L. H. \& Thompson, L. H. Characterization of the XRCC1-DNA ligase III complex in vitro and its absence from mutant hamster cells. Nucleic Acids Res. 23, 4836-4843 (1995).

90. Iles, N., Rulten, S., El-Khamisy, S. F. \& Caldecott, K. W. APLF (C2orf13) is a novel human protein involved in the cellular response to chromosomal DNA strand breaks. Mol. Cell Biol. 27, 3793-3803 (2007).

91. Breslin, C. et al. Measurement of chromosomal DNA single-strand breaks and replication fork progression rates. Methods Enzymol. 409, 410-425 (2006).

\section{Acknowledgements}

This work was supported by an MRC Programme grant (grant no. MR/P010121/1) and ERC Advanced Investigator Award (grant no. SIDSCA, 694996) to K.W.C. Microscopy was supported by the Wolfson Centre for Biological Imaging.

\section{Author contributions}

K.W.C. and M.A. conceived the study and designed the experiments. A.A.D. conducted the comet assays. R.H. performed the PARP1 biochemical experiments. E.K. established the primary neurons. J.B. generated the $H P F 1^{-/-}$gene-edited U2OS cell lines. S.E.W. performed the laser tracing experiments. A.G. generated the $\mathrm{USP}^{-/-}$and $\mathrm{XRCC1}^{-/-} \mathrm{USP}^{-/-}$ RPE-1 cell lines. H.H. generated the XRCC1 $1^{--}, X_{R C C 1^{-1-} P A R P 1^{-1-}}$ and $P A R P 1^{-1-} \mathrm{RPE}-1$ cell lines published previously ${ }^{8,18}$. M.A. conducted all of the other experiments. K.W.C. and M.A. wrote the manuscript. K.W.C. coordinated the project. All authors analysed the data.

\section{Competing interests}

The authors declare no competing interests.

\section{Additional information}

Extended data is available for this paper at https://doi.org/10.1038/s41556-021-00792-w. Supplementary information The online version contains supplementary material available at https://doi.org/10.1038/s41556-021-00792-w.

Correspondence and requests for materials should be addressed to Keith W. Caldecott.

Peer review information Nature Cell Biology thanks Alan Tomkinson and the other, anonymous, reviewer(s) for their contribution to the peer review of this work. Peer reviewer reports are available.

Reprints and permissions information is available at www.nature.com/reprints. 


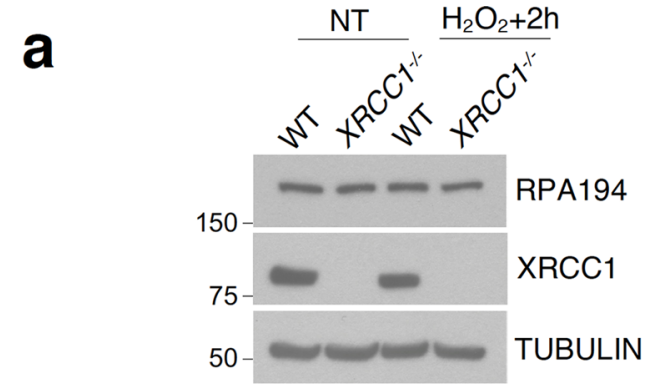

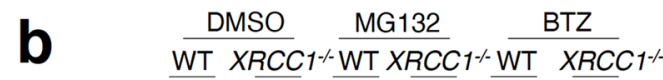

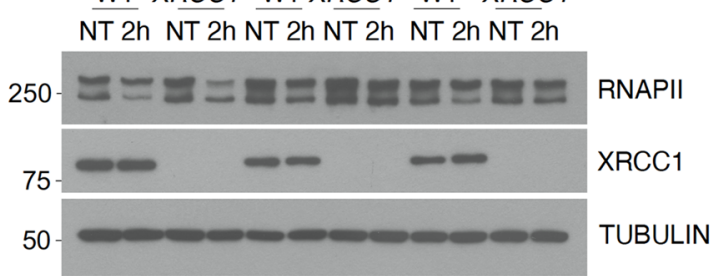

d

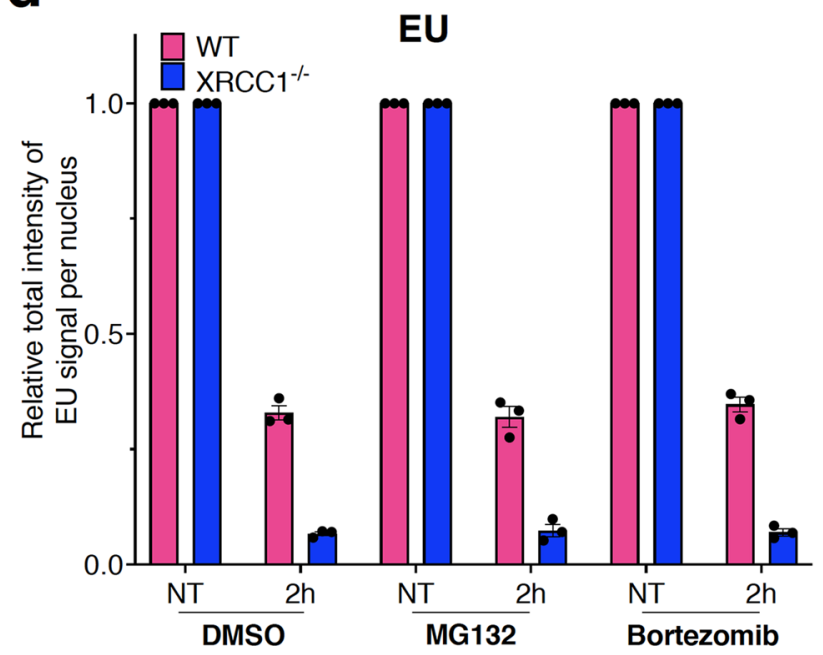

e

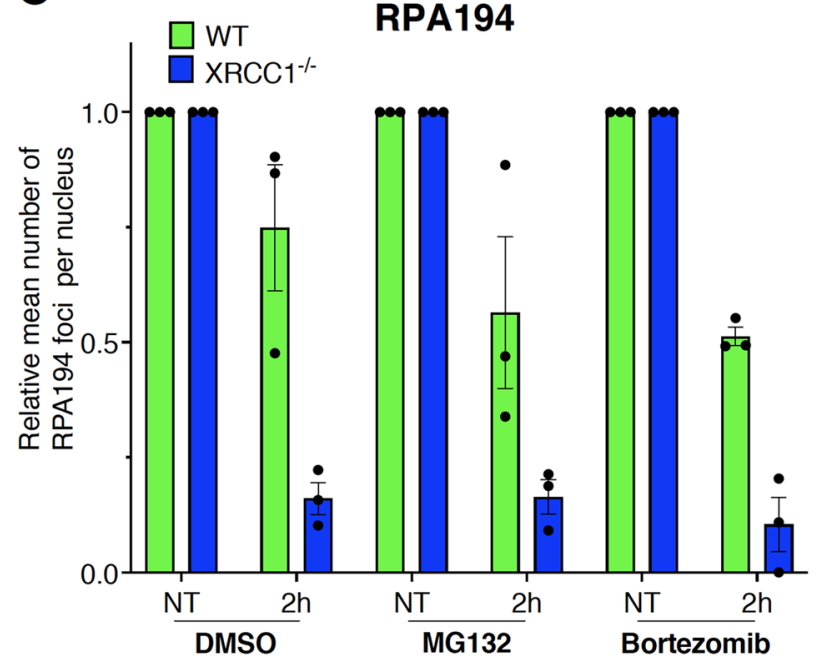

C
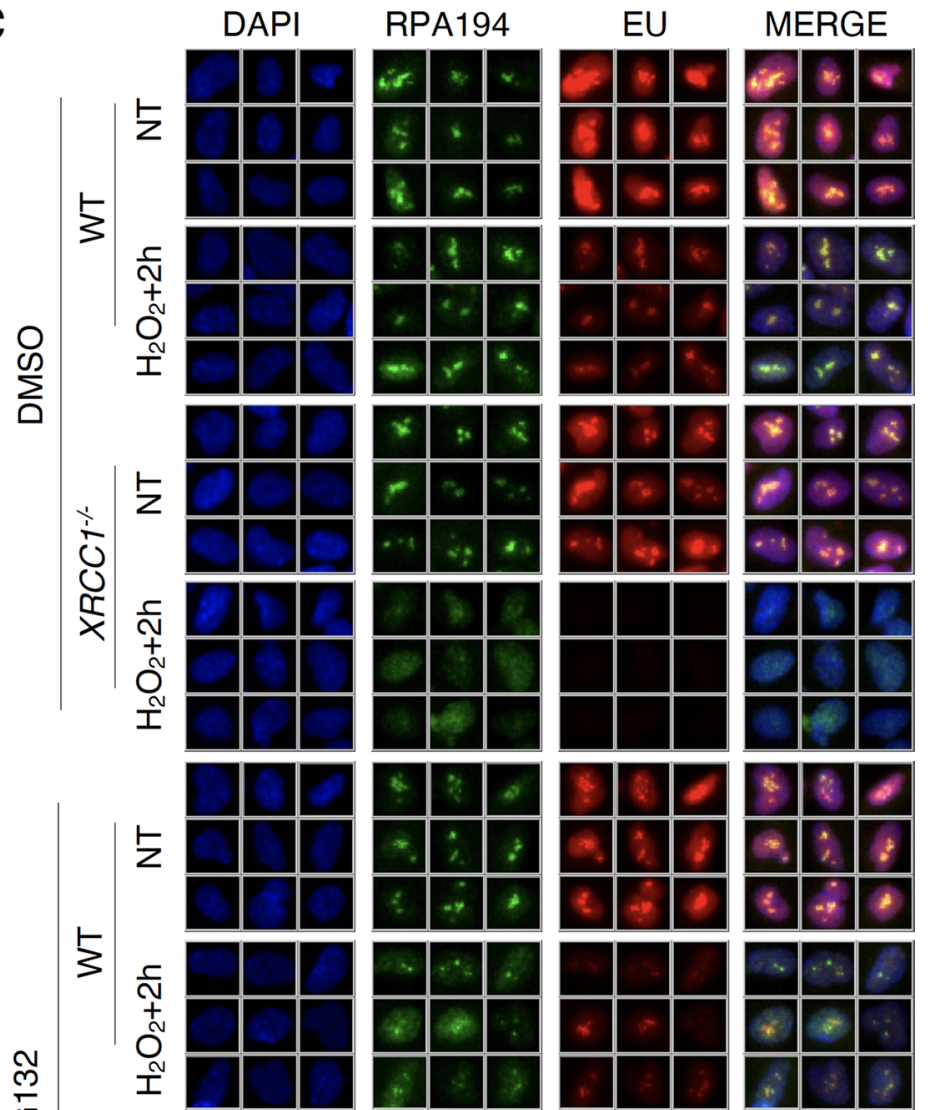

ர্

1
$\vdots$
0
0
$\frac{\pi}{x}$
$\frac{1}{x}$

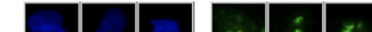

そ

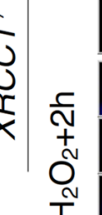
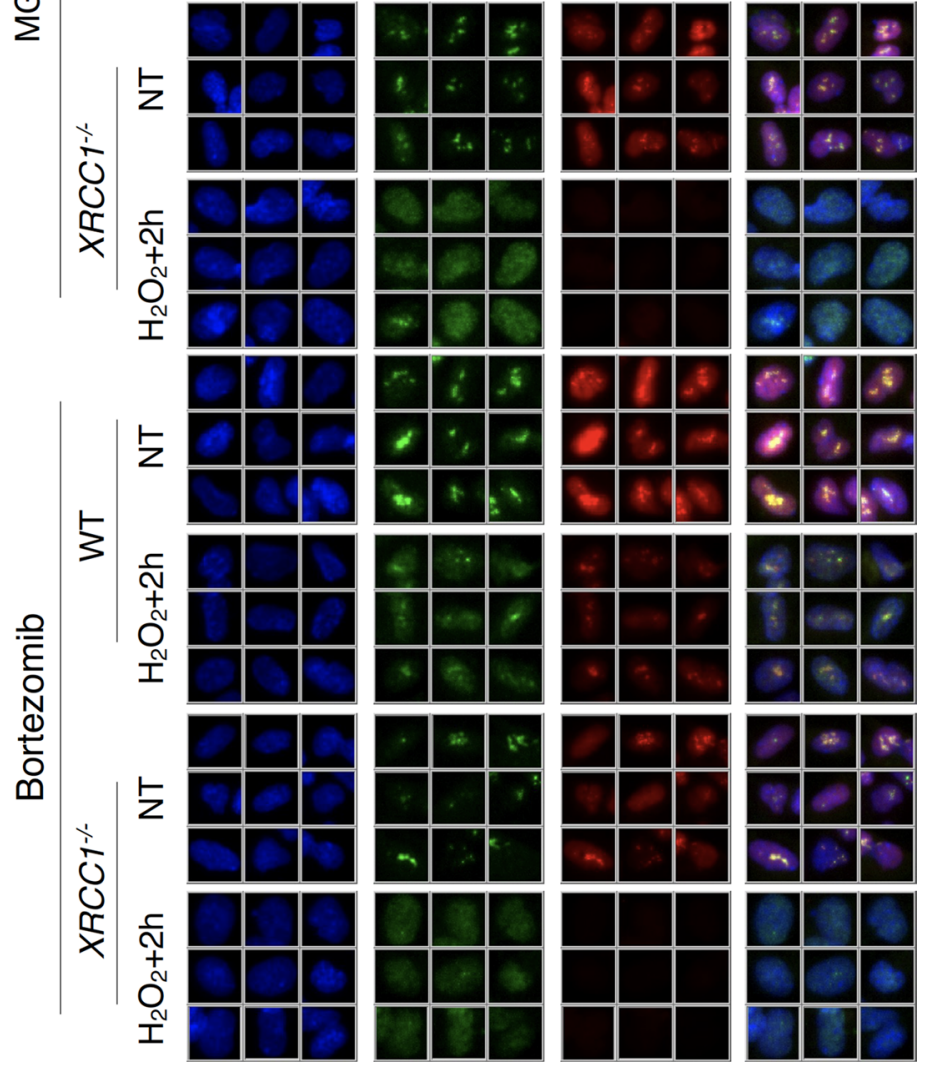

Extended Data Fig. 1 | See next page for caption. 
Extended Data Fig. 1 | XRCC1 promotes the recovery of transcription following oxidative damage. a, Immunoblot of RPA194 in WT and XRCC1 ${ }^{-/-}$RPE-1 cells following mock treatment or $2 \mathrm{~h}$ after treatment with $250 \mu \mathrm{M} \mathrm{H}_{2} \mathrm{O}_{2}$ for $5 \mathrm{~min}$. A representative image from one of three independent experiments is shown. b, Immunoblot of RNAPII hyperphosphorylation in WT and XRCC1-/- RPE-1 cells following mock treatment or $2 \mathrm{~h}$ after treatment with $250 \mu \mathrm{M} \mathrm{H} \mathrm{H}_{2}$ for $5 \mathrm{~min}$. Where indicated, cells were pretreated with either $10 \mu \mathrm{M} \mathrm{MG} 132$ or $1 \mu \mathrm{M}$ Bortezomib for $1 \mathrm{~h}$ before $\mathrm{H}_{2} \mathrm{O}_{2}$ treatment. A representative blot from one of three independent experiments is shown. c, RNAPI foci (RPA194) and levels of global transcription (EU immunofluorescence) in WT and XRCC1-1RPE-1 cells pretreated for $1 \mathrm{~h}$ with $10 \mu \mathrm{M} \mathrm{MG132}$ or $1 \mu \mathrm{M}$ Bortezomib following mock treatment or at $2 \mathrm{~h}$ after treatment with $250 \mu \mathrm{M} \mathrm{H} \mathrm{H}_{2}$ for 5 min. $\mathbf{d}$ and e, Quantification of the levels of global transcription (EU immunofluorescence) and RNAPI foci (RPA194) shown in (c). Data are means ( \pm s.e.m.) of three independent experiments. 
a

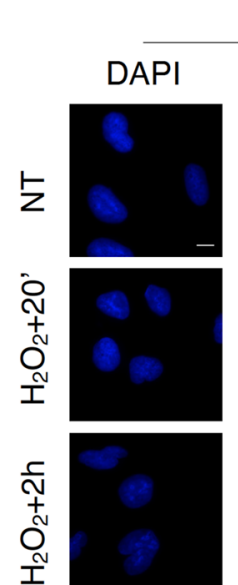

WT
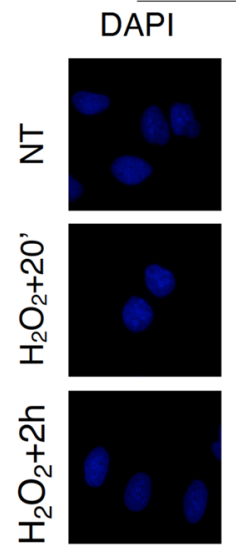

b

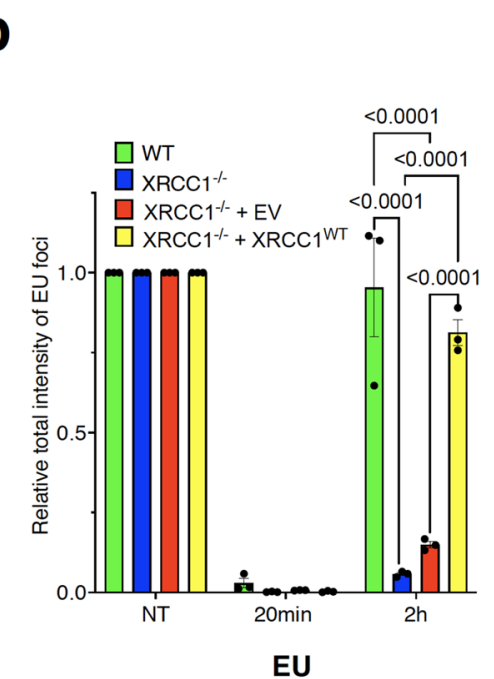

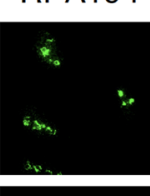
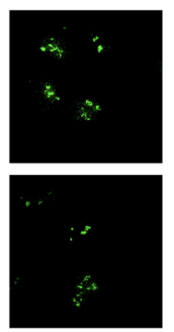

$X \mathrm{RCC}^{-\kappa}+\mathrm{EV}$

\section{EU}
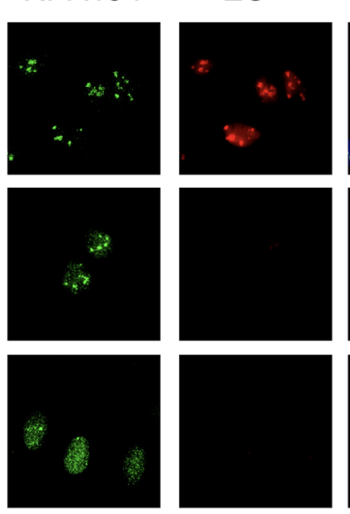

C
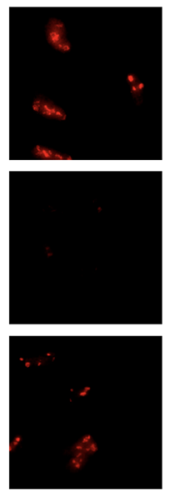

$\mathrm{EU}$

MERGE
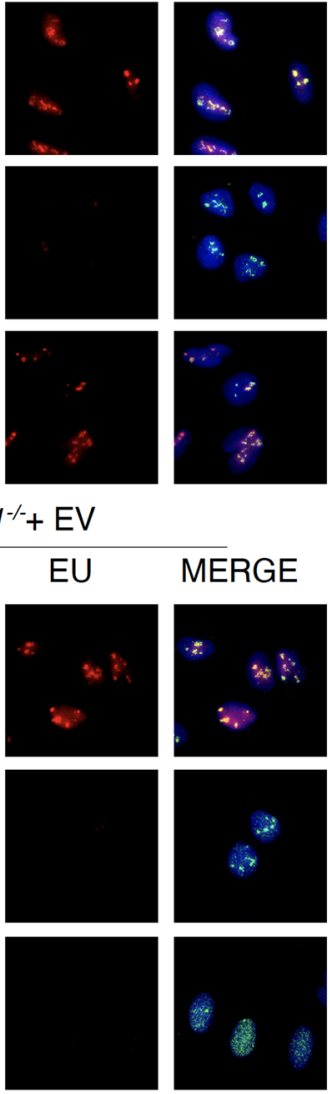
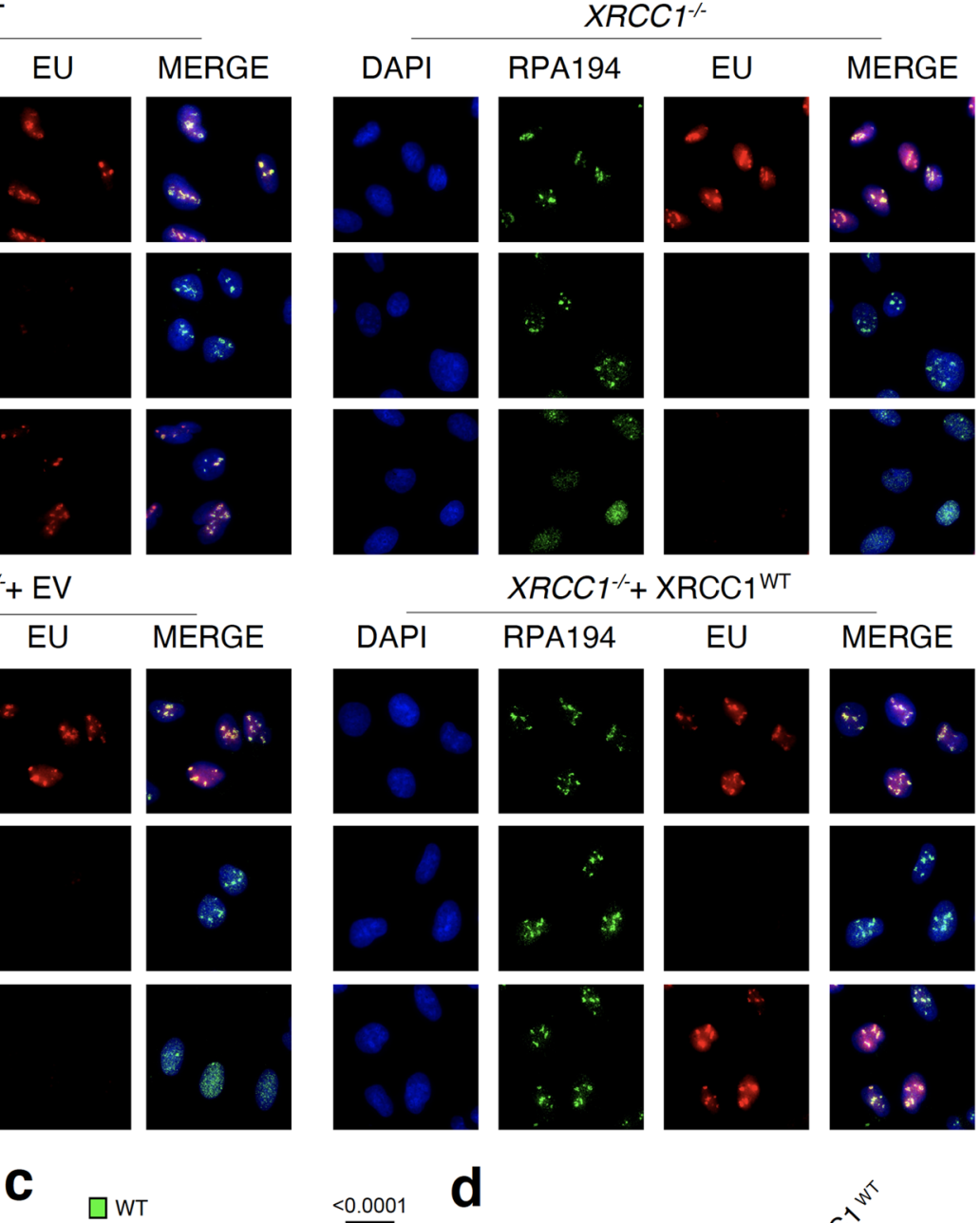

d
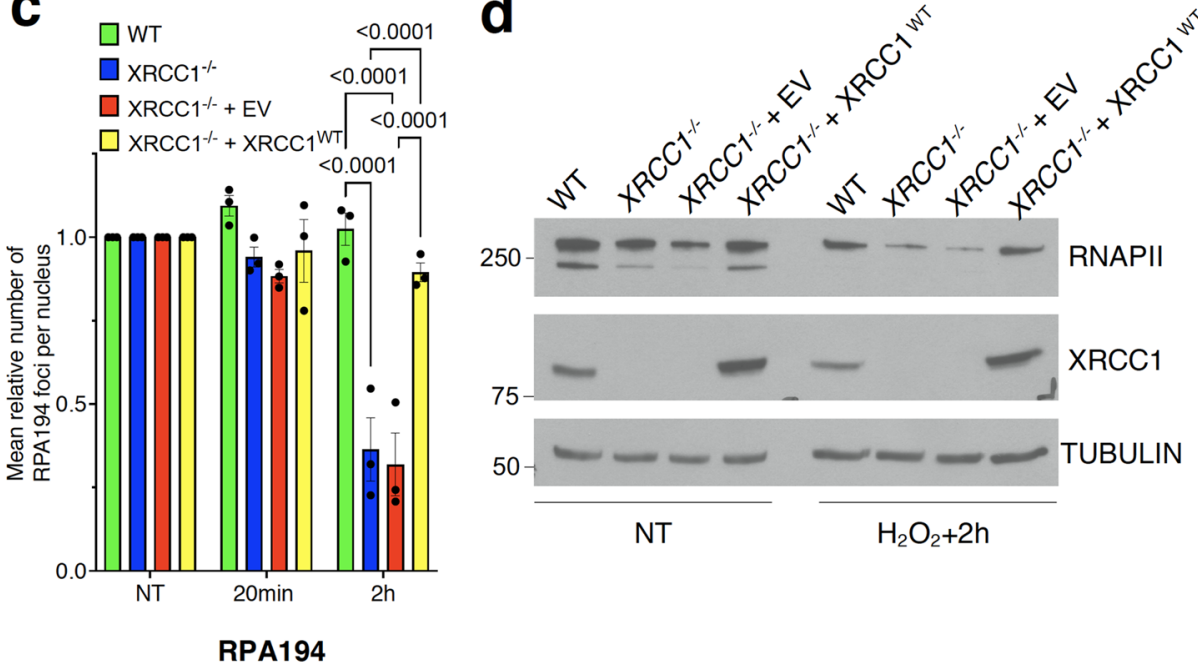

NT

$\mathrm{H}_{2} \mathrm{O}_{2}+2 \mathrm{~h}$

Extended Data Fig. 2 | XRCC1 promotes the recovery of transcription following oxidative damage. a, Representative images of the RNAPI foci (RPA194) and levels of global transcription (EU immunofluorescence) in WT and XRCC1-/- U2OS cells stably transfected with either empty vector (EV) or expression construct encoding full length $\mathrm{C}$-terminal histidine-tagged $\mathrm{XRCC1}\left(\mathrm{XRCC}{ }^{\mathrm{WT}}\right.$ ), following mock treatment or at the indicated times after treatment with $1 \mathrm{mM} \mathrm{H}_{2} \mathrm{O}_{2}$ for $20 \mathrm{~min}$. Scale bars, $10 \mu \mathrm{m}$. b and $\mathbf{c}$, Quantification of the RNAPI foci (RPA194) and levels of global transcription (EU immunofluorescence) shown in (a). Data are means ( \pm s.e.m.) of three independent experiments, and statistically significant differences were determined by two-way ANOVA with Tukey's multiple comparisons test ( $p$ values are indicated). d, Immunoblot of RNAPII hyperphosphorylation in WT U2OS cells, XRCC1-/- U2OS cells, and $X R C C 1^{-/-}$U2OS cells stably transfected with either empty vector (EV) or expression construct encoding full-length histidine-tagged XRCC1 $\left(X R C C 1^{W T}\right)$, following mock treatment or $2 \mathrm{~h}$ after treatment with $1 \mathrm{mM} \mathrm{H}_{2} \mathrm{O}_{2}$ for 20 min. A representative blot from one of three independent experiments is shown. 
a

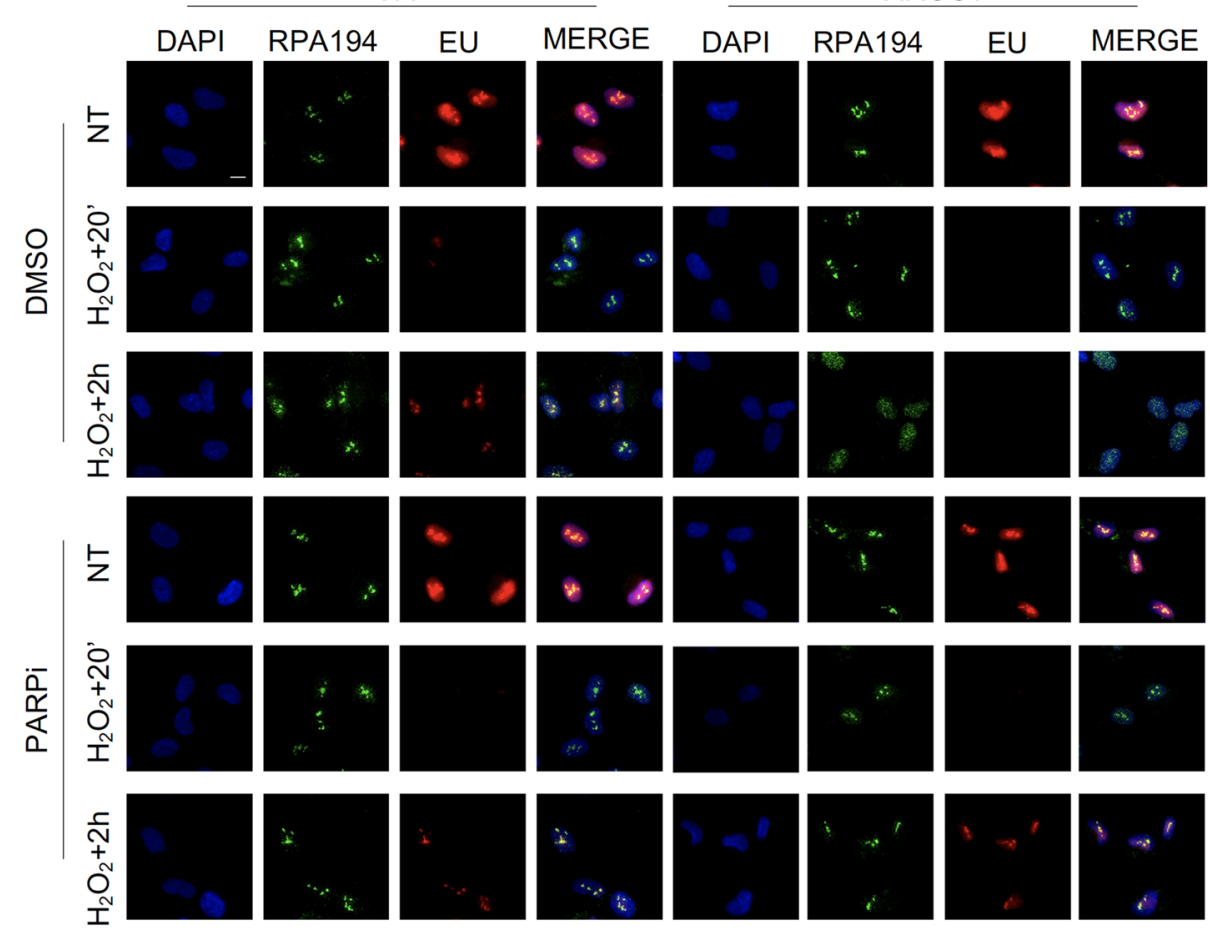

d

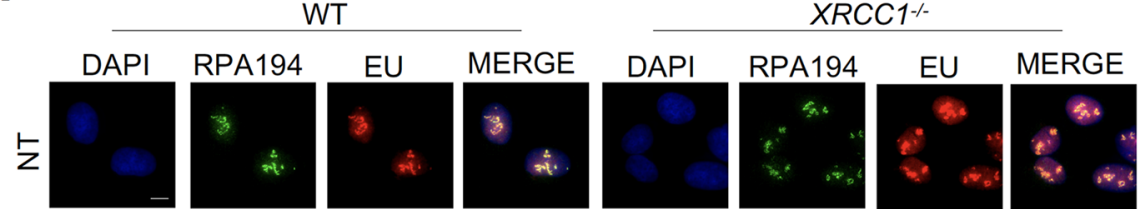

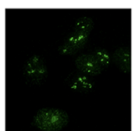
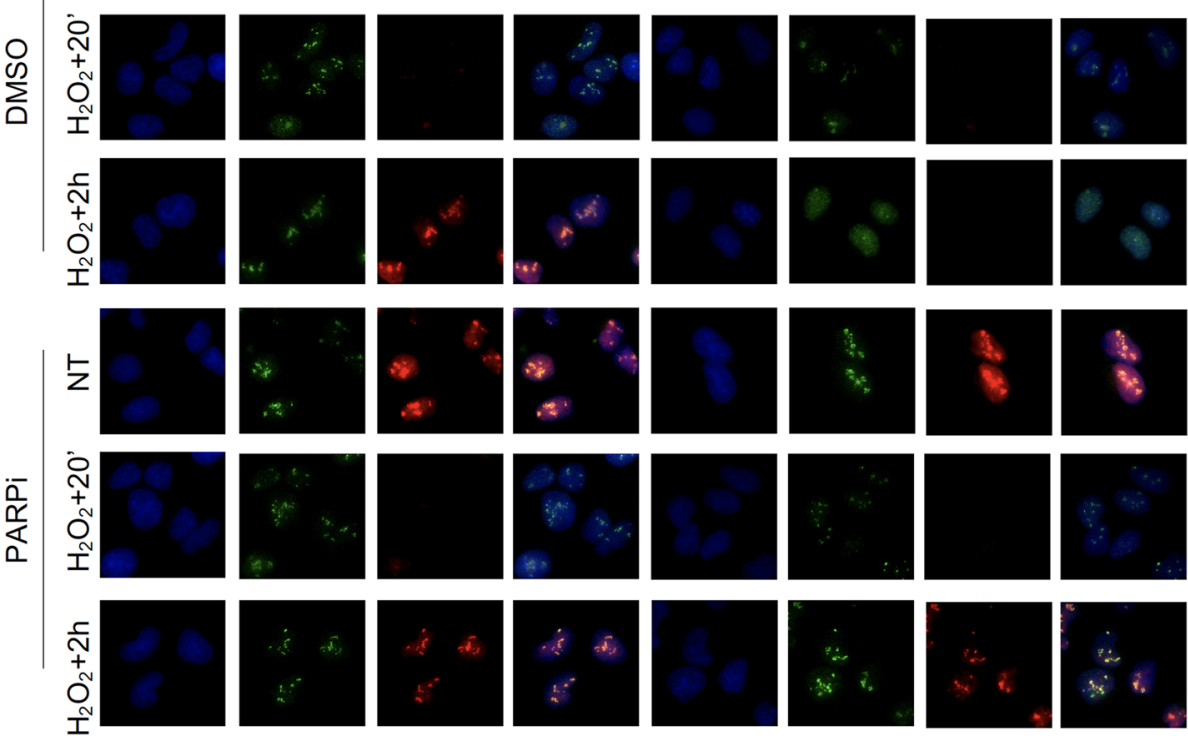

b

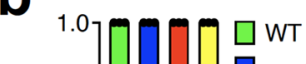

$\square \times \mathrm{XRCC}^{-1-}$

WT + PARP

$\square$ XRCC $1^{-1-}+$ PARPi
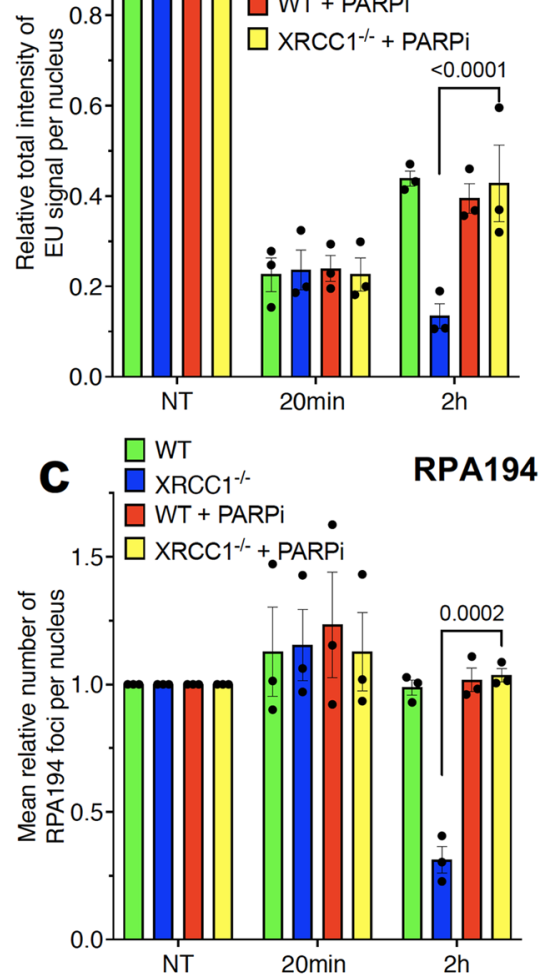

e EU
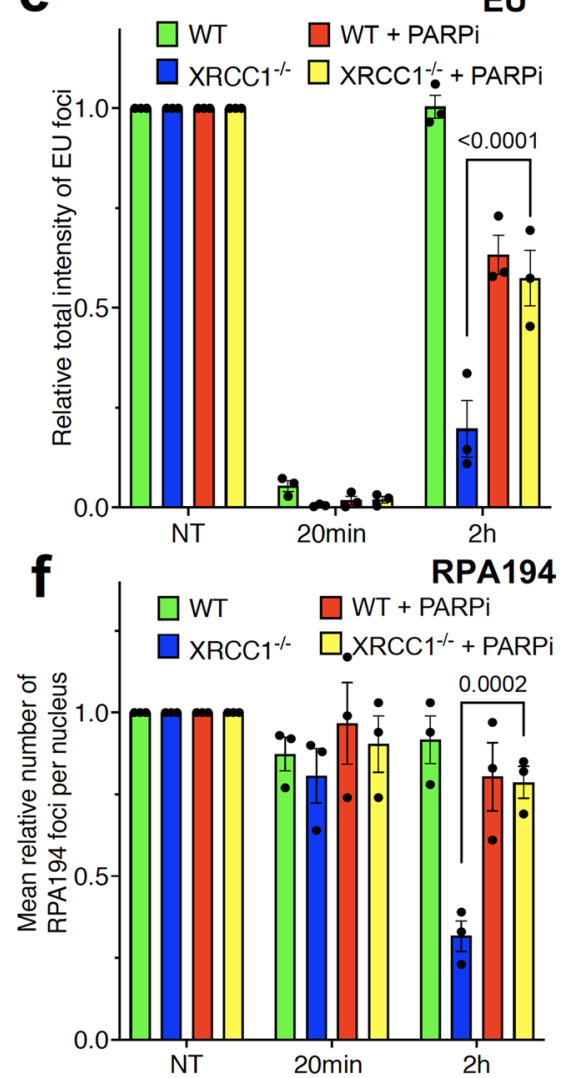

Extended Data Fig. 3 | See next page for caption. 


\section{NATURE CELL BIOLOGY}

Extended Data Fig. 3 | Reduced transcriptional recovery in XRCC1-deficient cells is a result of toxic PARP1 activity. a, Representative images of the RNAPI foci (RPA194 immunofluorescence) and levels of global transcription (EU immunofluorescence) in WT and XRCC1 ${ }^{-1-}$ RPE-1 cells pretreated with PARP1 inhibitor (PARPi) following mock treatment or at the indicated times after treatment with $250 \mu \mathrm{M} \mathrm{H}_{2} \mathrm{O}_{2}$ for 5 min. Scale bars, $10 \mu \mathrm{m}$. b and $\mathbf{c}$, Quantification of the RNAPI foci (RPA194) and levels of global transcription (EU immunofluorescence) shown in (a). Data are means ( \pm s.e.m.) of three independent experiments, and statistically significant differences were determined by two-way ANOVA with Tukey's multiple comparisons test ( $p$ values are indicated). d, Representative images of the RNAPI foci (RPA194) and levels of global transcription (EU immunofluorescence) in WT and XRCC1 ${ }^{-1-}$ U2OS cells pretreated with PARP1 inhibitor (PARPi) following mock treatment or at the indicated times after treatment with $1 \mathrm{mM} \mathrm{H}_{2} \mathrm{O}_{2}$ for 20 min. Scale bars, $10 \mu \mathrm{m}$. e and f, Quantification of the RNAPI foci (RPA194) and levels of global transcription (EU immunofluorescence) shown in (d). Data are means ( \pm s.e.m.) of three independent experiments, and statistically significant differences were determined by two-way ANOVA with Tukey's multiple comparisons test ( $p$ values are indicated). 
a

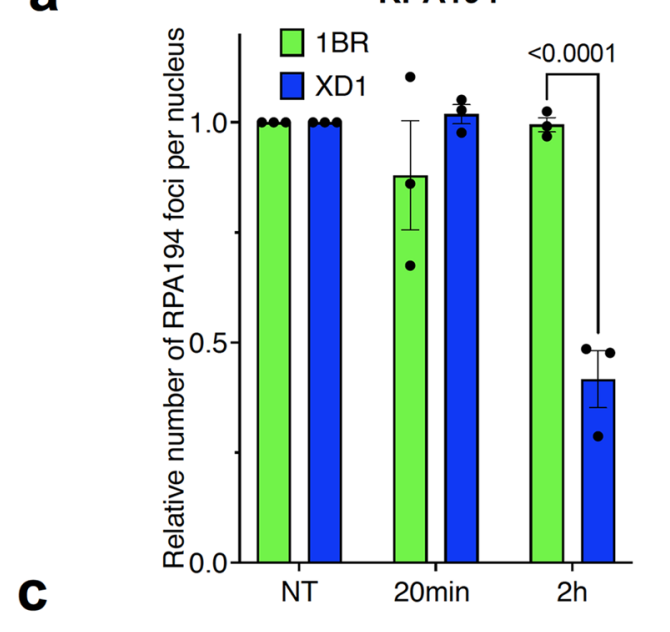

RPA194

DAPI
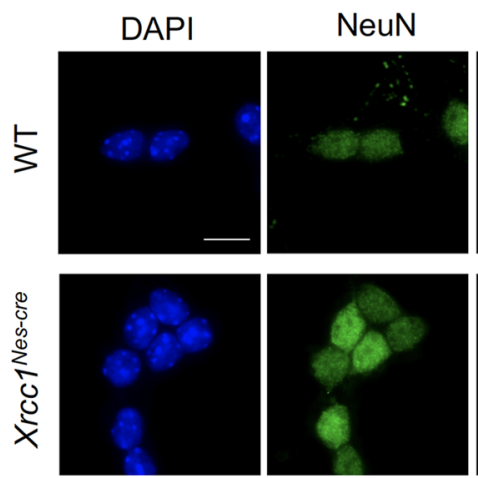
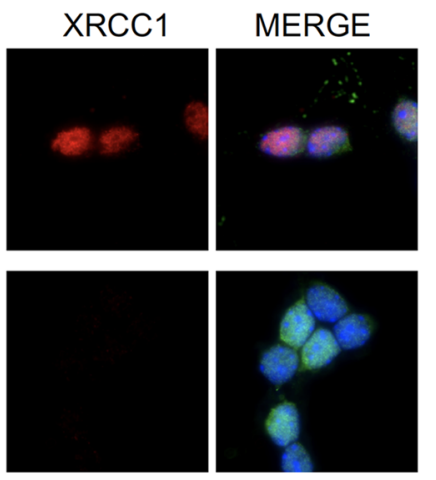

b

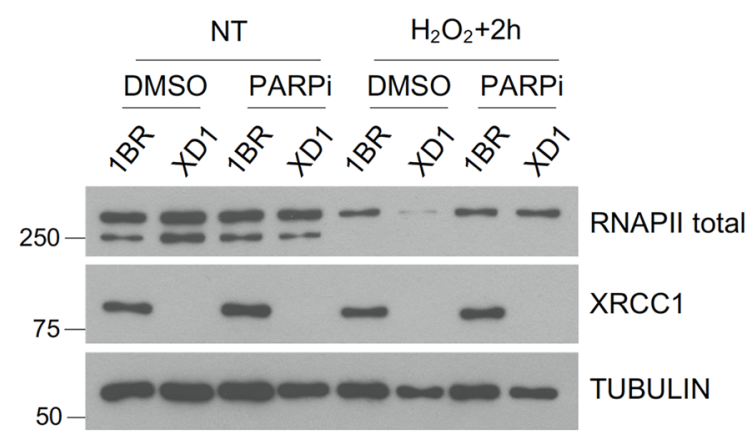

d

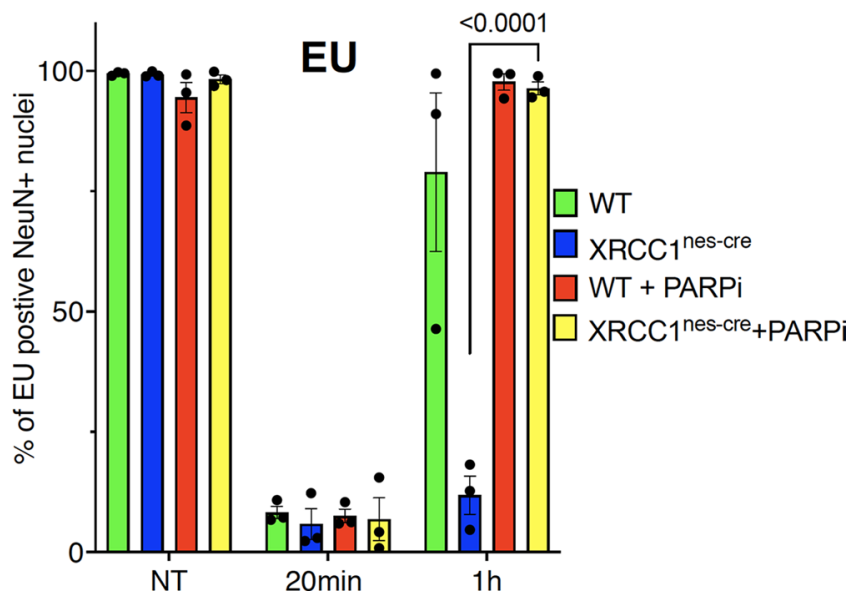

Extended Data Fig. 4 | Toxic PARP1 activity suppresses transcriptional recovery in XRCC1 patient fibroblasts and Xrcc1-deficient mouse cerebellar neurons. a, Quantification of the RNAPI foci (RPA194) shown in (Fig. 3a). Data are means ( \pm s.e.m.) of three independent experiments, and statistically significant differences were determined by two-way ANOVA with Sidak's multiple comparisons test ( $p$ values are indicated). b, Immunoblot of RNAPII hyperphosphorylation in normal fibroblasts (1BR) and XRCC1 patient fibroblasts (XD1) following mock treatment or $2 \mathrm{~h}$ after treatment with $60 \mu \mathrm{M}$ $\mathrm{H}_{2} \mathrm{O}_{2}$ for 5 min. Cells were incubated with DMSO vehicle or with $10 \mu \mathrm{M}$ PARP inhibitor (PARPi) for $1 \mathrm{~h}$ prior to, during, and following $\mathrm{H}_{2} \mathrm{O}_{2}$ treatment as indicated. A representative image from one of three independent experiments is shown. $\mathbf{c}, \mathrm{XRCC1}$ and NeuN immunofluorescence in WT and $\mathrm{Xrcc} \mathrm{T}^{\text {nes-cre }}$ mouse cerebellar neurons. Scale bars, $10 \mu \mathrm{m}$. d, Quantification of the levels of global transcription (EU immunofluorescence) shown in (Fig. 3c). Data are means ( \pm s.e.m.) of three independent experiments, and statistically significant differences were determined by two-way ANOVA with Tukey's multiple comparisons test. 
a

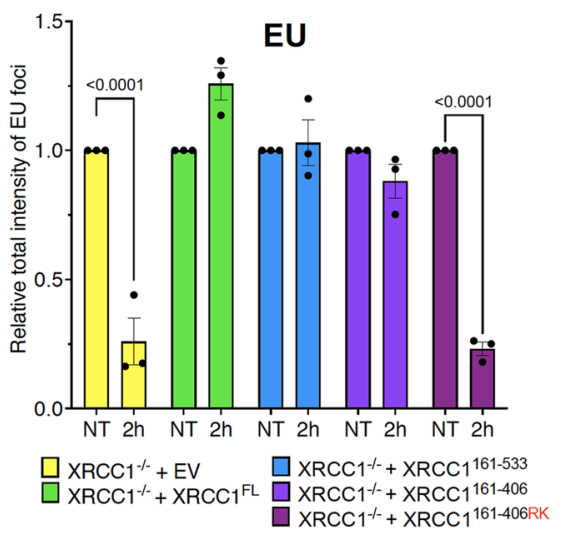

C

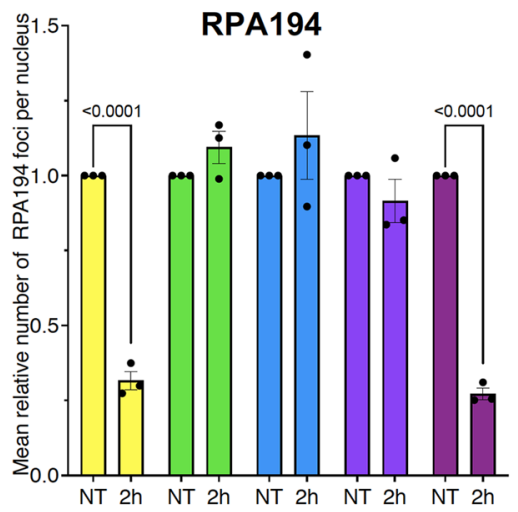

f

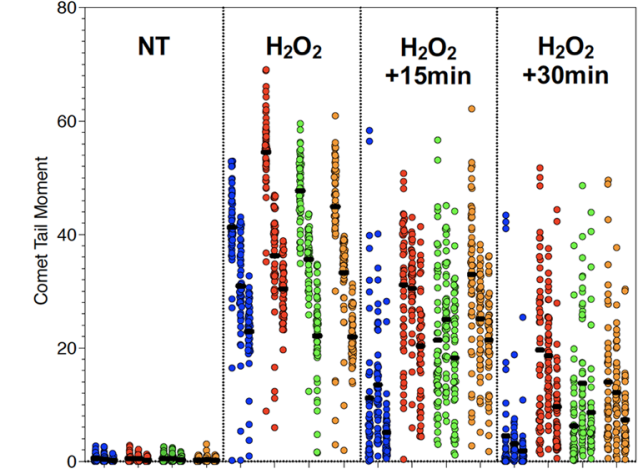

h

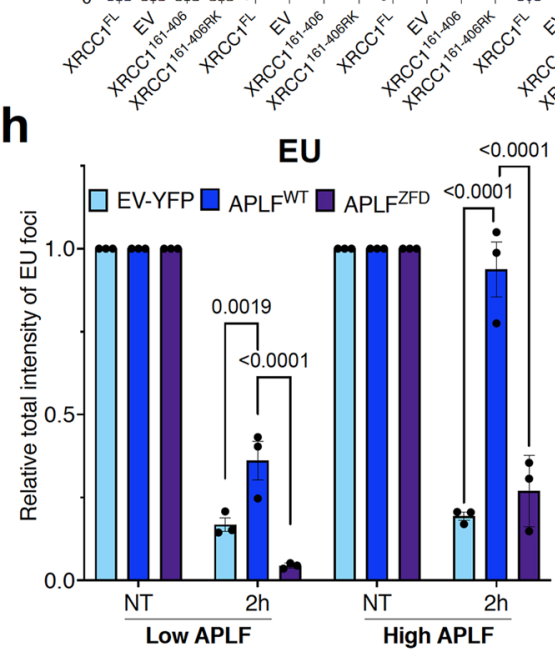

b

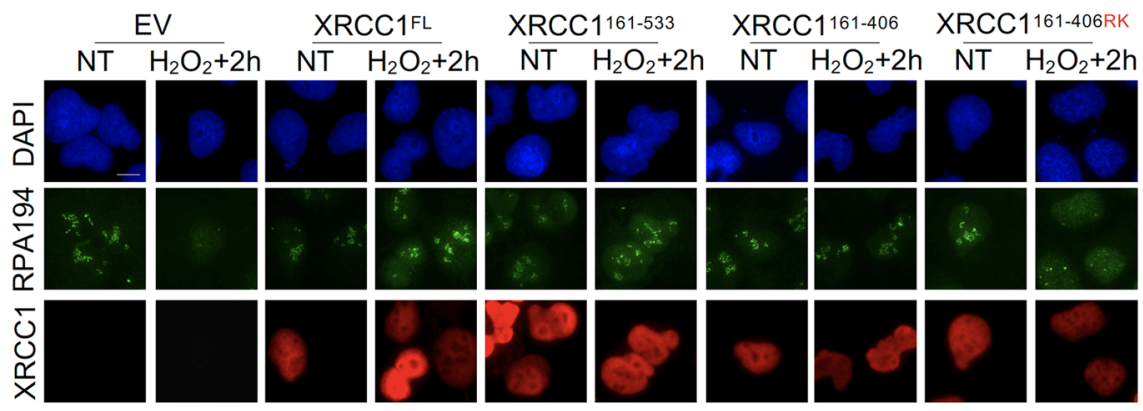

d

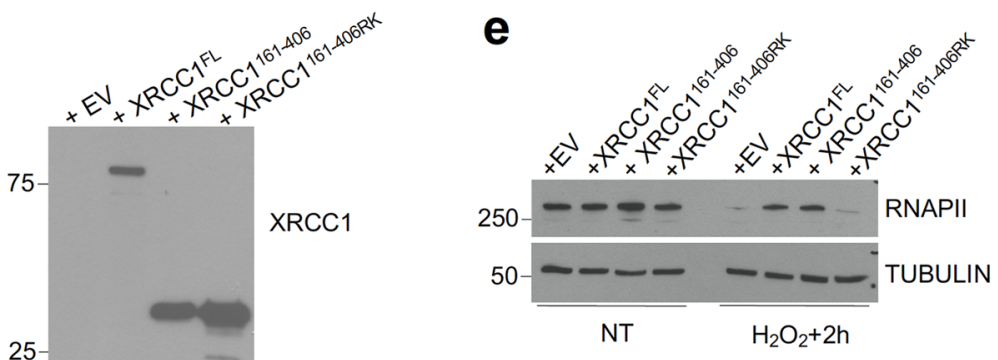

g

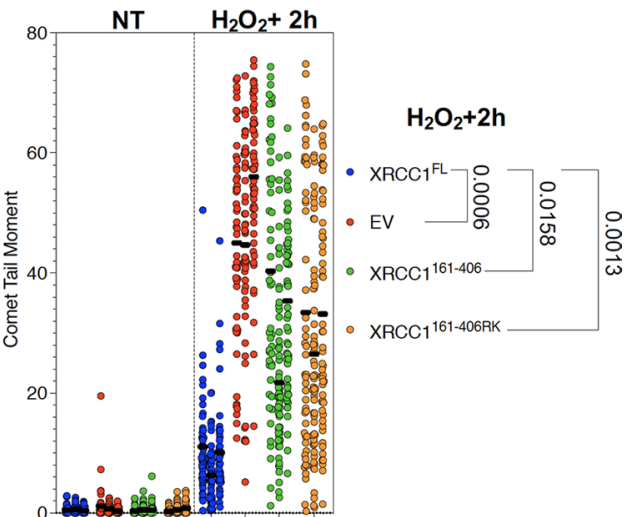

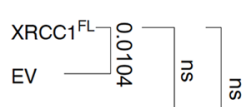

XRCC1
- XRCC1 $1^{161-406 R K}$
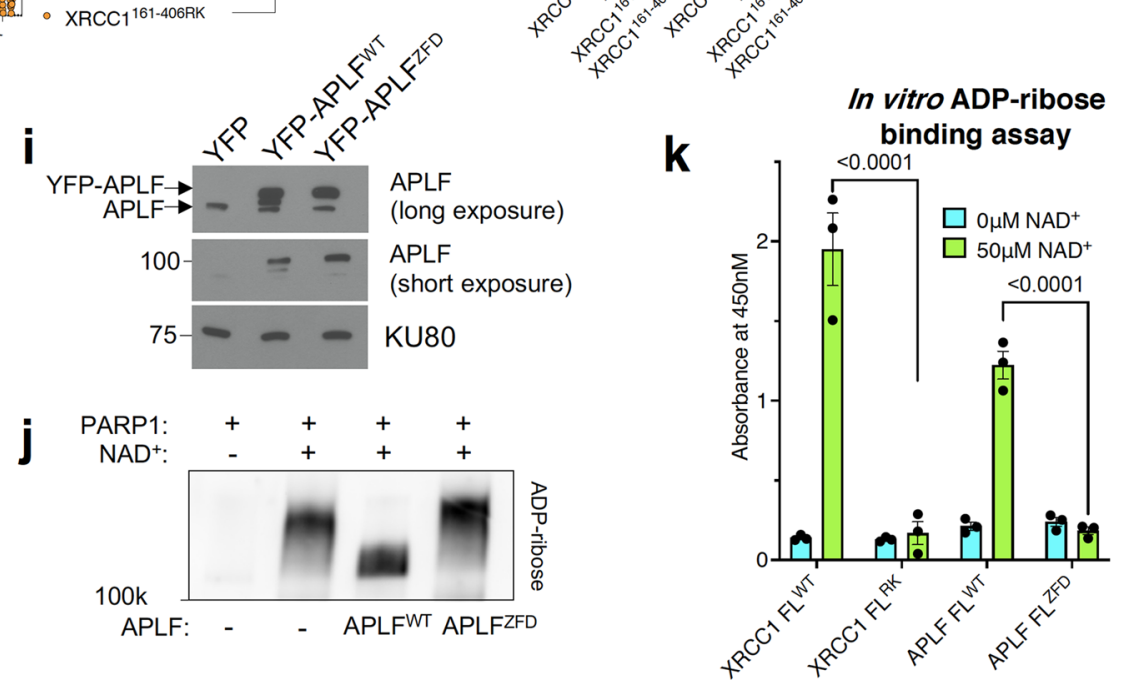

Extended Data Fig. 5 | See next page for caption. 
Extended Data Fig. 5 | The poly(ADP-ribose) binding activity of XRCC1 promotes transcriptional recovery following oxidative damage. a, Quantification of the levels of global transcription (EU immunofluorescence) shown in Fig. 4b. Data are means ( \pm s.e.m.) of three independent experiments, and statistically significant differences were determined by two-way ANOVA with Sidak's multiple comparisons test ( $p$ values are indicated). $\mathbf{b}$, Representative images of the RNAPI (RPA194) and XRCC1 immunofluorescence in WT U2OS cells, XRCC1-/- U2OS cells, and XRCC1 ${ }^{-/-}$U2OS cells transiently transfected with empty vector (EV) or expression construct encoding the indicated XRCC1 proteins, following mock-treatment or $2 \mathrm{~h}$ after treatment with $1 \mathrm{mM} \mathrm{H}_{2} \mathrm{O}_{2}$ for $20 \mathrm{~min}$. Scale bars, $10 \mu \mathrm{m}$. c, Quantification of the RNAPI foci (RPA194) shown in (b). Data are means ( \pm s.e.m.) of three independent experiments, and statistically significant differences were determined by two-way ANOVA with Sidak's multiple comparisons test ( $p$ values are indicated). d, Immunoblot of XRCC1 in XRCC1 $1^{-1-}$ U2OS cells stably expressing the indicated XRCC1 proteins. A representative blot from three independent experiments is shown. e, Immunoblot of RNAPII hyperphosphorylation in XRCC1-/- U2OS cells stably expressing the indicated XRCC1 proteins, following mock-treatment or $2 \mathrm{~h}$ after treatment with $1 \mathrm{mM} \mathrm{H}_{2} \mathrm{O}_{2}$ for 20 min. A representative image from one of three independent experiments is shown. $\mathbf{f}$ and $\mathbf{g}$, Quantification of DNA strand breaks measured by alkaline comet assays in XRCC1-/- U2OS cells stably expressing the indicated XRCC1 proteins, following mock treatment (not treated; ' $N \mathrm{TT}^{\prime}$ ) or at the indicated times after treatment with either $50 \mu \mathrm{M} \mathrm{H}_{2} \mathrm{O}_{2}$ for 10 min on ice (conditions to measure SSB repair kinetic; panel f) or with $100 \mu \mathrm{M} \mathrm{H}_{2} \mathrm{O}_{2}$ for $20 \mathrm{~min}$ (refreshed every $10 \mathrm{~min}$ ) in serum-free medium at $37^{\circ} \mathrm{C}$ followed by recovery for $2 \mathrm{~h}$ (conditions, at which transcription recovery is perturbed in XRCC1-/- cells; panel $\mathrm{g}$ ). Data show individual tail moments (an arbitrary measure of DNA breaks) from 50 cells per sample for three independent experiments. For each sample, the fifty tail moments are stacked vertically and the three experiments are positioned side-by-side (exp1, exp2, exp3) with the tick mark centred on exp2. Statistical significance was determined by one way ANOVA with Sidak's two tailed Student's t-test ( $p$ values are indicated). h, Quantification of the levels of global transcription (EU immunofluorescence) shown in Fig. 4d. Data are means ( \pm s.e.m.) of three independent experiments, and statistically significant differences were determined by two-way ANOVA with Tukey's multiple comparisons test ( $p$ values are indicated). $\mathbf{i}$, Immunoblot of APLF in the XRCC1-/- U2OS cells stably expressing the indicated APLF proteins. Single validation of SDS-PAGE mobility shift. $\mathbf{j}$, Immunoblot of PARP1 auto-ADP-ribosylation in an in vitro ADP-ribosylation assay. Human recombinant PARP1 (100 nM) was incubated for $30 \mathrm{~min}$ in the presence of ssDNA $(100 \mathrm{nM}), \mathrm{NAD}^{+}(2.5 \mu \mathrm{M})$ and with or without $1.5 \mu \mathrm{M}$ of wild type or Zn-finger double mutant APLF (APLFWT; APLFFF respectively). A representative blot from one of three independent experiments is shown. $\mathbf{k}$, Binding of full length XRCC1 and APLF, as well as their PAR binding mutants denoted as XRCC1RK and $A P L F{ }^{2 F D}$ respectively, to the indicated mock-ribosylated $\left(-N^{2} D^{+}\right)$or ribosylated $\left(50 \mu M N A D^{+}\right)$histones. Data are means ( \pm s.e.m.) of three independent experiments, and statistically significant differences were determined by two-way ANOVA with Tukey's multiple comparisons test ( $p$ values are indicated). 
a
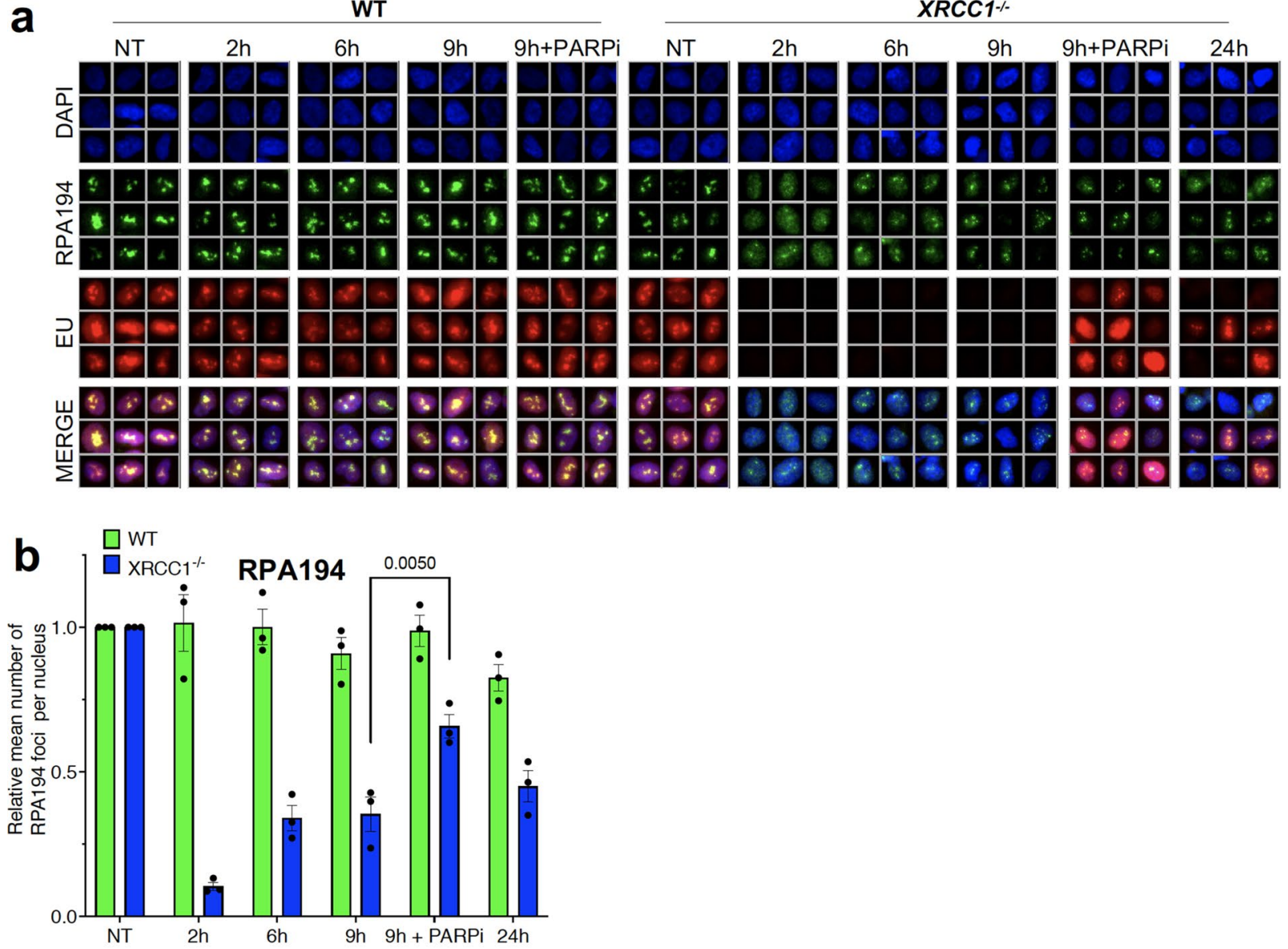

C

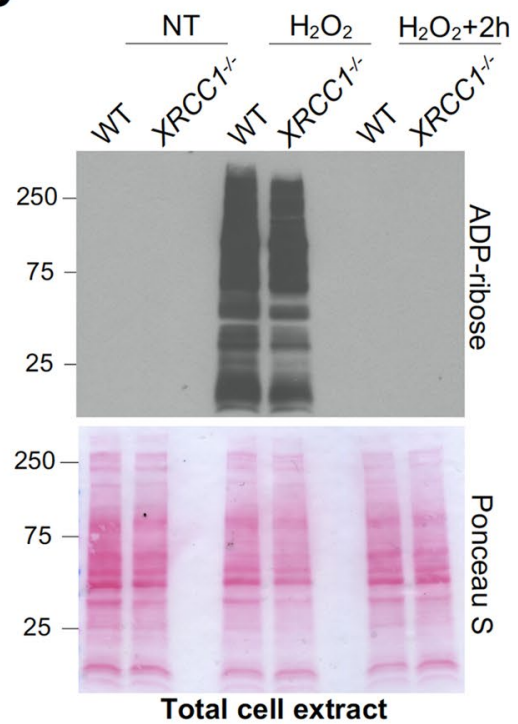

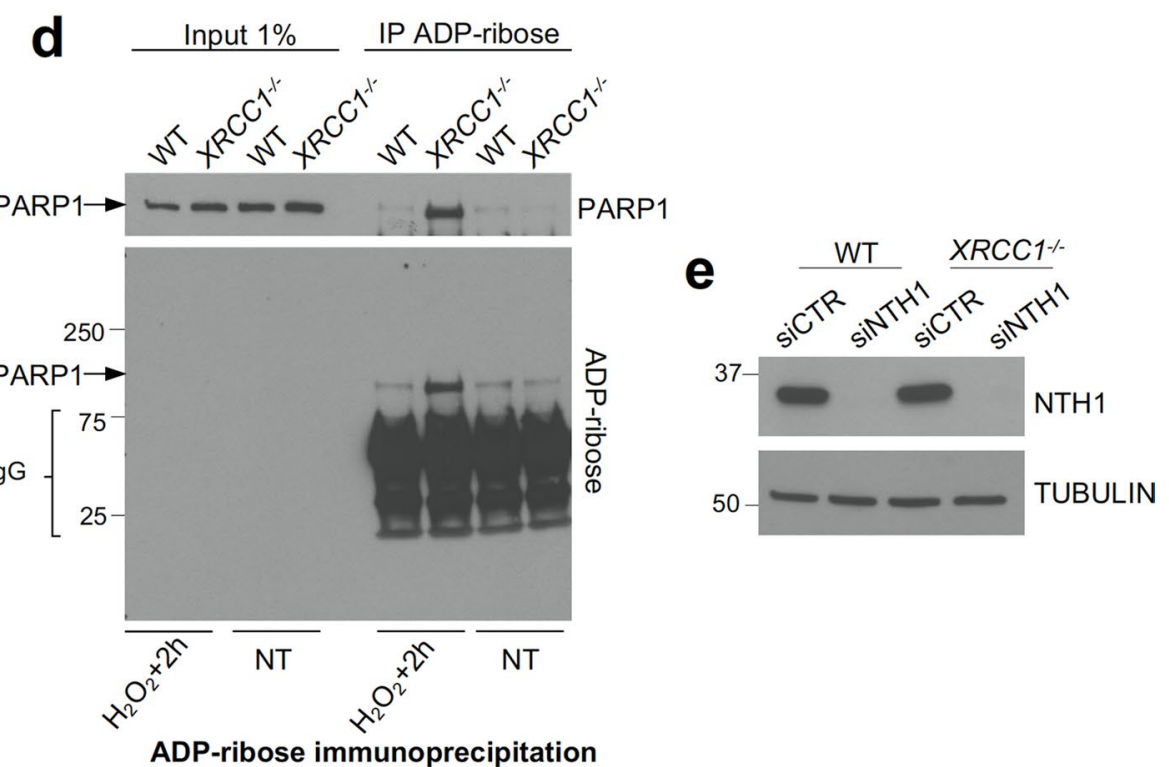

Extended Data Fig. 6 | Persistent PARP1 activation on the BER intermediates is a source of toxic PARP1 activity. a, Representative images of the RNAPI foci (RPA194) and levels of global transcription (EU Immunofluorescence) in WT and XRCC1 ${ }^{-1-}$ RPE-1 cells following mock treatment or at the indicated times after treatment with $250 \mu \mathrm{M} \mathrm{H}_{2} \mathrm{O}_{2}$ for 5 min. b, Quantification of the RNAPI foci (RPA194) shown in (a). Data are means ( \pm s.e.m.) of three independent experiments, and statistically significant differences were determined by two-way ANOVA with Sidak's multiple comparisons test ( $p$ values are indicated). $\mathbf{c}$ and $\mathbf{d}$, Immunoblot of PARP1 and/or ADP-ribose levels in total cell extract (panel c) and following ADP-ribose immunoprecipitation (panel d) prepared from WT and XRCC1-/- RPE-1 cells following mock treatment or at $2 \mathrm{~h}$ after treatment with $250 \mu \mathrm{M} \mathrm{H}_{2} \mathrm{O}_{2}$ for 5 min. Representative blots from one of three independent experiments are shown. e, Immunoblot of NTH1 in WT and XRCC1-/- RPE-1 cells treated for $72 \mathrm{~h}$ with $10 \mathrm{nM}$ siRNA against NTH1. A representative blot from one of two independent experiments is shown. 
a
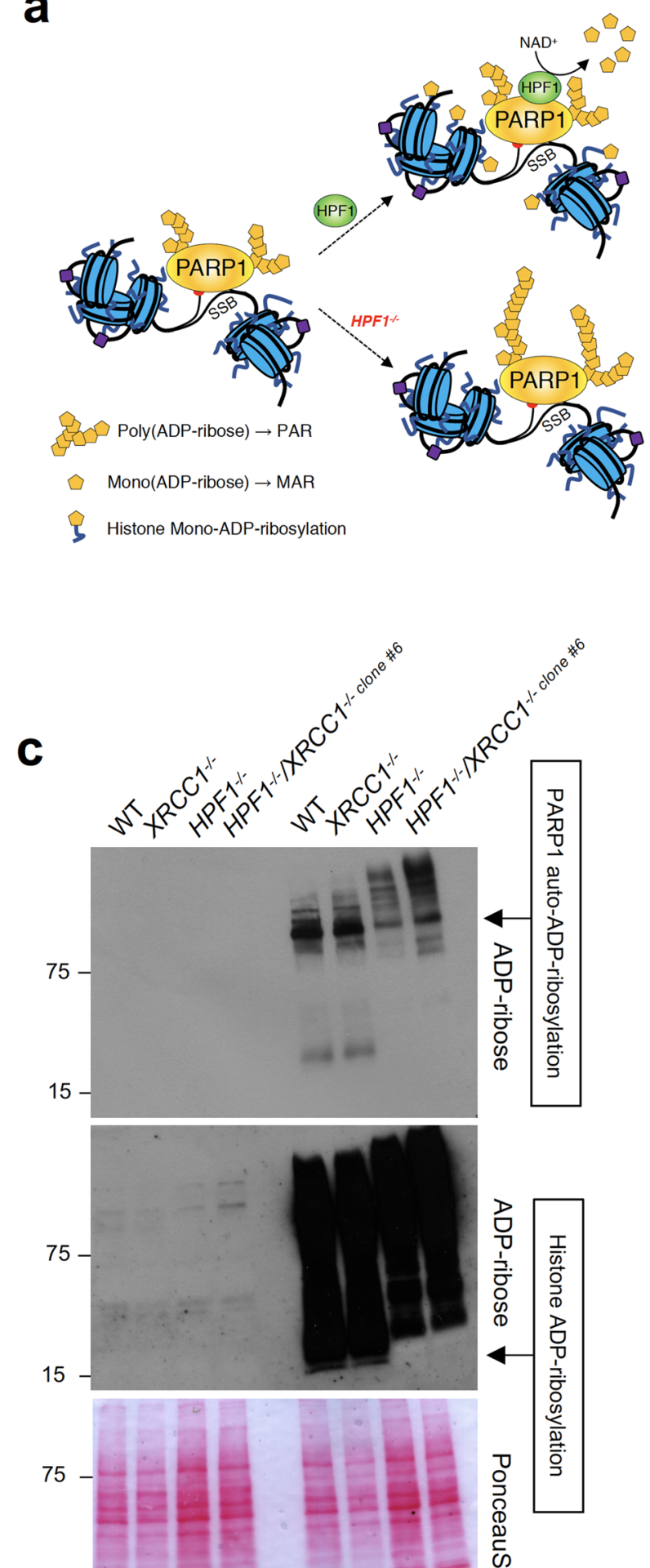

15

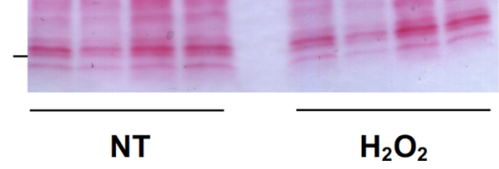

Extended Data Fig. 7 | See next page for caption.
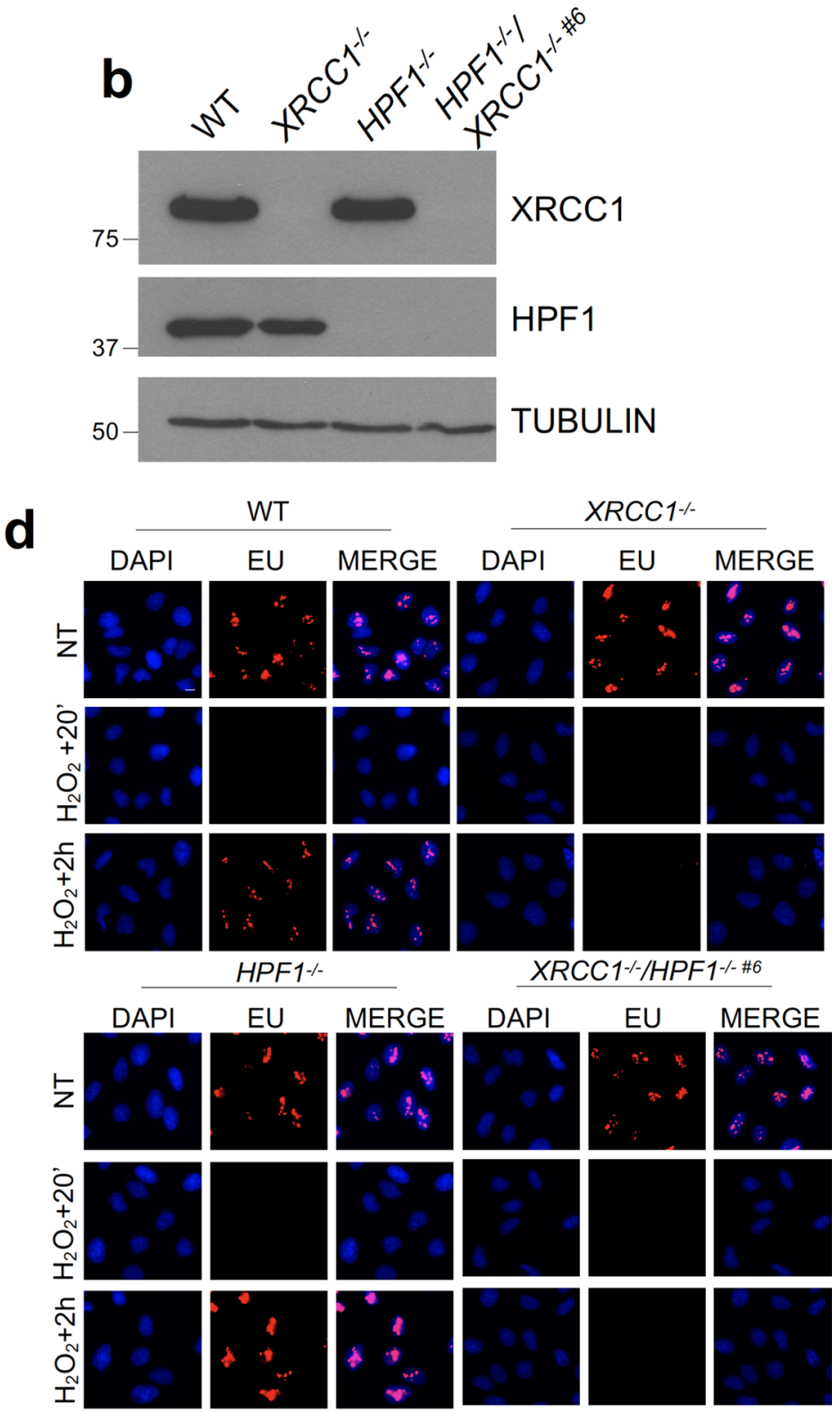

e

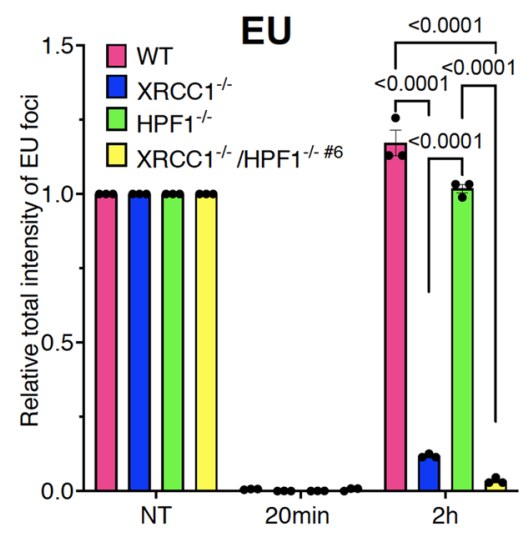


Extended Data Fig. 7 | Deletion of the histone ADP-ribosylation factor HPF1 does not rescue transcription recovery in XRCC1-/- RPE-1 cells. a, Model of the impact of HPF1 on PARP1-mediated histone ADP-ribosylation as well as PARP1 auto-ADP-ribosylation. $\mathbf{b}$, Immunoblot of HPF1 and XRCC1 in WT, $H P F 7^{-1-}, X R C C 1^{-1-}$, and HPF1 ${ }^{-/-} / X R C C 1^{-/-}$U2OS cells. A representative blot from one of three independent experiments is shown. $\mathbf{c}$, Immunoblot of ADPribosylation upon $\mathrm{H}_{2} \mathrm{O}_{2}$ treatment $(1 \mathrm{mM}, 5 \mathrm{~min})$ in WT, $\mathrm{HPF1}^{-/-}, \mathrm{XRCC1}^{-/-}$, and $\mathrm{HPF1}^{-/-} / \mathrm{XRCC1^{-/- }} \mathrm{U} 2 \mathrm{OS}$ cells. A representative blot from one of three independent experiments is shown. d, Global transcription (EU Immunofluorescence) in WT, HPF1 $1^{-/-}, X^{\prime} C C 1^{-/-}, H P F 1^{-/-} / X R C C 1^{-/-} \mathrm{U} 2 \mathrm{OS}$ cells following mock treatment or at the indicated times after treatment with $1 \mathrm{mM} \mathrm{H}_{2} \mathrm{O}_{2}$ for $20 \mathrm{~min}$. Scale bars, $10 \mu \mathrm{m}$. e, Quantification of the EU signal shown in (d). Data are means ( \pm s.e.m.) of three independent experiments, and statistically significant differences were determined by two-way ANOVA with Tukey's multiple comparisons test ( $p$ values are indicated). 

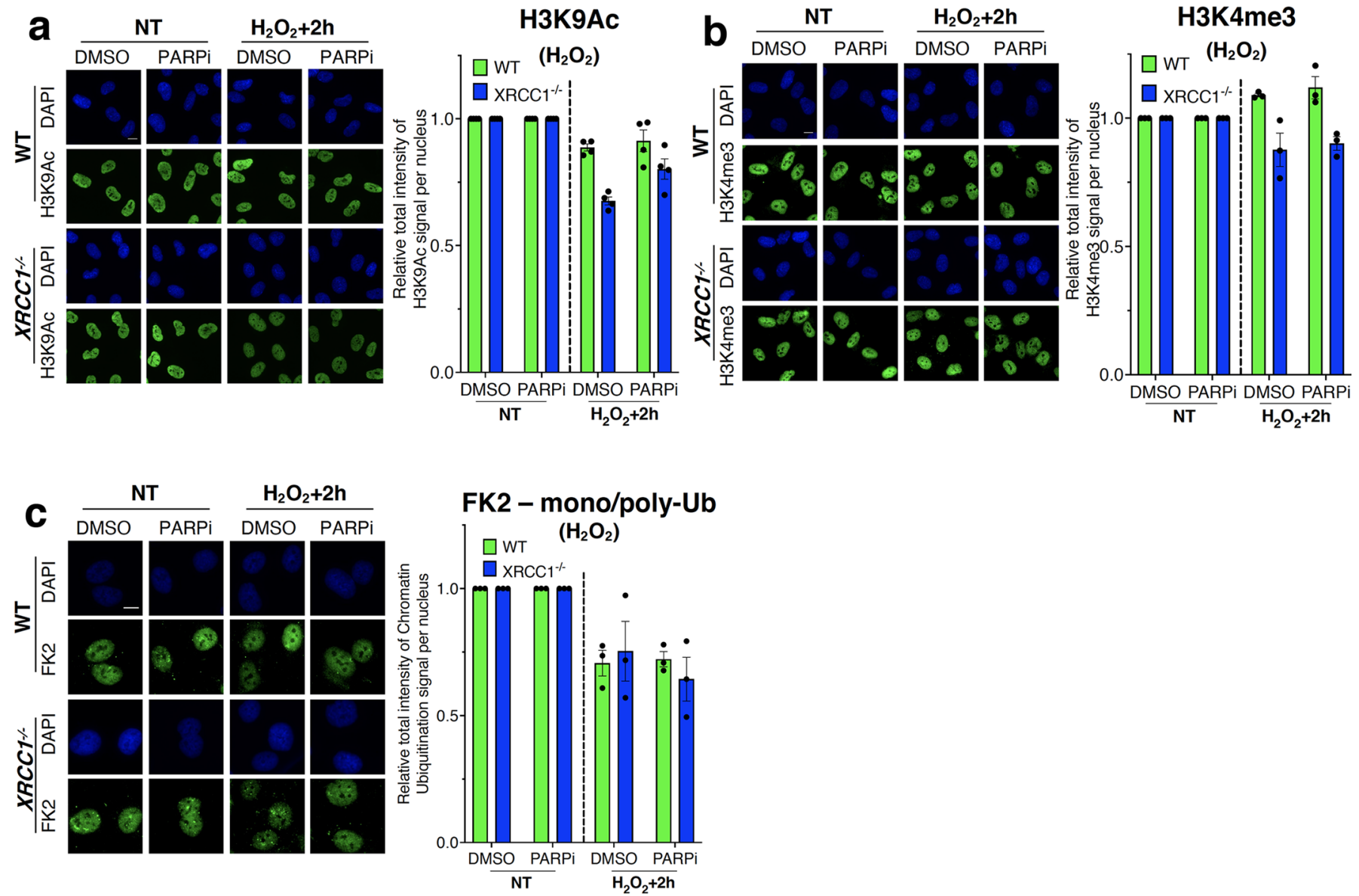

Extended Data Fig. 8 | Levels of histone acetylation, methylation, protein ubiquitylation in XRCC1-1- RPE-1 cells. a, Levels of H3K9Ac in RPE-1 cells, following treatment with $250 \mu \mathrm{M} \mathrm{H}_{2} \mathrm{O}_{2}$ for 5 min. Cells were incubated with $10 \mu \mathrm{M} \mathrm{PARP}$ inhibitor (PARPi) for $1 \mathrm{~h}$ prior to, during, and following $\mathrm{H}_{2} \mathrm{O}_{2}$ treatment. Quantification of $\mathrm{H} 3 \mathrm{~K} 9 \mathrm{Ac}$ immunofluorescence shown on the right. Data are means ( \pm s.e.m.) of four independent experiments. Scale bars, $10 \mu \mathrm{m}$. b, Levels of $\mathrm{H} 3 \mathrm{~K} 4 \mathrm{me} 3$ in RPE-1 cells, following treatment with $250 \mu \mathrm{M} \mathrm{H}_{2} \mathrm{O}_{2}$ for 5 min. Cells were incubated with $10 \mu \mathrm{M}$ PARP inhibitor (PARPi) for $1 \mathrm{~h}$ prior to, during, and following $\mathrm{H}_{2} \mathrm{O}_{2}$ treatment. Quantification of $\mathrm{H} 3 \mathrm{~K} 4 \mathrm{me} 3$ immunofluorescence shown on the right. Data are means ( \pm s.e.m.) of three independent experiments. Scale bars, $10 \mu \mathrm{m}$. c, Levels of chromatin mono/poly-ubiquitination (FK2) in RPE-1 cells, following treatment with $250 \mu \mathrm{M} \mathrm{H} \mathrm{O}_{2}$ for 5 min. Cells were incubated with $10 \mu \mathrm{M}$ PARP inhibitor (PARPi) for $1 \mathrm{~h}$ prior to, during, and following $\mathrm{H}_{2} \mathrm{O}_{2}$ treatment. Quantification of chromatin mono/ poly-ubiquitination immunofluorescence shown on the right. Data are means ( \pm s.e.m.) of three independent experiments. Scale bars, $10 \mu \mathrm{m}$. 

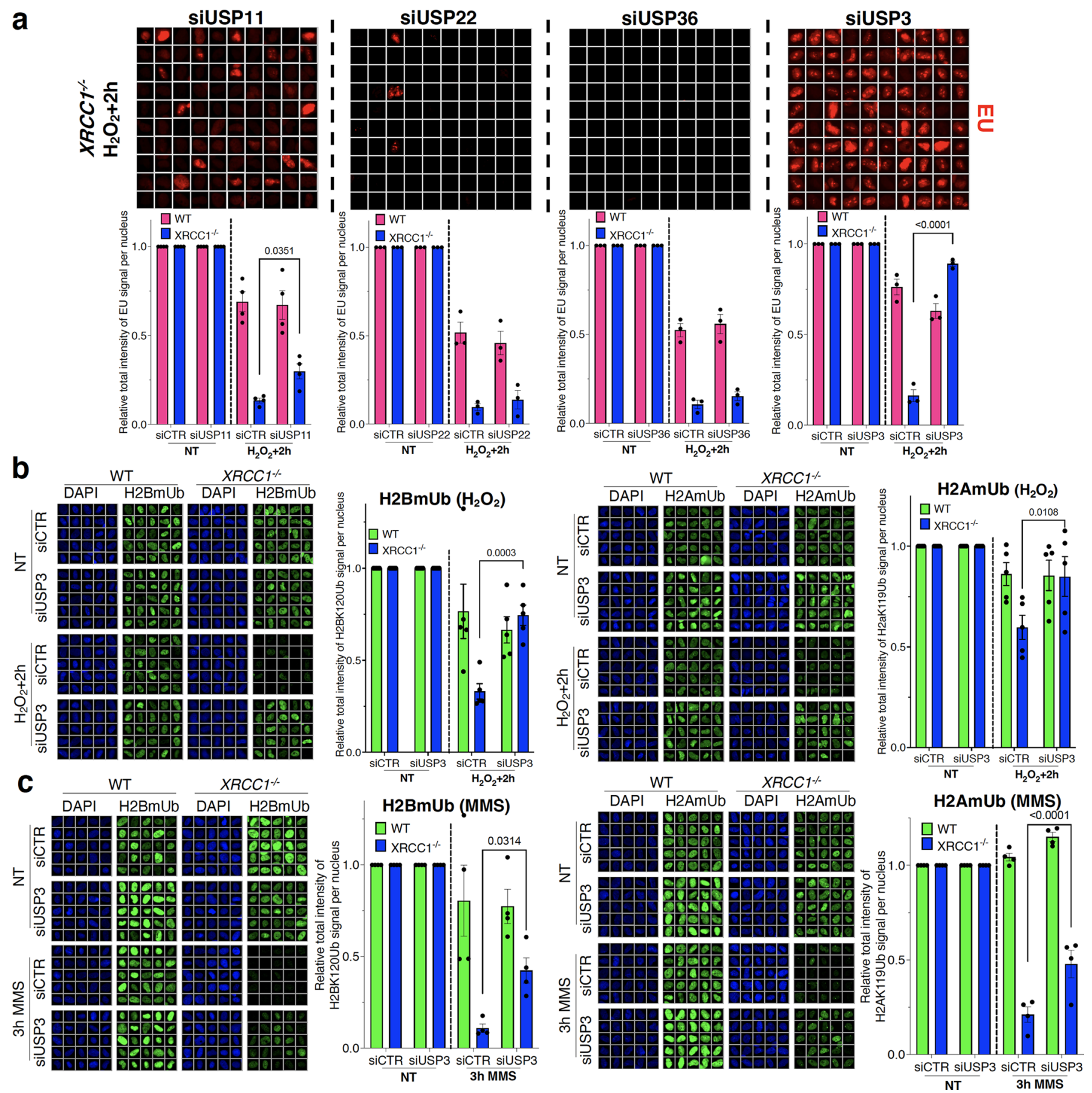

Extended Data Fig. 9 | Activated PARP1 recruits USP3 to induce histone deubiquitination and transcription inhibition. a, Global transcription (EU Immunofluorescence) in RPE-1 cells, following treatment with $250 \mu \mathrm{M} \mathrm{H}_{2} \mathrm{O}_{2}$ for 5 min. Representative images of cells $2 \mathrm{~h}$ after $\mathrm{H}_{2} \mathrm{O}_{2}$ are shown. Cells were pre-treated for $72 \mathrm{~h}$ with control or siRNA targeting USP11, USP22, USP36 and USP3. Quantifications are shown below images. Data are means ( \pm SEM) of three or four independent experiments with statistical significance determined by Two-way ANOVA, Sidak's multiple comparisons test ( $p$ values are indicated). b, Levels of $\mathrm{H} 2 \mathrm{BK} 12 \mathrm{OmUb}\left(\mathrm{H} 2 \mathrm{BmUb}\right.$; left) and $\mathrm{H} 2 \mathrm{AK} 119 \mathrm{mUb}\left(\mathrm{H} 2 \mathrm{AmUb}\right.$; right) in RPE-1 cells, following treatment with $250 \mu \mathrm{M} \mathrm{H}_{2} \mathrm{O}_{2}$ for 5 min. Cells were pre-treated for $72 \mathrm{~h}$ with control or siRNA targeting USP3. Data are means ( \pm SEM) of five independent experiments with statistical significance determined by two-way ANOVA with Sidak's multiple comparisons test ( $p$ values are indicated). c, Levels of H2BmUb (left) and H2AmUb (right) in RPE-1 cells, following treatment with $0.1 \mathrm{mg} / \mathrm{ml}$ MMS for $3 \mathrm{~h}$. Cells were pre-treated for $72 \mathrm{~h}$ with control or siRNA targeting USP3. Data are means $( \pm$ SEM) of four independent experiments with statistical significance determined by two-way ANOVA with Sidak's multiple comparisons test ( $p$ values are indicated). 
a
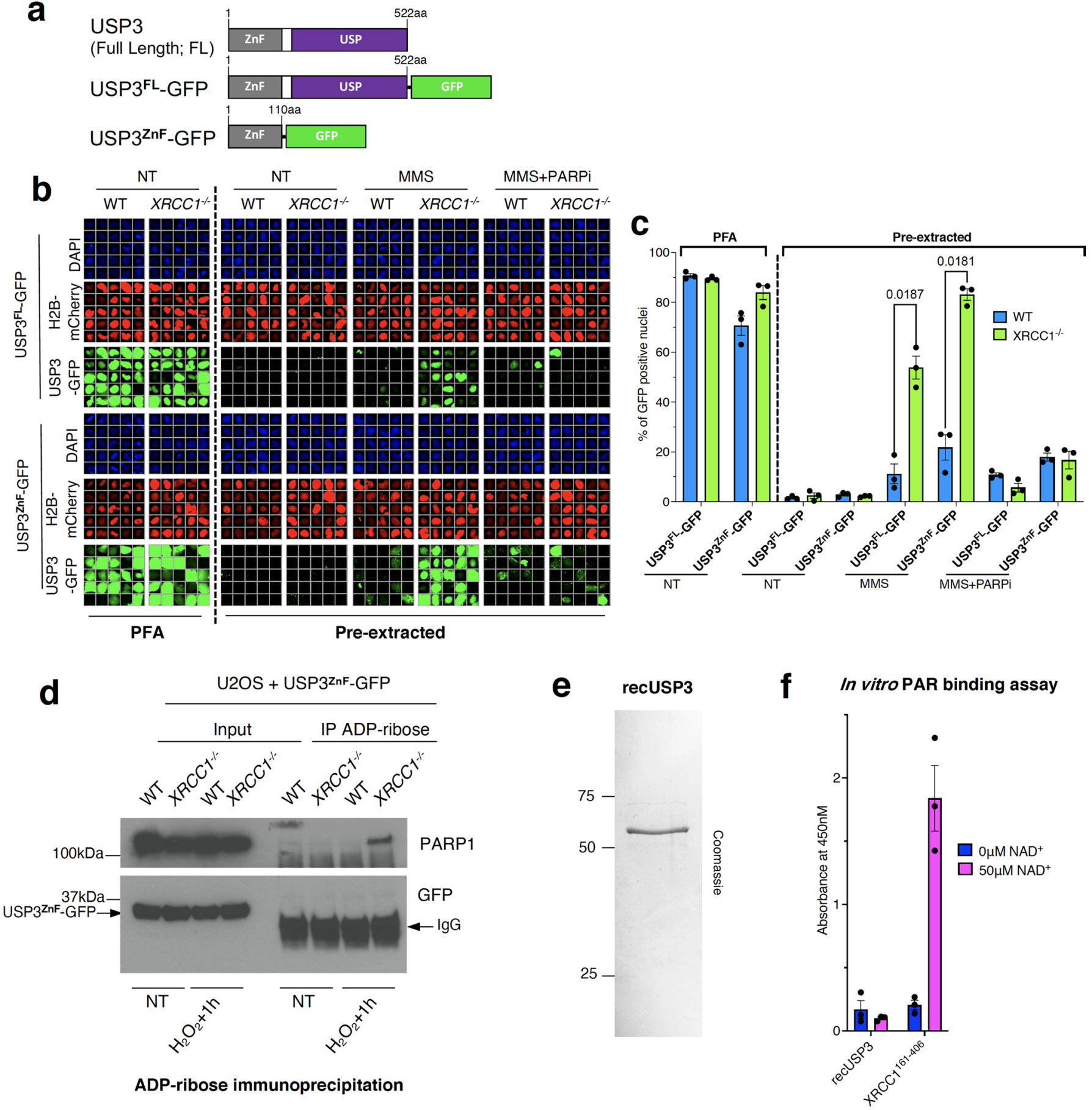

ADP-ribose immunoprecipitation

Extended Data Fig. 10 | USP3 does not interact directly with Poly-ADP-ribose chains. a, Cartoon of GFP-tagged USP3 constructs employed in this work. b, Representative ScanR images of chromatin retention of USP3 ${ }^{\mathrm{FL}}$-GFP and USP3 ${ }^{\mathrm{ZnF}}$-GFP in WT and XRCC1 ${ }^{-/-}$U2OS cells, following mock-treatment or for $4 \mathrm{~h}$ with $0.1 \mathrm{mg} / \mathrm{ml} \mathrm{MMS}$ in the presence/absence of $10 \mu \mathrm{M}$ PARPi as indicated. Cells were transfected with H2B-mCherry and USP3-GFP constructs $24 \mathrm{~h}$ before experiment. Cells were fixed with PFA to show total protein levels or were pre-extracted with detergent prior to fixation to show chromatin-bound proteins. c, Quantification of experiments depicted in b. Data are means ( \pm s.e.m.) of three independent experiments, and statistically significant differences were determined by two-way ANOVA with Sidak's multiple comparisons test ( $p$ values are indicated). $\mathbf{d}$, Immunoblot of PARP1 and USP3ZnF-GFP levels in anti-ADP-ribose immunoprecipitates from WT and XRCC1-/- U2OS cell extracts following mock treatment or $1 \mathrm{~h}$ after treatment with $1 \mathrm{mM} \mathrm{H}_{2} \mathrm{O}_{2}$ for $20 \mathrm{~min}$. A representative blot from one of two independent experiments is shown. e, Coomassie staining of purified recombinant human USP3 employed in the ADP-ribose binding assay shown in $\mathbf{f}$. Single purification. f, Binding of full length USP3 and XRCC1 ${ }^{161-406}$ (positive control) to calf thymus histones mock-ribosylated $\left(-\mathrm{NAD}^{+}\right)$or $\mathrm{ADP}$-ribosylated $\left(50 \mu \mathrm{MNAD}{ }^{+}\right)$with recombinant PARP1. Data are means $( \pm$s.e.m.) of three independent experiments. 


\section{Reporting Summary}

Nature Portfolio wishes to improve the reproducibility of the work that we publish. This form provides structure for consistency and transparency in reporting. For further information on Nature Portfolio policies, see our Editorial Policies and the Editorial Policy Checklist.

\section{Statistics}

For all statistical analyses, confirm that the following items are present in the figure legend, table legend, main text, or Methods section.

$\mathrm{n} / \mathrm{a}$ | Confirmed

$\bigotimes$ The exact sample size $(n)$ for each experimental group/condition, given as a discrete number and unit of measurement

$\square \bigotimes$ A statement on whether measurements were taken from distinct samples or whether the same sample was measured repeatedly

The statistical test(s) used AND whether they are one- or two-sided

Only common tests should be described solely by name; describe more complex techniques in the Methods section.

$\bigotimes \square$ A description of all covariates tested

Х $\square$ A description of any assumptions or corrections, such as tests of normality and adjustment for multiple comparisons

$\square$ A full description of the statistical parameters including central tendency (e.g. means) or other basic estimates (e.g. regression coefficient)

AND variation (e.g. standard deviation) or associated estimates of uncertainty (e.g. confidence intervals)

For null hypothesis testing, the test statistic (e.g. $F, t, r$ ) with confidence intervals, effect sizes, degrees of freedom and $P$ value noted

Give P values as exact values whenever suitable.

Х $\square$ For Bayesian analysis, information on the choice of priors and Markov chain Monte Carlo settings

Х $\square$ For hierarchical and complex designs, identification of the appropriate level for tests and full reporting of outcomes

Х $\square$ Estimates of effect sizes (e.g. Cohen's $d$, Pearson's $r$ ), indicating how they were calculated

Our web collection on statistics for biologists contains articles on many of the points above.

\section{Software and code}

Policy information about availability of computer code

Data collection scanR software, Comet Assay IV software,Graphpad Prism 9

Data analysis scanR software, Comet Assay IV software,Graphpad Prism 9

For manuscripts utilizing custom algorithms or software that are central to the research but not yet described in published literature, software must be made available to editors and

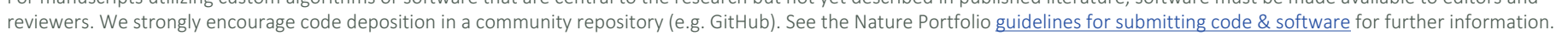

\section{Data}

Policy information about availability of data

All manuscripts must include a data availability statement. This statement should provide the following information, where applicable:

- Accession codes, unique identifiers, or web links for publicly available datasets

- A description of any restrictions on data availability

- For clinical datasets or third party data, please ensure that the statement adheres to our policy

Data availability: Source data are provided with this study. Because of their large number,all raw microscope quantification data sets involved in this work such as Excel and scanR/comet fluorescence quantification tables (which generated the provided source data) are available from the corresponding author on reasonable request, citing the experiments of interest. 
Please select the one below that is the best fit for your research. If you are not sure, read the appropriate sections before making your selection.

\ Life sciences

Behavioural \& social sciences

Ecological, evolutionary \& environmental sciences

For a reference copy of the document with all sections, see nature.com/documents/nr-reporting-summary-flat.pdf

\section{Life sciences study design}

All studies must disclose on these points even when the disclosure is negative.

$\begin{array}{ll}\text { Sample size } & \begin{array}{l}\text { No statistical method was used to predetermine sample size, but we routinely employed at least three biological repeats for each } \\ \text { experiment, in each case scoring as many technical replicates as possible (typically several hundred/thousand cells) using the applicable } \\ \text { automated microscope software (scanR/comet assay IV). }\end{array}\end{array}$

Data exclusions no data was excluded

Replication all findings were independently replicated at least 3 times. All replicates were successful and included in the data

Randomization this is not appropriate because all of our samples/experiments were specific genetically defined cell lines

Blinding Samples/investigators were not blinded during experiments and outcome assessment because all numerical data was software automated and independent of investigator subjectivity.

\section{Reporting for specific materials, systems and methods}

We require information from authors about some types of materials, experimental systems and methods used in many studies. Here, indicate whether each material, system or method listed is relevant to your study. If you are not sure if a list item applies to your research, read the appropriate section before selecting a response.

\begin{tabular}{|c|c|c|c|}
\hline \multicolumn{2}{|r|}{ Materials \& experimental systems } & \multicolumn{2}{|c|}{ Methods } \\
\hline $\mathrm{n} / \mathrm{a}$ & Involved in the study & $\mathrm{n} / \mathrm{a}$ & Involved in the study \\
\hline ᄂ & $\bigotimes$ Antibodies & Х & $\square$ ChIP-seq \\
\hline${ }^{-}$ & $\bigotimes$ Eukaryotic cell lines & Х & $\square$ Flow cytometry \\
\hline 邓 & $\square$ Palaeontology and archaeology & Х & $\square$ MRI-based neuroimaging \\
\hline $\mathrm{L}^{\mathrm{a}}$ & $\bigotimes$ Animals and other organisms & & \\
\hline Х & $\square$ Human research participants & & \\
\hline 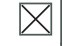 & $\square$ Clinical data & & \\
\hline$\bigotimes$ & $\square$ Dual use research of concern & & \\
\hline
\end{tabular}

\section{Antibodies}

Antibodies used

see below

Primary abs:

Antibody: Provider: Use: Cat. No.: Species:

XRCC1 Novus IF 1:300 WB 1:8000 NBP1-87154 Rabbit

TUBULIN Sigma WB 1:20000 T6074 Mouse

PARP1 BioRad WB 1:1000 MCA1522G Mouse

RNAPII Santa Cruz WB 1:100 sc-9001 Rabbit

RNAPII Santa Cruz WB 1:100 sc-55492 Mouse

NeuN Millipore IF 1:500 MAB377 Mouse

RNAPII pS2 Abcam WB 1:30000 ab5095 Rabbit

RNAPII pS5 Abcam WB 1:30000 ab5131 Rabbit

ADP-ribose binding reagent Millipore IF 1:1000 WB 1:10000 MABE1016

Rabbit

RPA194 Santa Cruz IF 1:200 WB 1:100 sc-48385 Mouse

NTH1 Santa Cruz WB 1:200 sc-130644 Mouse

HPF1 Novus WB 1:1000 NBP1-93973 Rabbit

H2BK120mUb Cell Signaling IF 1:800 5546T Rabbit

H2AK119mUb Cell Signaling IF 1:1000 8240T Rabbit

H3K9Ac Cell Signaling IF 1:1000 9649T Rabbit

H3K4me3 Abcam IF 1:400 Ab8580 Rabbit

USP11 Proteintech WB 1:1000 10244-1-AP Rabbit

FK2 BioRad IF 1:300 MCA6035 Mouse 
Secondary abs:

Alexa Fluor 488 Invitogene IF 1:1000 A21206 Donkey,

(anti-Rabbit)

Alexa Fluor 488 Invitogene IF 1:1000 A11001 Goat,

(anti-Mouse)

Alexa Fluor 647 Invitogene IF 1:1000 A21245 Goat,

(anti-Rabbit)

Alexa Fluor 647 Invitogene IF 1:1000 A21235 Goat,

(anti-Mouse)

APLF Invitogene WB 1:1000 PAS39226 Rabbit

USP3 Abcam WB 1:500 Ab229348

Validation

antibodies were chosen based on published literature/recommendation and were either not further validated or were internally validated by the use of cell lines lacking the target antigen

\section{Eukaryotic cell lines}

Policy information about cell lines

Cell line source(s)

RPE1 cells and U2OS cells were both from ATCC. Mouse cerebellar neurons were generated from mice in-house and human fibroblasts from our previous work (Hoch et al Nature 2017)

Authentication

these are all authenticated by fingerprinting in our cell culture facility

Mycoplasma contamination

all cells were confirmed mycoplasma negative.

Commonly misidentified lines

(See ICLAC register)

no commonly misidentified cell lines were employed in this study

\section{Animals and other organisms}

Policy information about studies involving animals; ARRIVE guidelines recommended for reporting animal research

Laboratory animals

Wild animals

Field-collected samples

Ethics oversight no live laboratory animals were used in this study. We used only isolated neurones.

no wild animals were employed

not applicable

we are governed by the UK Home Office and by the University Ethics committee. Our animal and research licenses are fully approved by such.

Note that full information on the approval of the study protocol must also be provided in the manuscript. 